\title{
Development, implementation and evaluation of two Dutch smoking prevention programs
}

Citation for published version (APA):

Dijkstra, M. C. F. M. (1995). Development, implementation and evaluation of two Dutch smoking prevention programs. [Doctoral Thesis, Maastricht University]. Datawyse / Universitaire Pers Maastricht. https://doi.org/10.26481/dis.19950614md

Document status and date:

Published: 01/01/1995

DOI:

10.26481/dis.19950614md

Document Version:

Publisher's PDF, also known as Version of record

\section{Please check the document version of this publication:}

- A submitted manuscript is the version of the article upon submission and before peer-review. There can be important differences between the submitted version and the official published version of record.

People interested in the research are advised to contact the author for the final version of the publication, or visit the DOI to the publisher's website.

- The final author version and the galley proof are versions of the publication after peer review.

- The final published version features the final layout of the paper including the volume, issue and page numbers.

Link to publication

\footnotetext{
General rights rights.

- You may freely distribute the URL identifying the publication in the public portal. please follow below link for the End User Agreement:

www.umlib.nl/taverne-license

Take down policy

If you believe that this document breaches copyright please contact us at:

repository@maastrichtuniversity.nl

providing details and we will investigate your claim.
}

Copyright and moral rights for the publications made accessible in the public portal are retained by the authors and/or other copyright owners and it is a condition of accessing publications that users recognise and abide by the legal requirements associated with these

- Users may download and print one copy of any publication from the public portal for the purpose of private study or research.

- You may not further distribute the material or use it for any profit-making activity or commercial gain

If the publication is distributed under the terms of Article $25 \mathrm{fa}$ of the Dutch Copyright Act, indicated by the "Taverne" license above, 
Development, implementation and evaluation of two Dutch smoking prevention programs 
CIP-DATA KONINKLIKE BIBLIOTHEEK, DEN HAAG

Dijkstra, Margaretha Catharina Francisca Maria

Development, implementation and evaluation of two

Dutch smoking prevention programs / Margaretha Catharina

Francisca Maria Dijkstra. - Maastricht : Universitaire

Pers Masstricht, - IIl.

Thesis Rijksuniversiteit Limburg Maastricht. - With ref. -

Win sumnary in Dutch.

ISBN $90-5278-1842$

Subject headings: smoking prevention ; the Netherlands.

Produktie: Datawyse | Universitaine Pers Matistricht 


\section{Development, implementation and evaluation of two Dutch smoking prevention programs}

\section{PROEFSCHRIFT}

ter verkrijging van de graad van doctor

aan de Rijksuniversiteit Limburg te Maastricht, op gezag van de Rector Magnificus, Prof.mr. M.J. Cohen, volgens het besluit van het College van Dekanen, in het openbaar te verdedigen op woensdag 14 juni 1995 om 16.00 uur

door

Margaretha Catharina Francisca Maria Dijkstra

geboren te Oss op 23 juni 1964

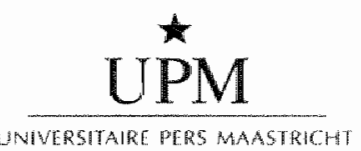




\section{Promotor:}

Prof.dr. G.J. Kok

\section{Co-promotor:}

Dr. H. de Vries

\section{Beoordelingscommissie:}

Prof.dr. F.J.N. Nijhuis (voorzitter)

Dr. A. Charlton (University of Manchester, Manchester, UK)

Dr. R. Knibbe

Prof.dr. S. Maes (Rijksuniversiteit Leiden)

Prof.dr. W.H.F.W. Wijnen

The study described in this thesis and the publication of this thesis was financially supported by the Dutch Cancer Society. 


\section{Acknowledgements}

Many people have been involved in the study described in this thesis. First of all I would like to thank the health educators, students, teachers, and staff of the schools who made execution of the project feasible.

During several phases of the project I received much support from my research assistants: Ingeborg Wijnands, Simone Seelen, Marieke Wiebing, Anja Korsten and Maria Dolders, who I want to thank for their contributions and pleasant collaboration.

I would like to thank my promotor Gerjo Kok for his advises on the project and co-promotor Hein de Vries for his support during my development from student to research assistant and subsequently to associate researcher, and his help in writing this thesis. Furthermore, I thank Guy Parcel for his advice during the project and useful comments on the articles. I also thank Gerard van Breukelen for his support during the analyses of the data.

I would like to thank my colleagues from the department of health education, in particular Patricia van Assema, Rineke Vasse and Manon Savelkoul for their support they have given. Furthermore, I would like to thank Angélique van de Kar from the Public Health Department of Midden-Limburg, for her stimulance to finish this thesis.

Finally, I would like to thank my paranimfen Ilse Mesters and Ingeborg Wijnands, who have been very stimulating during the project, during the writing of this thesis and in organizing the dissertation.

Margo Dijkstra

Maastricht, March 1995 


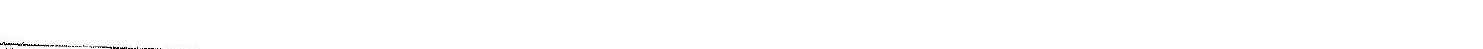




\section{Contents}

Chapter 1 Overview 11

1 Introduction 11

2 The ABC-planning model 12

3 Smoking prevalence in the Netherlands 15

4 Smoking prevention programs at schools 16

4.1 Early approaches to smoking education and prevention 16

4.2 Newer interventions 16

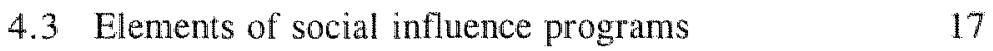

5 Development of two Dutch smoking prevention programs $\begin{array}{ll}\text { and booster for high schools } & 18\end{array}$

5.1 The programs and boosters 19

5.2 Pretesting the programs 22

6 Diffusion of the intervention 23

7 Implementation of the intervention 25

8 Evaluation 25

8.1 Evaluation of the diffusion of the intervention 26

8.2 Evaluation of the implementation of the intervention 27

$\begin{array}{lll}8.3 \text { Program evaluation } & 29\end{array}$

8.4 Effect evaluation 30

9 Methodological issues 34

10 Implications for smoking prevention 37

10.1 Diffusion of smoking prevention programs 37

10.2 Implementation and structure of smoking prevention programs $\quad 37$

10.3 Content of smoking prevention programs 38

10.4 Boosters 39

10.5 Long-term follow-up $\quad 40$

10.6 Comprehensive efforts needed to prevent adolescents from smoking 41

References $\quad 45$ 
Chapter 2 The linkage approach applied to a schoolbased smoking prevention program in the Netherlands

1 Introduction

2 Implementing the approach 55

2.1 Identification of linking agents 55

2.2 Collaboration process $\quad 56$

3 Evaluating the approach 57

4 Implications for professional practice 59

References 61

Chapter 3 Predictors of implementation and continuation of a Dutch smoking prevention program 63

1 Intraduction 63

2 Methods 65

2.1 Intervention 65

2.2 Data collection 66

2.3 Questionnaire 67

2.4 Data analysis $\quad 68$

3 Results 68

3.1 Sample characteristics 68

3.2 Differences in level of implementation 69

3.3 Predictors of intended future use of the smoking prevention program $\quad 70$

3.4 Elements of the program deemed preferable for future use of the program $\quad 72$

3.5 Characteristics of the organization $\quad 72$

4 Discussion $\quad 72$

5 Conclusion 74

$\begin{array}{ll}\text { References } & 75\end{array}$

Chapter 4 Program evaluation of two smoking prevention programs: an application of the program matrix

$\begin{array}{lll}1 \text { Introduction } & 77\end{array}$

2 Method 79

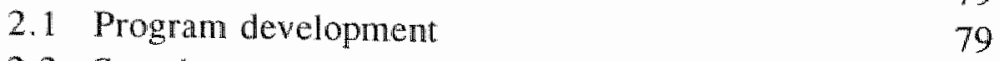

2.2 Sample $\quad 83$ 
2.3 Design 83

2.4 Questionnaire 83

2.5 Analysis 84

3 Results 85

4 Discussion $\quad 89$

References 91

Chapter 5 Effectiveness of two Dutch smoking prevention programs with boosters 95

1 Introduction 95

2 Methods 97

2.1 Sample 97

2.2 Design 98

2.3 The programs and boosters 99

2.4 Procedure 100

2.5 Questionnaire 101

2.6 Analysis 103

3. Results 104

3.1 Program effects on smoking 104

3.2 Effects on attitude, knowledge, social norms, perceived behavior, pressure, self-efficacy, and intention 108

4 Discussion 111

References $\quad 113$

$\begin{array}{ll}\text { Summary } & 117\end{array}$

$\begin{array}{ll}\text { Samenvatting } & 121\end{array}$

$\begin{array}{ll}\text { Curriculum vitae } & 125\end{array}$ 



\section{Chapter 1}

\section{Overview}

\section{$1 \quad$ Introduction}

The incidence of cancer and cardiovascular diseases in the Netherlands is high. It is expected that the incidence of cancer will increase substantially in the next few decades, mainly due to changes in the size and age structure of the Dutch population. "With regard to cancer it is estimated that approximately $80 \%$ of all cancer deaths are related to life-style factor $\mathrm{s}^{2,3}$, and the most important life-style factor regarding lung cancer and cardiovascular diseases is cigarette smoking. Cigarette smoking is related to $30 \%$ of all cancer cases (and to $90 \%$ of all lung cancer cases), $75 \%$ of the mortality due to asthma, emphysema and bronchitis, and $25 \%$ of mortality due to coronary heart diseases. ${ }^{4}$ In the United States an estimated 390,000 people die each year of smoking-related illnesses ${ }^{5}$, while in the Netherlands smoking is associated with 28,000 deaths per year. ${ }^{4}$ Primary prevention of cancer is possible by reducing risk behavior, such as smoking. Therefore, smoking control activities as smoking cessation and smoking prevention are of great relevance. Since the majority of smokers start to smoke before the age of 18, and giving up smoking is not easy, it has been assumed that prevention is the best option to reduce adult prevalence.

This thesis describes the development, diffusion and evaluation of two smoking prevention programs for high schools. First, the interventions were developed, based on a study of literature with regard to the determinants of smoking in adolescents and results of smoking prevention programs in general, and the results of a former Dutch smoking prevention program. ${ }^{6-8}$ Second, the interventions were diffused to schools using the linkage approach to innovationdevelopment and diffusion planning to improve diffusion of the two programs. The linkage approach was evaluated to determine the feasibility of the approach applied to a school-based smoking prevention program. Accordingly, schools implemented the program. A process evaluation was conducted to assess whether the intervention was implemented as planned. In the effect evaluation, the experimental schools were compared to the control schools to assess changes in smoking behavior due to the interventions. Program evaluation was conducted to assess students' and teachers' evaluation of the program. 
This chapter, Chapter 1, provides an overview of the entire research project. The purpose of this overview is to give a summary of the research project that can be read independently of the other chapters which provide more "in-depth analyses" of specific elements of the project. Therefore, in Chapter 1 only the most essential points of the steps undertaken and the main results will be discussed. The introduction to this thesis is followed by a description of the planning model used for the research project. Subsequently, smoking prevalence and incidence in the Netherlands is reported, and a review is presented of smoking prevention programs that have been subject to research during the last two decades. The remainder of this overview describes the different phases of the research project and the evaluation of these phases. Finally, general conclusions are formulated and some methodological aspects, implications and recommendations for smoking prevention are discussed. Chapter 2 of this thesis reports the evaluation of the diffusion of the smoking prevention programs. In Chapter 3 the implementation of the programs by teachers is evaluated. Chapter 4 discusses the evaluation of the programs by teachers, students and peerleaders. The results of the effect evaluation of the two smoking prevention programs are presented in Chapter 5 .

\section{The ABC planning model}

The research project in this thesis is based on a theoretical model for prevention planning. This model, the circular ABC health promotion framework? distinguishes three important phases: A. Analysis of the health problem, B. Behavior change, and C. Continued prevention (see Figure 1). In the analysis phase the severity of the health problem, the behaviors that are related with the problem, the preventability of these behaviors, the target group, and the factors that determine a person's behavior, are assessed. In the case of smoking, epidemiological and medical research has already provided firm evidence for the relations between smoking and cancer, heart disease and respiratory disorders. This evidence makes a strong case for smoking control activities such as smoking cessation and smoking prevention. However, because the effectiveness of cessation interventions has only been limited until now, prevention of the onset of smoking is a very important goal in health education. ${ }^{10.12}$ Therefore, the study described in this dissertation is directed on smoking prevention.

Before developing an intervention, the determinants of the behavior should be analyzed. A national study of the determinants indicated that the following factors are important as determinants of smoking behavior in adolescents: 
demographic factors (e.g., age, type of school, and gender) and cognitive factors (e.g., attitudes, perceptions of social influence, social pressure, modeling and self-efficacy). ${ }^{11.13-15}$ The results of the analysis phase provide the essential ingredients to formulate ideas of which issues need to be addressed in interventions, and how these issues can be managed.

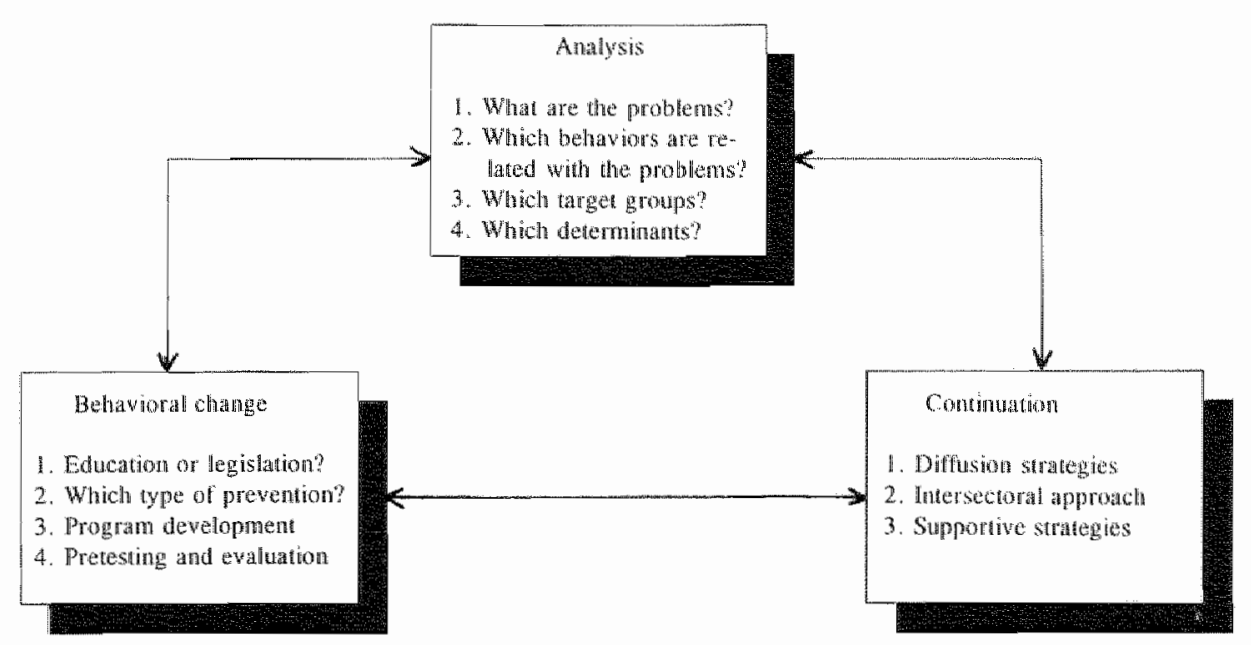

Figure 1

The ABC planning model (De Vries, 1993)

The second phase consists of developing an intervention program adjusted to the determinants. First, a choice has to be made on whether behavior needs to be changed by interventions directed at individuals, by providing facilities, and/or by developing (supportive) regulation or legislation to change the smoking environment, or by combinations of interventions. ${ }^{11.16}$ Morcover, a decision has to be made as to what type of prevention is needed (primary, secondary or tertiary prevention), and what the program goals will be. For careful planning of behavioral interventions a program matrix can be used. ${ }^{15}$ Chapter 4 of this dissertation describes the development and evaluation of the intervention based on the program matrix. Furthermore, during the behavioral change phase, an evaluation of the intervention should be conducted to assess the behavioral and other effects. Health education programs can be evaluated at one or more of three levels: process, impact, and outcome. ${ }^{17}$ In process or formative evaluation, the potential objects of interest include all program inputs (e.g., 
policy, specificity of goals, resources), implementation activities (e.g., staff performance, organizational activity), and stakeholder reactions (e.g., levell of participation, response of collaborating organizations, participants' evaluations). Impact evaluation assesses the immediate effect the program has on target behaviors and their determinants. Finally, outcome evaluation refers to the evaluation of the program in terms of health status and quality-of-life indicators. They are typically given in terms of for instance mortality, disease or disability rates. In Chapters 2,3 and 4 of this dissertation different elements of the process evaluation are discussed. Chapter 5 concentrates on the impact evaluation.

The last phase of the $\mathrm{ABC}$ health promotion framework discusses the continuation of the preventive activities. Interventions will only be effective if they are used on a large scale during a substantial period of time. Diffusion strategies can be used to enhance implementation and use of interventions. One approach that helps to improve diffusion is the linkage approach to innovation development and diffusion planning. ${ }^{18-24}$ In Chapter 2 a case study is described in which the linkage approach is applied to a school-based smoking prevention research project. One of the goals was to provide feedback on barriers and enabling factors that improve program diffusion in a broader context.

In this thesis the analysis phase will not be discussed, since enough information on, for example, the severity of the health problem and the determinants of smoking in Dutch adolescents, is already available. ${ }^{11,13,25-27}$ Therefore, the study in this thesis is directed at the development of the two programs with booster, process and impact evaluation, and diffusion and implementation of the interventions.

Although continuation is reported as the last phase in the framework, the circular character of the framework suggests that when starting programs, factors enabling continuation should be analyzed before program development and implementation occurs. This suggests that, ideally, relevant stakeholders should be involved in the process of the development of the intervention (see Section 6 in this chapter and Chapter 2). The study described in this thesis started with the development of the programs. Meanwhile, diffusion strategies were used to determine an effective way to diffuse the programs to schools, resulting in an implementation manual. Then, when the programs were available, they were diffused and implemented in schools. Finally, process evaluation including diffusion (Chapter 2), implementation (Chapter 3) and program evaluation (Chapter 4), and impact evaluation (Chapter 5) were conducted. 
The next section provides insight into the severity of the smoking problem in the Netherlands.

\section{Smoking prevalence in the Netherlands}

The first step in the analysis of the health problem is to determine the severity of the health problem. Cigarette smoking is an individual risk behavior that is responsible for $30 \%$ of all cancer deaths (and to $90 \%$ of all lung cancer cases), $75 \%$ of the mortality due to asthma, emphysema and bronchitis, and $25 \%$ of mortality due to coronary heart diseases. ${ }^{4}$ It was estimated that in the Netherlands in 1993 over 28,000 persons died prematurely from diseases caused by smoking. In 1958 the first national research was conducted to determine smoking behavior in the Netherlands. ${ }^{4}$ At that moment smoking was very popular among men: about $90 \%$ of the male population of 15 years and older were smokers compared to $29 \%$ of the women. Since then smoking prevalence has dropped significantly among men to $37 \%$ in 1993. Smoking prevalence in women increased from $29 \%$ in 1958 to $42 \%$ in 1967 . This increase has been described as being the result of the emancipation effect. ${ }^{26}$ However, since 1970 smoking prevalence in women has declined, to $30 \%$ in 1993. As can be seen in Table 1, smoking prevalence in Dutch teenagers aged 10 to 14 , decreased from $11 \%$ in 1983 to $7 \%$ in 1991 . However, since 1991 smoking prevalence increased again to $11 \%$ in 1993 . These percentages are calculations based on interviews carried out with youngsters every year. Smoking was assessed by asking adolescents if they had smoked during the last four weeks. Since 1992 also 15-to-19-year-old adolescents have been interviewed. In $199246 \%$ of these adolescents were smokers and in $1.99345 \%$.

Table 1

Smoking prevalence (\%) from 1983-1993 in adolescents aged 10-14 and 15-19 (Data obtained from Dutch Smoking and Health Foundation $)^{4}$

\begin{tabular}{lcccccccc}
\hline Age & 1983 & 1985 & 1987 & 1989 & 1990 & 1991 & 1992 & 1993 \\
\hline $10-14$ & 11 & 13 & 9 & 9 & 7 & 7 & 9 & 11 \\
$15-19$ & & & & & & & 46 & 45 \\
\hline
\end{tabular}




\section{Smoking prevention programs at schools}

Many smoking prevention programs have been developed and reviews of numerous smoking prevention programs have been published. ${ }^{28.36}$ The history of smoking prevention programs wil] be discussed briefly below.

\subsection{Early approaches to smoking education and prevention}

The early interventions in the 1960 s and 1970 s were based on rationally oriented information. The focus of these interventions was on factual information about smoking, the effects of smoking and the consequences. The assumption was that such information would change children's attitudes towards smoking, resulting in fewer children who would start smoking. ${ }^{37}$ These programs were effective in changing knowledge. ${ }^{31}$ However, these programs have not been effective in preventing adolescents from starting to smoke. ${ }^{30,31,38,39}$

\subsection{Newer interventions}

In 1976 Evans and colleagues ${ }^{40}$ started to develop a new approach to smoking prevention. This approach was based on the assumption that health, personal and social factors influence the development of smoking behavior in an individual. According to Evans, smoking prevention programs should focus on the more immediate physiological and sociall effects of smoking, direct social pressures to smoke exerted by parents, media, and smoking peers, and on increasing resistance in non-smoking adolescents towards these pressures. Evans based his studies on the Social Learning Theory of Bandura ${ }^{41}$. The interventions utilized in Evans's study were directed towards training adolescents to become aware of individuals with whom they are in contact, e.g., parents, older peers, and personalities in mass media presentations, who model smoking behavior. Another conceptual base for Evans's study was the Social Inoculation Theory. ${ }^{42}$ It was assumed that adolescents could be trained to recognize and to cope with pressures to start smoking. The program used videotapes of non-smoking peers to impart information and to teach skills needed to resist social influences. ${ }^{43}$

Evans's work provided the foundation for much of the smoking-prevention research that followed over the next decade. Many researchers elaborated on Evans's work but have included important innovations that resulted in successful programs. ${ }^{8.44 .58}$

The newer programs are developed based on several different theories, including the Social Inoculation Theory ${ }^{42}$, the 'Theory of Reasoned Action' 
proposed by Ajzen \& Fishbein ${ }^{59}$ and Bandura's Social Learning Theory ${ }^{60}$. The approach of the newer interventions was based on the assumption that the social environment is the most important determinant of smoking onset. ${ }^{43}$ Programs that attend to skills needed to resist social influences generally included a group of components that include training in resisting social pressures (e.g., media) and peer pressures to smoke. Furthermore, these interventions focused on the negative shortterm consequences of smoking, including social undesirability and physiological impairment, on techniques of tobacco advertising that may be falsely appealing to adolescents, and on the socially salient advantages of being a nonsmoker. Students learn that cigarefte smoking is not a normative behavior for adolescents their age and that the majority of persons in any age group are nonsmokers. Botvin ${ }^{61}$ has developed another variation of the social influence approach that includes resistance skills, behavioral rehearsal, role playing, selfcontrol, decision making, problem solving, and self-reward, as well as components devoted to increasing self-esteem, self-confidence, autonomy, and assertiveness.

The above-mentioned reviews on smoking prevention programs report that only the social influence approaches have been scientifically demonstrated to reduce or delay adolescent smoking. Hence, school districts wishing to include classroom interventions targeting adolescent smoking should consider adopting a social reinforcement program. ${ }^{31}$ The most common elements of social influence programs will be outlined in more detail in the next section.

\subsection{Elements of social influence programs}

In effective social influence programs, models on film or peers in the classrooms demonstrate resistance skills. Students then role-play the skills, and the instructor provides students with feedback to improve their skills. Students discover how media can influence their behavior without their being aware of this. They learn to recognize and be skeptical of advertising strategies used "to trick" people into believing that smoking only has positive consequences. The delivery strategy of most of the social influence programs include media materials such as videotapes of same-age peers demonstrating resistance skills. In most programs, instructors guide students to discovery rather than lecturing them. This principle is called active learning and suggests stimulation of the students active participation: instead of providing them with information, students are stimulated to search for relevant information. ${ }^{51}$ Furthermore, behavioral role-play and practice of resistance skills in the classroom is important because students are unlikely to learn skills if they do not practice 
them. Finally, in most of the social influence programs, specially chosen and trained peer-leaders assist specially trained teachers in the delivery of the programs. Strong evidence exists to suggest that the best prevention programs use a teacher-]ed, student involvement/peer-assistant approach. ${ }^{44.56}$ Students appear to respond well to information presented by chosen peers, but the programs work best when teachers remain primarily responsible for delivery. ${ }^{62}$ The advantages of using peer-leaders are increased attractiveness and comprehensibility of the program, and increased chances of imitation of the non-smoking behavior of the peer-leader ${ }^{63}$ Peer-leaders have higher source credibility with adolescents than adults. They may be most effective when used as models for social skills. ${ }^{6}$ Various methods have been used to choose peerleaders who can help present the information in a smoking prevention program. ${ }^{62}$ For example, teachers selected the peer-leaders, peer-leaders were appointed by a student organization, or they were voted on by class members on basis of their popularity. Furthermore, some programs choose older students as peer-leaders $44,53,56,58,65.67$, while other programs used same age peerleaders ${ }^{11,40.68}$. To be successful, peers should receive adequate training. ${ }^{62}$

The first Dutch smoking prevention project was based on Evans's principles and on an adaptation of the Fishbein and Ajzen model, containing attitudes, social influences and Bandura's self-efficacy expectations as important factors to guide the development of the content of the program. ${ }^{11,13,49}$ The next section discusses the reasons for starting the study described in this thesis, and the development of the two smoking prevention programs.

\section{Development of two Dutch smoking prevention programs and boosters for high schools}

The results and recommendations of the first smoking prevention project were the reason for starting the second smoking prevention project. ${ }^{8,11,49,69}$ During the first project a social influence program on video was developed for second grade vocational and high school students. The results of this project showed differential effects for vocational and high school students. The program prevented the onset of regular smoking among vocational school students and thus national implementation of the program in vocational schools was recommended. However, the program did not have an impact on regular smoking for high school students. Process evaluation suggested three explanations for this absence: a relatively low educational level of the program, a low smoking incidence in second grade high school students, and a need to discuss the decision-making process more elaborately. "Recommendations suggested 
further research with regard to development of effective smoking prevention programs for high schools. Three recommendations were given: to adapt the social influence program to the educational level of high school students, to implement it in a higher grade, and to develop a decision-making program for high school students. Another Dutch smoking prevention project, which was a replication of Leventhal's Wisconsin study, also concluded that different programs should be developed for the different types of secondary schools. ${ }^{70}$

Based on these recommendations two different programs with boosters were developed: a social influence program and a decision-making program. The target group of both programs were students of the second (13-14-year-old students) and third grade (14-15-year-old students) of high schools. Dutch high schools consist of three different educational levels. The lowest has a four-year education track, the middle level has a five-year education track, and the highest level has a six-year education track preparing students for university. The main goal of the programs was to prevent students from starting to smoke.

The development of the programs and boosters was based on a program matrix to plan behavioral interventions. ${ }^{15}$ According to this matrix behavioral change can be considered as a process where three phases can be distinguished: 1. attention to and comprehension of the message; 2 . changes in determinants of behavior (attitudes, social influences and self-efficacy); and 3. a change in behavior and behavior maintenance. According to the matrix, the persuasive impact of the message is determined by four types of input or communication variables: target group, message, channel, and source variables. Target group variables refer to the characteristics of the target group that influence information processing (e.g., educational level, gender and age). The message needs to be adapted to the educational level of the target group to ensure that the information will be understood. Message variables focus on the persuasive effect of the message. Channel variables refer to the methods by which messages are delivered (e.g., newspapers, television, local newsletters, schools). Source variables focus on who is going to deliver a message to the target group (e.g., a doctor, famous artists, adolescents). The framework served as a checklist for the developers of the programs and boosters to ensure that the intervention included the important issues. The application of the framework to program planning and evaluation is described in Chapter 4 .

\subsection{The programs and boosters}

By applying the program matrix, two smoking prevention programs, a social influence program and a decision-making program, and boosters were 
developed. The same structure of the first Dutch smoking prevention program with some small changes was used. "Both programs consisted of five lessons, each of 45 minutes and were given in weekly sessions in the second and third grade of high schools. The structure and content of both programs, presented on video by adolescents, can be summarized as follows: a. introduction of the theme on video, $b$. peer-led activity, c. feedback on the activity and continuation of the lesson on video, d. peer-led activity, e. feedback on the activity, and $f$. homework assignments.

Peer-led activities were conducted in small groups consisting of four or five students. Groups were formed and peer-leaders were chosen before the first lesson. The peer-leader was a person from the same class as the students and served as a chairperson of the small activity group. Teachers could use various methods to form groups and to choose peer-leaders. Mostly, teachers formed the groups and than the students in the groups choose their own peer-leader. However, it also happened that the teacher choose the peer-leaders. The peerleader was always a nonsmoker. During the activities, active participation of students was stimulated. Instead of providing information, students were encouraged to discover information (active learning). Thus, students may discover gaps in their knowledge which will make them more receptive to new information. ${ }^{51}$

Teachers coordinated the lessons, stimulated students and assisted peerleaders. Teachers received a one-hour training from health educators consisting of information about the structure and content of the program, how to stimulate students, and how to train peer-leaders. For the training of the peer-leaders, a special training video was developed which discussed the tasks of the peerleaders and showed them how to handle different situations. Peer-leaders were trained by teachers with help of a training video. Teachers, peer-leaders and students received their own manual with activities, and information on their tasks. At the end of each lesson teachers handed out a summary of the lesson, which could be added to the manuals.

As in the first Dutch social influence program, the content of the social influence program in the project of this thesis, was based on the Attitude -Social influence - Self-efficacy model (ASE model). ${ }^{7,8,14,15,71}$ Several theoretical models can be used for explaining human behavior, such as the Theory of Reasoned Action ${ }^{59}$, the Health Belief Mode $]^{72}$, Social Learning Theory ${ }^{73}$ and the Theory of Planned Behavior ${ }^{74}$. The ASE model can be regarded as an integration of the most important psycho-social behavioral determinants. According to this model, behavior is determined by people's attitude towards the behavior, social influences and self-efficacy. An attitude represents a 
person's general feeling of faworableness or unfavorableness towards a behavior, and is determined by perceived positive and negative consequences of the behavior. ${ }^{59}$ Social influences can be divided in social norms, modeling and pressure. ${ }^{15,75}$ Social norms refer to the perceived subjective norms from other people. Modeling refers to perceived behavior of orher people, and pressure refers to perceived pressure from others to conduct the specific behavior. Selfefficacy refers to a person's expectation regarding his capability to realize a (desired) behavior. ${ }^{73}$ Attitudes, social influences and self-efficacy predict the intention to perform the behavior which, in turn, predicts the behavior itself. External variables, such as demographic variables, influence behavior via the three determinants and the intention. Between intention and behavior there may be barriers or lack of skills. These barriers and skills only become important if the behavior is actually performed. Actual performance of the behavior leads to a feedback process that, in turn, influences the three determinants. Recently, the description by Prochaska et al. ${ }^{76}$, of groups differing in their intention and behavior, has been integrated in the ASE model as well. ${ }^{77}$

With regard to the attitude, the social influence program focused on reasons why people do or do not smoke and why people quit smoking, primarily shortterm effects of smoking and some long-term effects of smoking, dangers of experimentation with smoking, passive smoking, addiction, quitting smoking, and alternatives for smoking. Regarding social influences, the program discussed differences between direct and indirect pressure to smoke, direct pressure to smoke from peers, indirect pressure to smoke from adults and advertisements, and influence of government measures. Self-efficacy was incorporated by demonstrating and practicing resistance skills in various "at-risk situations".

The decision-making program concentrates on the development of basic decision-making skills, which were applied in the lessons on smoking. The decision-making skills training focused on using five steps to evaluate information and draw a conclusion: 1 . What is the situation in which you have to make a decision? 2. What are the possible decisions? 3. What are the pros and cons of the possible decisions? 4. Make a decision based on the pros and cons; 5 . Practice the decision. The goal of using these steps is to teach students a rational way to make decisions. The five steps to make a decision were based on the five decision-making stages described by Janis ${ }^{78}$. He based the five stages on studies of people who displayed vigilance in reaching a difficult personal decision that they subsequently carried out successfully, such as giving up smoking, losing weight on a low-calorie diet, or undergoing a prescribed medical treatment. Janis's five stages are: $\mathbb{1}$. Appraising the challenge; 2 . Surveying alternatives; 3 . Weighing alternatives; 4 . Deliberating about 
commitment; and 5. Adhering despite negative feedback. In the first stage a person is exposed to information about a threat or opportunity that effectively challenges a current course of action. This challenging information can be an event that disturbs the person's equanimity because a particular threat can no longer be ignored. Once the decision maker gives a positive response to the challenging information, he proceeds to search for alternatives. Stage two is largely devoted to discovering and selecting viable alternatives. In stage three the decision maker proceeds to a thorough search and evaluation, focusing on the pros and cons of each of the alternatives. The goal is to select the best available course of action by weighing the advantages and disadvantages of each alternative. After the decision maker decided about the best alternative, he begins to deliberate about implementing it and conveying his intentions to others. In the last stage, the decision maker implements his choice.

Because of the teachers' tight curriculum it was not feasible to develop additional lessons on smoking prevention. Therefore, three newsletters were developed containing information that was also given in the video. Teachers were asked to give the newspapers to the students, who could read them at home or during a break at school. In the three newspapers famous national and international singers and sportspersonalities served as models and gave their opinion on smoking. There were interviews with non-smoking actors from the video and with a co-worker of Greenpeace (ecology group). Information was given on effects of smoking, passive smoking, helping other people to quit smoking, and on reasons not to smoke. Furthermore, each newspaper included a competition, a cartoon about smoking, and letters to the editor from students.

\subsection{Pretesting the programs}

The messages of both programs were pretested during several phases of the development of the programs. A group of students, teachers and experts were asked to read and comment the scripts of both programs. This resulted in some changes. Then, scripts were discussed with a film director, who put the two scripts on film. The same group of students were asked to view the programs and give comments. During the viewing, the reactions of the students were observed. Based on the comments and reactions of the students the film director adapted the video-programs. Finally, the first lesson of both programs was pretested in two high schools, which resulted in only some small changes.

During the development of the intervention, diffusion strategies were used to determine an effective way to diffuse the programs to schools. At the moment 
when the programs were available, the actual diffusion of the intervention started. The next section discusses the diffusion process.

\section{Diffusion of the intervention}

Diffusion of the two smoking prevention programs is described in more detail in Chapter 2 of this thesis. Diffusion can be regarded as the process by which an intervention is communicated through certain channels over time among members of a social system. ${ }^{18,20 \cdot 23,79-86}$. The purpose of the diffusion process is to attain awareness, adoption, implementation, and maintenance of the program by a target group.

One approach that may help to improve diffusion is the linkage approach to innovation development and diffusion planning. ${ }^{18-24,87}$ This approach suggests collaboration among three systems during the implementation of an innovation: resource system, linkage system, and user system. ${ }^{23}$ The resource system consists of researchers, developers, trainers, consultants, services, products, and materials. The linkage system can include representatives from both the resource system and the user system, but it can also consist of an objective third party. ${ }^{21,22}$ The user system consists of individuals, organizations, agencies, groups, and networks that are potential adopters of the innovation.

The linkage system serves as a connection between the resource system, which provides the innovation, and the user system, which adopts, implements, and maintains the innovation. It bridges the gap between the users and providers. ${ }^{21,22}$ Hence the linkage system should be familiar with the innovation available from the resource system and with the needs of the user system as well as with the enabling factors and barriers with regard to implementation of the imnovation in the user system.

The linkage approach was applied to diffuse the two smoking prevention programs. District health educators, asked by the resource system (universitybased researchers) to participate in the smoking prevention research project, formed the linkage system. These health educators work for Dutch district health centers which have the responsibility for public health care and health protection. The health educators' role is to reduce the risk of cliseases in their community by means of health promotion and health education. They were identified as linking agents because they serve as a link between the resource system, which developed the program, and the user system (the schools), the adopters of the programs.

The reasons for integrating the health educators into the project were to involve them during the implementation of the intervention, to use their 
assistance in evaluating the intervention, and to provide feedback on barriers and enabling factors that may improve future program diffusion.

The identification of the linkage system started in September 1989. The selection of the district health educators was aimed at an optimal geographical representation of districts throughout the Netherlands. Accordingly, health educators in 20 districts received letters inviting them to participate during the implementation of the smoking prevention project in the experimental senting. They were also invited to attend a meeting for more information about the project. After the meeting, 16 health educators in 15 districts agreed to participate in the research project.

The implementation of the school-based smoking prevention programs involved collaboration between the resource system and linking agents. The collaboration started with a first introduction meeting. During this meeting the purpose of the research project and the participation of the health educators was explained. Health educators were given the opportunity to comment and to give advice with regard to methods for project dissemination and implementation as proposed by the researchers. After the first meeting, a special implementation manual was developed based on advice and comments the health educators gave. The manual contained a time schedule, information about the programs, how to contact the schools, how to instruct the teachers about the use of the programs, and letters they could use to send to schools. The health educators recruited schools in January, February, and March 1990. How the schools were recruited is described in more detail in Chapter 2 of this thesis. Because of random assignment, health educators had to ask schools to decide on participation without knowing the condition they would be in. Schools that agreed to participate $(N=52)$ selected a contact person who signed an agreement. The health educators passed the names and some characteristics (e.g., type of school) of the recruited schools to the researchers. Accordingly, the researchers matched them on type of school (four year level versus five/six year level) and grade (second grade versus third grade) and then assigned them randomly to one of the experimental conditions $(\mathrm{N}=32)$ or the control condition $(N=20)$. In September 1990 , a second meeting was convened to explain implementation methods and how to instruct the teachers about use of the programs. Then, in October 1990, health educators provided teachers at the experimental schools with instructions about how to use the program. In November and December, 32 schools in the experimental condition implemented the programs. At the end of the program in December 1990 , health educators conducted group interviews with the teachers as part of the process evaluation. Before the pretest and each posttest, health educators 
contacted the schools to plan the positest administration. Finally, health educators were responsible for returning the questionnaires to the university.

\section{Implementation of the intervention}

An important element in the evaluation of a school health education intervention is whether and how the intervention is implemented. ${ }^{18.20 .88 .89}$ The factors that influence the decision of teachers to adopt and implement a program and the factors that affect the level of implementation are of importance to those developing health education programs. Barriers to implementation of school health education are for example a lack of adequately prepared teachers, teachers" perception of their own self-efficacy in implementing interventions and of the value of the intervention, weak local administrative commitment, health education's insufficient credibility as an academic subject, insufficient time, insufficient funds, lack of community or parental support, and controversial topics. ${ }^{18.88 .90-93}$

Of the total of 52 participating schools only the 32 experimental schools received either the social influence program or the decision-making program. To attain complete implementation, the aim of both programs was to be somewhat teacher-independent. Therefore, the structure and content of both programs were presented on video by adolescents. Accordingly, teachers do not have to be experts in teaching smoking prevention, meaning that the programs could be implemented within a variety of subjects. The subjects in which the programs were implemented included: biology, sociology, tutorial, religious instruction, Dutch language instruction, geography, chemistry, German language instruction, and history, as well as after school. The tasks of the teachers were to coordinate the lessons, to stimulate the students and to assist the peer-leaders. Teachers received a one-hour training from health educators addressing the structure and content of the program, how to interest their students, and how to train student peer-leaders with the help of a special training video. The lessons did not require much preparation time for the teachers. The implementation of the programs started in November 1990.

\section{$8 \quad$ Evaluation}

A health education program can be evaluated at one or more of three levels: process, impact and outcome. ${ }^{17}$ In the evaluation of the Duich smoking prevention project both process data and impact data were collected. Process data were collected in the diffusion, implementation and program evaluation. 
Impact data were collected in the effect evaluation. No outcome data have been collected because it is unlikely that a smoking prevention project for adolescents will have an immediate impact on mortality, disease or disability rates for example.

\subsection{Evaluation of the diffusion of the intervention}

Effective diffusion is a critical component of effective school-based health education interventions. ${ }^{18}$ To evaluate the diffusion process, health educators evaluated their role as a linking agent by completing an open-ended questionnaire that addressed support activities provided by the researchers, time spent on the project, the advantages and disadvantages of participation, the intention to continue implementation, preferences to participate in the program planning process, and willingness to participate in other research projects. The evaluation of the diffusion of the smoking prevention programs is reported in detail in Chapter 2 of this thesis.

The results of the diffusion evaluation showed that the health educators evaluated their participation as positive and they were satisfied with the support of the researchers. However, some activities took more time than expected. Consequently, time investment was the most important disadvantage. The most important advantage of participation was to become familiar with the materials and potential of the smoking prevention program. The implementation manual was evaluated as very clear, effective, and helpful. Finally, most health educators reported they intended to continue their involvement in the project.

The diffusion study showed that collaboration between a resource and a linkage system during a smoking prevention research project made small-scale implementation feasible. It can be concluded that health educators were the right persons to serve as the linkage system in the project, because of their previous experience with the user system (the schools). Furthermore, the evaluation of the collaboration made it clear that, when using a linkage system in a research project, the linkage person should be clearly informed about the conditions for participation such as time and responsibilities. This may prevent false expectations about tasks and time investment. Furthermore, it seems important to consider participation of a linkage system during other phases of the project as well. Consequently, besides the implementation phase, participation of the linkage system during the analysis of the health problem, the development of the intervention, and during continuation of the intervention, may enhance the effectiveness of the project. For large-scale implementation of the programs, once a program has proven to be effective, health educators, who had a 
function as linking agent during a small-scale project, may serve as linking agents for large-scale implementation of the project at the national level, and can assist other health educators and function as role models. ${ }^{13}$ Further research is recommended, however, to show the effects of collaboration of a linkage system during large-scalle implementation.

\subsection{Evaluation of the implementation of the intervention}

The smoking prevention programs were implemented in 32 schools. The evaluation of the implementation of the smoking prevention programs by teachers is reported in detail in Chapter 3 of this thesis.

The purpose of the evaluation was to determine differences between teachers who implemented the programs completely as planned and teachers who did not use every element of the program. Characteristics of teachers, such as attitude, social norm and self-efficacy with regard to teaching the program, years of teaching experience, previous experience in teaching health education, and age, may be important with regard to complete implementation of the program. These characteristics can contribute to successful future implementation of the program. Furthermore, the purpose was to assess predictors of future use of the smoking prevention programs, and to determine elements of the smoking prevention program that are preferable for future use.

Data for this evaluation study were collected after the last lesson of the programs. Teachers received a questionnaire about the implementation and use of the programs. From the 32 experimental schools, 59 teachers $(96 \%)$ returned the questionnaire.

The results of implementation evaluation suggest that teachers were convinced that smoking prevention is an important subject, although the majority of them had never taught any smoking prevention program before. In general the teachers implemented the programs completely. Moreover, teachers of subjects in which the content and teaching techniques of the plogram had the best fit, such as biology, religious instruction, and sociology, implemented the program more completely than teachers of other subjects. Furthermore, the level of implementation was best predicted by a positive social norm and by having previous experience in teaching health education.

Essentially, every teacher was supposed to receive training. However, a small percentage reported that they have not received the training. Although other studies in the literature suggest that teacher training is a precondition for successful implementation ${ }^{13,88,90-93}$, the present study showed no difference in 
level of implementation between teachers who received training and those who did not. Smith and colleagues ${ }^{94}$ reported a similar finding.

Regarding maintenance or continuation of the program, teachers with a positive attitude towards the observed level of success of the program were more convinced about teaching the program in the future compared with teachers with a negative attitude with regard to the level of success.

Teachers indicated their preference for a program of three lessons instead of five. However, research suggests that more lessons are necessary to make an effective program. ${ }^{30,43,62, \%}$ Furthermore, teachers prefer to determine the grade in which the program will be taught. However, a smoking prevention program is usually developed for a specific grade level. For example, the grade where smoking onset is greatest or before onset is a consideration. Finally, teachers reported that they would teach the program again if they could determine the moment of teaching. In Dutch schools this is usually possible.

According to the teachers in this study, the decision to implement a smoking prevention program is usually made by the school administrator, while the teachers usually choose the specific program to use.

It can be concluded that a program with the structure used in the present study enhances the likelihood of complete implementation. However, this does not guarantee complete implementation should the program be diffused on a large scale. Therefore, further research is necessary to determine the level of implementation when the program is diffused on a large scale without a concurrent effectiveness study. Furthermore, the study revealed that behavioral factors of teachers, such as attitudes, social norms and self-efficacy, are important in the process of implementation. ${ }^{19}$ Attitudes include the level of success teachers connect to the program, perceived complexity of the program. and the fit of the program in the curriculum and in the way of teaching. Social. influence describes the perceived support of colleagues, school administrators, and students with respect to teaching the program. Finally, self-efficacy refers to the perceived ability to teach the program. Based on the results of the implementation study the following diffusion strategy is recommended. First, regarding the dissemination of the program, school administrators should receive information to convince them of the importance of teaching smoking prevention at schools. Then, when school administrators are convinced of the importance of smoking prevention, preferably teachers who have prior experience teaching lessons on health education, or teachers of subjects in which the content and teaching techniques of the program have the best fit, can be asked to participate. With regard to the adoption of the program, teachers should be given information about the program's perceived and actual level of 
success, complexity, and organizational fit. Once the decision is made to adopt a program, the goal is successful implementation. Therefore, programs with a high chance of being implemented completely are preferable. The present study suggests that a teacher-independent smoking prevention program can attain a high level of complete implementation. Furthermore, it is important that teachers who are going to implement a smoking prevention program perceive a positive social norm from colleagues, school administrators, and students. Concerning maintenance of the use of the program, it is important to pay attention to teachers' attitudes, social norms and self-efficacy with regard to teaching the program.

\subsection{Program evaluation}

The program evaluation of the smoking prevention programs is reported in detail in Chapter 4. The sample for the program evaluation consisted of students of 32 high schools who received either the decisionmaking program or the social influence program. All students of a school received the same program. The data for the program evaluation were gathered at the end of each lesson: students, peer-leaders and teachers answered questionnaires containing questions about the different channels and sources used in the lessons. The channels of the programs were evaluated by questions about the video, the activities, working in groups, and the manual. The sources of the programs were evaluated by questions on the assistance of the peer-leaders and the teacher. The boosters were evaluated during the third posttest evaluation. Furthermore, health educators conducted interviews with teachers after the end of the program to obtain more in-depth information about the use of the program.

The results of the program evaluation indicated that in general students and teachers evaluated the programs positively. However, students of the social influence program evaluated the channels and sources of the program more positively compared to students of the decision-making program. Furthermore, four-year education students, second grade students (13-14-years-old), girls and nonsmokers evaluated both programs more positively compared to five/six-year education students, third grade students (14-15-years-old), boys and smokers.

The evaluation of the boosters indicated that only small percentages of students of both programs reported having read all three newspapers. A possible explanation for the small percentages is that students were not guided in reading the boosters; moreover, they could read them where and when they preferred. Students of the decision-making program were more positive about the lay-out and topics of the newspapers. Furthermore, girls and four-year education 
students evaluated all aspects of the newspapers more positively compared to boys and five/six-year education students.

Teachers of both programs did not differ in their evaluation of the different channels and sources. However, the interviews with the teachers revealed that some teachers of the decision-making program said that students did not like the constant application of the steps to make a decision in most activities. In general teachers indicated that students enjoyed the lessons of the program, though students were less interested during the last lesson. Therefore, teachers recommended shortening the programs. Teachers were positive about working in groups with a peer-leader: working in groups increased involvement and selfreliance of the students. However, teachers of four-year education students revealed that their students needed intensive support to stimulate them to work in groups.

Finally, some teachers indicated that they would like to have the opportunity to go further into matters that were discussed or happened during the lessons. However, during the lessons there was no time left for further discussion.

It can be concluded that the sources and channels used in the two programs were effective in providing information about non-smoking. However, in general the social influence program was evaluated more positively compared to the decision-making program. With regard to the small percentages of students who read all three newspapers, it is recommended to advise teachers to discuss the newspapers at class level. Furthermore, teachers recommended shortening the programs. However, as mentioned earlier, research has shown that at least five lessons are necessary to make an effective program. ${ }^{30,43,62.70}$ Finally, for future video-peer-led programs it is recommended to allow time during the lessons to give teachers the opportunity to go further into matters that were discussed or happened during the lessons.

\subsection{Effect evaluation}

The effect evaluation of the two smoking prevention programs is reported in detail in Chapter 5 of this thesis. The effect of the programs on smoking behavior was studied by means of a pretest-posttest control group design, with three posttests. ${ }^{95}$ Health educators obtained formal consent from the schoolboards, since parental consent was not needed. The schools were recruited by health educators (see Chapter 2) and randomly divided into one of the experimental groups or the control group by the researchers. However, since Dutch high schools consist of three different educational levels, and some schools provide one education, while others provide two or three educations, it 
appeared impossible to match an equal number of schools with similar education. Students of five- and six-year education were united in one group. In each school students in the second (13-14-year-old students) or third grade (1415-year-old students) participated in the project. All students of one school were in the same condition and received either the social influence program, the decision-making program, or served as a control group. Thus, after matching at type of school and grade, schools were randomly divided in experimental $(\mathrm{N}=32)$ and control $(\mathrm{N}=20)$ conditions. Twenty-seven four-year education classes and 24 five- or six-year education classes received the social influence program, while 32 four-year education classes and 32 five- or six-year education classes received the decision-making program. Furthermore, 35 fouryear education classes and 32 five- or six-year education classes served as the control group. With regard to the boosters, the two experimental conditions were matched on type of school and grade and then randomly divided in a group that received the boosters and a group that did not receive the booster.

Students of all participating schools received a questionnaire for the pretest in October 1990 (T1). Accordingly, in November and December 1990, the students of the experimental schools received the five lessons (Int.). Three posttests were conducted: in April 1991 (T2), in October 1991 (T3) and in April 1992 (T4). The first booster session (B1) was in September 1991, between $\mathrm{T} 2$ and $\mathrm{T} 3$, the second and third booster sessions (B2 and B3) were in January and March 1992, between T3 and T4. The design of the effect study is shown in Table 2.

Table 2

Design of effect study

\begin{tabular}{l|cccccccc} 
& T1 & Int & T2 & $B 1$ & T3 & $B 2$ & $B 3$ & D4 \\
\hline Expl & 0 & 0 & 0 & & 0 & & & 0 \\
Expl $+B$ & 0 & 0 & 0 & 0 & 0 & 0 & 0 & 0 \\
$\operatorname{Exp2}$ & 0 & 0 & 0 & & 0 & & & 0 \\
$\operatorname{Exp2}+B$ & 0 & 0 & 0 & 0 & 0 & 0 & 0 & 0 \\
$\operatorname{Con}$ & 0 & & 0 & & 0 & & & 0 \\
\hline
\end{tabular}

Expl = Social influence program

Expl $+B=$ Social infinence program with booster

Exp2 $=$ Decision-making program

Exp2 + B $=$ Decision-making program with booster

Con $=$ Control group 
Questionnaires for the effect evaluation were distributed by teachers. No procedures to enhance self-report validity were used because of organizational difficulties. However, questions to check the self-reported behavior were used to minimize errors of self-reporting. These questions were: Do you smoke? (yes/no); Did you smoke the last seven days (a cigarette or a puff of a cigarette)? (yes/no); Did you ever smoke last year? (yes/no); How many cigarettes do you smoke per day?; Since how many days/weeks/months/years do you smoke? Self-reports, however, have been demonstrated to be accurate when anonymity and confidentiality were assured and an identification coding system was used. ${ }^{\text {96-102 }}$ Therefore, subjects were assured of anonymity and confidentiality and that no one but the researchers had access to the data. When subjects finished their questionnaire, teachers put them in an envelope, sealed it and sent it via the health educators to the researchers. Moreover, at each assessment students provided an identification code consisting of the subjects initials, date of birth, gender, school, and class. This code was the same in each test. With regard to possible selective drop-outs, students were not informed when the measurements would take place. To naximize numbers of subjects and minimize possible attrition artifacts, all subjects who participated at any posttest survey who could be matched with pretest data were included in the analysis. ${ }^{103}$ This resulted in overlapping but not identical samples at $\mathrm{T} 2$ $(\mathrm{N}=4060), T 3(\mathrm{~N}=3653)$ and at $\mathrm{T} 4(\mathrm{~N}=3104)$.

The goal of the effect evaluation was to assess the effects of the smoking prevention programs and boosters, as well as possible differential treatmenteffects between the four year education stuclents and the five/six-year education students, and possible differential treatment-effects between students of the second and third grade.

The questionnaires, based on the ASE model, included questions on attitudes, knowledge, social norms, modeling, social pressure, self-efficacy, intention and smoking behavior, and also measured demographic variables. Smoking behavior was based on self-reports, categorizing students as: 1 . never a smoker: never smoked one (puff of a) cigarette; 2 . initial smoker: tried smoking up to five times; 3. quitter; 4. occasional smoker: smokes occasionally but not every week; 5 . weekly smoker: smokes at least one cigarette per week; 6 . daily smoker: smokes at least one cigarette per day. The main goal of the programs was to prevent students form (regular) smoking. Therefore, occasional, weekly and daily smokers formed one group of smokers, while never smokers, initial smokers and quitters formed one group of nonsmokers.

The results indicated that four months after the implementation of the interventions, both programs were effective in preventing smoking among 
students who were nonsmokers at pretest. No program effects were found for smokers. Smoking increased by $2.1 \%$ in the decision-making group compared to $2.0 \%$ in the social influence group, and $3.9 \%$ in the control group. Ten and sixteen months after the intervention, the social influence program including the boosters resulted in a preventive effect on smoking for the entire high school population, whereas the social influence program without the booster failed to show an effect. Ten months after the intervention the decision-making program without the booster was effective in preventing smoking compared to the control group. At sixteen months after the intervention, this effect was smaller and just failed to be statistically significant. With regard to the decision-making program, at ten as well as at sixteen months after the intervention, boosters did not contribute to a greater effect and even appeared to be counter-productive. At ten months after the intervention, smoking increased by $8.1 \%$ in the decision-making group without the booster compared to $10.6 \%$ in the decisionmaking group with the booster, $12.2 \%$ in the social influence group without the booster, $5.6 \%$ in the social influence group with the booster, and $12.6 \%$ in the control group. At sixteen months after the interventions these percentages were, respectively, $10.4 \%, 12.8 \%, 13.9 \%, 9.7 \%$ and $14.9 \%$.

Although expected, no interactions were found between type of school and treatment. In both experimental groups the increase in smoking at the different posttests was lower compared to the increase in smoking in the control group. Moreover, fewer students of the social influence program started smoking compared with students of the decision-making program at T2. At T3 and T4, fewer students of the social influence program with the boosters started smoking compared with students of the social influence program without the booster and the decision-making program with and without the boosters.

Chapter 5 also reports about the effects of the programs on attitude, knowledge, social norms, perceived behavior, social pressure, self-efficacy, and intention at $\mathrm{T} 2$ and $\mathrm{T} 4$. Results at $\mathrm{T} 3$ were not reported, but showed the same patterns. The most profound results were found regarding knowledge, selfefficacy and intention. With regard to knowledge, at T2 and T4 both programs resulted in an increase in knowledge compared with the control group. Only in the second grade did the boosters have a contribution in this increase. With respect to self-efficacy, at $\mathrm{T} 2$ both programs resulted in higher levels of selfefficacy for nonsmokers, and among the decision-making program for smokers. However, at T4 these effects had disappeared. It may be that repetition of practicing skills to resist pressure to smoke by performing role-plays is necessary to attain long term effects. A change in intention to smoke was achieved only in the third grade. At $\mathrm{T} 2$ both programs resulted in a more 
negative intention to smoke; at $\mathrm{T} 4$ only the decision-making program resulted in a greater negative intention to smoke.

\section{$9 \quad$ Methodological issues}

Reviews of the smoking prevention research have yielded several points of criticism on methodological grounds..$^{30-33,36}$ These critiques centered on 1 . the use of appropriate comparison groups; 2 . the unit of analysis; 3 . the validity of dependent variable assessment; 4 . no acknowledgement of pretest differences; 5. construct vallidity of the prevention model; 6 . the control of research attrition; and 7 . the effect of completing questionnaires. In discussing the present project we will focus on these issues below.

Reviewers have consistently expressed concern over the appropriateness and comparability of control groups since most school-based studies have assigned units other than individuals to conditions. With few units to assign, the potential for achieving equivalence between comparison groups is reduced. The present study did use schools as unit of assignment. Moreover, the number of schools needed for participation in the project was based on the purpose to use schools as the units of analysis. Furthermore, four-year education schools and five/sixyear education schools were randomly assigned to treatment and control conditions. Because in this study the unit of assignment as well as the unit of analysis were schools, we may conclude that in the present study appropriate comparison groups were used.

Although many effect studies utilized students as unit of analysis, the use of schools or classrooms as unit of analysis is recommended on statistical grounds. ${ }^{30,32,33,104}$ Therefore, in the present study, schools were the units of analysis, because program implementation was on the level of schools. Since the programs had a three-level sample (schools, classes, students), multilevel analyses using VARCL were performed to check the results of SPSS X analysis (which ignored the nested character of our sample) against VARCL analysis. Logistic regression was used for binary effect measures. Since VARCL only gives an approximation to logistic regression which sometimes runs into computational problems, model reduction was done using SPSS. The initial models were reanalyzed with VARCL to check if any substantial inter-school or inter-class effects occurred that might distort the SPSS results.

The dependent variable in the present study is smoking behavior. Self-reports were used to measure smoking behavior. No procedures to enhance self-report validity were used because of organizational difficulties. However, self-reports have been demonstrated to be accurate when anonymity and confidentiality were 
assured and a coding system was used. ${ }^{56-102}$ Therefore, at each assessment students provided an identification code consisting of subjects' initials, date of birth, gender, school, and class. Moreover, anonymity was assured and teachers were ordered to put the questionnaires in an envelope and to seal the envelope in the classroom, in front of the students. Consequently, it is plausible to state that the reported smoking behavior is probably not an underestimation of real smoking behavior. However, a method that might add to confidentiality is to allow students to seal their own questionnaire in a plain envelope. ${ }^{105-107}$

Statisticall methods can be employed to reduce the likelihood of selection bias because of pretest differences. Consequently, in analyzing the effects of the programs, pretest scores were taken into account by including them as covariates,

McCaul \& Glasgow ${ }^{108}$ describe three reasons why assessing construct validity may be important. First, research on the construct validity will improve theory testing and development. The validity of the theoretical models can best be assessed by evaluating whether successful treatments do influence the theoretically relevant intervening variables and whether these variables are associated with treatment outcome. Second, for generalization purposes it may be wise to know which components are the most powerful since program users do not always adopt the program in its entirety. Third, an understanding of construct validity may lead to more efficient and less costly programs. It is therefore essential to determine how effects of programs are obtained by assessing the effects of prevention programs on process measures, such as attitudes, self-efficacy scores, and intentions. The results of the study described in this thesis indicate that, with regard to different grade levels and different types of schools, the programs significantly impacted on a number of hypothesized mediating variables in a direction consistent with non-smoking. The results do not provide a clear insight in the most important components of the programs. ${ }^{108}$ However, a notable finding from the present study is that the effect on self-efficacy expectations to refuse a cigarette in different situations for nonsmokers at T2, had disappeared at T4. This result suggests that a social influence program may not be effective in maintaining tobacco refusal skills. Consequently, repetition of practicing skills by conducting role-play, may be necessary to attain long-term effects. Another explanation for the results is that at $\mathrm{T} 2$, four months after the intervention, students were still convinced of their ability to cope with pressure and challenging situations, while sixteen months after the intervention, students may have obtained more realistic expectations about the actual difficulties of these situations. 
Attrition can be a threat to the validity of prevention research studies. ${ }^{109}$ Attrition can limit the degree to which findings can be generalized to all participants, particularly if one type of subject is more likely to drop out of the study. Further, if there is differential attrition by condition or if there is a behavior status-by-condition interaction in attrition such that different kinds of people are dropping out of different conditions, the internal validity of a study is brought into question. Many studies failed to report condition specific rates of attrition or conduct statistical tests for differential atrition. Studies that did document rates of attrition and direction of bias indicated that attrition was generally greater among baseline smokers than baseline nonsmokers and among control than treatment subjects. ${ }^{33}$ In the present study, at T3 and T4 more baseline smokers dropped out compared to baseline nonsmokers. Although there was no interaction between baseline smoking and treatment condition, the attrition analysis indicated that treatment was a factor of attrition at $\mathrm{T} 2$ and $\mathrm{T} 4$. At T2 attrition among control subjects was greater than among treatment subjects. However, at T4 attrition among subjects on the decision-making program was greater than among control subjects. Although students were not forewarned about the time of assessment, and attrition can partly be attributed to factors such as illness and changing to another school, the treatment effects on attrition required that the effects at both measurements were reanalyzed with dropouts receiving the last recorded smoking status they had. Fortunately, the results of these reanalyses were comparable with the results of the analysis without the dropouts. Consequently, the assumption can be made that the preventive effects of both programs at $\mathrm{T} 2$ and $\mathrm{T} 4$ are reliable.

Although students of the control group did not receive a smoking prevention program, the questionnaire they had to complete at four points in time can be seen as an intervention. Consequently, completing the questionnaire can influence the answers of the control students. Therefore, it is advisable to compare the smoking rates of subjects in the study also with rates of a national reference group. Because schools in the present project are located in districts throughout the Netherlands, smoking rates of subjects in the study can be compared to national figures. National figures showed that the increase in smoking in high school students, in the same time period from T1 to T4, is $30 \%$, from $10 \%$ among 13-14-year-old students, to $40 \%$ among 15-16-year-old students (smoking was assessed by asking adolescents if they had smoked during the last four weeks, which is comparable to smoking in the study reported in this thesis). ${ }^{110}$ The increase of smoking prevalence among control students appeared to be less than in the national reference group, which may be caused by the intervention effect of completing questionnaires. 


\section{Implications for smoking prevention}

To enhance the impact of smoking prevention programs, this section provides several suggestions for future interventions and future research, regarding diffusion, implementation, structure of a smoking prevention program, content of a smoking prevention program, boosters, long-term follow-up, and comprehensive efforts needed to prevent adolescents from starting to smoke.

\subsection{Diffusion of smoking prevention programs}

A linkage approach in the small-scale implementation of a smoking prevention program at schools was found to be successful. Although further research may be necessary to study the use of the linkage approach in large-scale implementation, the application of a linkage system during diffusion of interventions is nevertheless recommended. Moreover, to make future health education interventions more effective, the linkage system should be incorporated in the entire process, ranging from problem analysis to continuation of the intervention.

Careful diffusion is essential for effective implementation of smoking prevention programs at schools. Future research should reveal if the proposed diffusion strategy, based on the results of the study on the predictors of implementation and continuation of the Dutch smoking prevention program (Chapter 3), can contribute to effective diffusion of school-based interventions.

\subsection{Implementation and structure of smoking prevention programs}

The teacher-independent character of the programs resulted in complete implementation of the programs. Because of the intention of the programs to be teacher-independent, all the information on the content and structure was given on video. Consequently, there was no time left for teachers to go further into matters that were discussed or happened during the lessons. However, some teachers indicated they would like to have the opportunity for further discussion. Therefore, in future video-peer-led programs it is recommended to include time during the lessons or the program to give teachers the opportunity for this.

Both the implementation evaluation and the program evaluation indicated that teachers preferred a program less than the current five lessons. There are three alternatives to handling this problem. The first is to modify the program by developing a program of, for example, three lessons. However, research, has 
shown that more lessons are necessary to make an effective program. ${ }^{30,43.62 .70}$ To be sure that a program will yield positive results, a program must consist of a miminum of five lessons completed with booster sessions. ${ }^{62}$ The second alternative is to incorporate a message into the diffusion strategy to change the perceptions of teachers regarding the number of lessons, i.e., it must be made clear that a program of two or three lessons may be ineffective. If teachers still prefer to use the program flexibly, they should be advised to focus on the most important topics such as social pressure and raising self-efficacy towards handling social pressures by role-play. The third alternative is to make the program part of a more comprehensive approach for health education, in which topics such as peer-group pressure are also dealt with when discussing other subjects, such as alcohol, gambling, and AIDS prevention.

Although, in the Netherlands, smoking increases rapidly between the ages of 13 and $14^{13}$, prevalence among 13 - and 14 -year-old high school students is still relatively low. Therefore, the two programs were implemented both in the second and in the third grade of high schools. Because the results showed no significant interaction between grade and treatment, the programs can be implemented in the second as well as the third grade. It is recommended that high-school teachers base the decision about the grade in which a smoking prevention program will be taught, on perceived smoking prevalence at their school.

\subsection{Content of smoking prevention programs}

The results of the first Dutch Smoking Prevention Program suggested different programs for vocational and high schools. "As Dutch high schools consist of three levels, it is possible that different programs are needed for these levels as well. It was assumed that five/six-year education students would have a higher need for cognitive processing of information compared to four-year level students. Accordingly, it was expected that the decision-making program would result in better preventive effects in five/six-year level students compared to four-year level students. However, there were no significant interactions between type of school and treatment. Thus, it can be concluded that the results of this project do not suggest that differential programs are necessary for the different levels of high schools to enhance effective smoking prevention programs.

The social influence program with the booster showed the best preventive effects, followed successively by the decision-making program without the booster, the decision-making program with the booster, and finally the social 
influence program without the booster. The results of the program evaluation indicated that students of both programs were positive about the sources and channels of the program. However, students receiving the social influence program were more positive compared to those receiving the decision-making program. Furthermore, interviews with teachers revealed that some students tired of applying the five steps to make a decision all the time. Nevertheless, the decision-making program without the booster appeared to be effective in preventing smoking at ten months after the intervention, and slightly effective at sixteen months after the intervention. Although the effectiveness of separate elements of the programs was not investigated, the present study indicates that the decision-making component in the decision-making program contributed to enduring effects compared to the social influence program. For future smoking prevention programs that include a decision-making component, it is advised to determine whether less frequent application of the steps to make a decision will be effective in preventing students from smoking.

The preventive effect of the social influence program without the booster disappeared after the first posttest. A possible explanation for this short-term effect is that a program of five lessons is not enough for effective skills training to resist smoking. Moreover, the significant effect on self-efficacy expectations at T2 disappeared at T4. Another study also found that their prevention programs did not produce long-term changes in refusal skills. ${ }^{111}$ Therefore, future research should assess whether repetition of refusal skills by conducting role-play is necessary to enhance preventive effects of the social influence program. Another factor that plays a role in becoming a smoker is self-esteem. Compared with nonsmoking adolescents, those who begin to smoke appear to have lower self-esteem and self-images. For these adolescents, smoking becomes a self-enhancement mechanism: they smoke cigarettes to enhance their low self-esteem by improving their external image by appearing mature or "cool". ${ }^{43}$ Including personal skills training to enhance students" self-esteem might contribute to successful smoking prevention.

\subsection{Boosters}

To stimulate maintenance of the non-smoking behavior, boosters were added to the program. Because of the teachers" tight curriculum, it was not feasible to develop additional lessons on smoking prevention. Therefore, three newsletters were developed. These newsletters were not discussed at class level. Consequently, few students on either program reported having read all three newsletters. However, at sixteen months after the intervention, the boosters 
appeared effective in enhancing the preventive effects of the social influence program. Further research is needed to assess whether regular distribution of newspapers can contribute to long-term effects of the social influence program, or whether a more intensive use of the newsletters, for example discussing them at class level, is needed. If regular distribution of newsletters appears to be an effective method to enhance behavioral effects, the time-interval between distribution of the newsletters and till what grade or age the newsletters need to be distributed needs to be determined.

The booster did not contribute to the effects of the decision-making program. Moreover, although not significant, the decision-making program without the booster showed better preventive effects compared with the decision-making program with the booster. It is not clear why the booster reduced the effectiveness of the decision-making program. A possible explanation is that the newsletters had a better link with the social influence program, since their content focused mostly on issues related to social influence. Because the effects of the decision-making program just failed to be statistically significant at $\mathrm{T} 4$, further research should determine whether boosters with decision-making related issues, e.g., issues based on the five steps to make a decision, contribute to long-term preventive effects of the decision-making program.

\subsection{Long-term follow-up}

Although the results indicate that the social influence program with the boosters can be used to delay the onset of smoking among a small percentage of high school students at sixteen months after the intervention, additional follow-up is needed to determine the durability of these findings. If school-based smoking prevention programs are to contribute significantly to reducing the morbidity and mortality caused by cigarette smoking, it is necessary to demonstrate a long-term reduction in smoking prevalence. Studies that conducted long-term follow-up indicated that reported effects become smaller at longer terms, until they disappear altogether at six-year follow-up. ${ }^{12,113}$ However, long-term effects of smoking prevention are reported when the program was embedded in a more comprehensive community approach. ${ }^{14,115}$

A difficulty with regard to long-term follow-up is tracking individuals, including drop-outs, over time. Recently, investigators have begun to develop a practical set of techniques to facilitate follow-up of adolescents. "16 Most important are good background data on each student and long-term cooperation by participating schools. Specific data items which are particularly useful in tracking younger adolescents include full names of both parents or guardians, 
birthdate of child, Social Security numbers of parents and child, and information on school transfers. The names of contact persons and future plans of the familly are also useful. Further research is necessary to determine if these tracking techniques are also feasible in the Netherlands.

\subsection{Comprehensive efforts needed to prevent adolescents from smoking}

Since the majority of smokers start to smoke before the age of 18 , and giving up smoking is not easy, it has been assumed that prevention is the best option to reduce adult prevalence. In practice, research suggested that prevention programs for adolescents can only make a small contribution because interventions at school only have a temporary delaying effect on teenage smoking, and because those interventions are targeted primarily at the individual adolescent and do not create a supportive environment. Therefore, it can be recommended to embed smoking prevention in a community-wide intervention, which also addresses the social environment to aid adolescents to remain nonsmokers. Two studies that nested school-based smoking prevention programs within a community-based intervention, after six years still found lower smoking prevalences in the intervention communities compared to reference communities. ${ }^{114,115}$ Community interventions should include different components directed on adolescents (such as school-based smoking prevention programs, smoking prevention outside the school, and cessation programs), adults (e.g., cessation programs) and the community as a whole (e.g., structural changes, national support, mass media campaigns). When both school and community channels are used for affecting adolescent tobacco-use behavior, better preventive effects can be achieved. Moreover, an advantage of community interventions is the possibility to reach youths who leave or drop out of the school, since several studies reported high rates of smoking by early school leavers or dropouts. ${ }^{112,117}$ Messages concerning tobacco use will be more acceptable for these adolescents when embedded in community groups or programs to which these youths already belong. ${ }^{43.118}$

In the Netherlands there are no documented examples of the effectiveness regarding smoking prevention activities for youngsters outside the schools. However, in countries like the UK, France, Portugal and Australia, clubs were launched to try to reduce the uptake of smoking in children aged $11-14 .{ }^{11 \%}$ For instance, the UK "Smoke Busters club" aims to promote a non-smoking lifestyle amongst young teenagers by providing quarterly newsletters, a membership/discount card valid at many shops in the area, and activities such 
as discos and competitions. Membership is intended to provide the young person with a peer group which is positive about non-smoking and to provide hints on how to refuse cigarettes without a loss of face. Moreover, non-smoking is portrayed as the norm. An evaluation study suggested that after 22 months, those who joined Smoke Busters were more than twice as likely to remain nonsmokers as those who were non-members. ${ }^{119}$ However, it was not possible to know whether this was the result of the campaign or not, and whether these clubs also appeal to older adolescents.

Despite efforts to prevent adolescents from starting to smoke, many of them will still start to smoke. Although there is strong evidence that many adolescent smokers do want to stop ${ }^{51}$, until now little attention has been paid to smoking adolescents. Although, there are examples of prevention oriented programs that produce (short-term) cessation. ${ }^{8,30,64}$, cessation programs, containing components designed to motivate adolescents and young adults to consider quitting, should be developed. However, what makes a successful teenage quitter is still largely unknown. ${ }^{120}$ Only few studies ${ }^{12+124}$ have examined adolescent smoking cessation interventions in and outside the school ${ }^{43}$. These interventions revealed that it is difficult to recruit and retain adolescent smokers in programs. Adolescents may be concerned about parents or teachers learning that they smoke, since parental consent could be required for participation. Adolescents may also be less motivated than adults to quit, since long-term health consequences are less important for them. Adolescent smokers frequently try to quit, but they are often unsuccessful, have withdrawal reactions much like adult smokers, and are not responsive to programs thus far developed. Charlton ${ }^{121,125}$ identified several factors which appear to mediate the success of cessation programs. These included awareness of the health and social issues of smoking, motivations such as future career which demands a non-smoking status, grouping students with a common goal together for a course (e.g., students with the same career aims), arranging course sessions at times when students must be in college, not at lunchtime or after the college day, small groups meeting regularly and within a short time span, feedback on progress such as is provided by a carbon monoxide monitor, and constant reinforcement and encouragement by the tutors. Furthermore, she recommends to start smoking cessation programs at the age of 16 , since at that stage adolescents show an increase in the serious intention to quit smoking, because of their relative maturity, and their nearness to leaving school and taking up training for a career which might require them to be nonsmokers. ${ }^{21.125}$ Further basic research and new directions for cessation interventions for adolescents are recommended, because in the absence of intervention, adolescent smokers will most likely become adult smokers. 
Besides cessation programs, prevention programs are needed for 15 - to 25 m year-old adolescents, because smoking incidence is high in this group. ${ }^{110}$ However, in the Netherlands, no information is available about the determinants of smoking in this group and about how to reach this group. Therefore, it is recommended to start a study on the determinants and the channels to reach this group and to developing intervention programs.

It is hardly credible that smoke-free cohorts of young people can be achieved by the year 2000 on the basis of school based programs alone, while the tobacco industry can continue the promotion and sale of its products. Cigarette advertising appears to increase young people's risk of smoking by affecting their perceptions of the pervasiveness, image, and function of smoking. It is therefore recommended to the Dutch government to take a far more active role in enhancing smoking prevention, for instance by legislative means, the integration of smoking prevention in the curriculum of secondary schools, providing financial resources for diffusion and implementation of successful smoking prevention programs in schools, and promotion of community programs. Since the programs of the project described in this thesis, appeared to be effective in preventing adolescents from starting to smoke, it is strongly recommended to implement these programs in Dutch high schools. As described above, community programs in combination with school programs can produce synergistic effects with regard to adolescent smoking. Moreover, the Dutch government can be recommended to consider increase of the price of tobacco products. Studies have found a relationship between cigarette prices and cigarette smoking, suggesting that increased excise taxes on cigarettes would significantly reduce overall rates of cigarette smoking..$^{43}$ Moreover, these studies concluded that much of the impact of higher prices would come from encouraging cessation among current smokers and discouraging initiation among young smokers. The effects on adolescents is at least as high, if not significantly higher, than that on adults, suggesting that an increase in cigarette taxes would result in large reductions in smoking prevalence and cigarette consumption among teenagers. For example, in Canada, over the last ten years, cigarette consumption fell by a third while the "real" price doubled. ${ }^{126}$ "Real" prices are prices controlling for the effect of inflation. Goods, including tobacco, can also become relatively more affordable as real incomes rise, and more people can buy more goods. This means that nominal prices of tobacco have to be increased regularly, just to keep up with the effects of generally rising prices and incomes. What is most encouraging from the increase in tobacco prices in Canada, is that the gains have been realized particularly among adolescents: teenage consumption was reduced by 62 percent. ${ }^{43}$ 
The recommendations discussed are summarized below.

Diffusion of smoking prevention programs
Implementation and structure of smoking prevention programs
1. Application of a linkage system during diffusion of interventions, and further research to study the use of the linkage approach in large-scale implenentation of smoking prevenvion programs.

2. Participation of a linkage system in the entire process, ranging from problem analysis to continuation of the intervention.

3. Further research to reveal the effectiveness of the proposed diffusion process.

1. Inclusion of time during the lessons of the program to give teachers the opportunity for further discussion.

2. Need to convince teachers of the ineffectiveness of less than five lessons or devellopment of a more comprehensive approach for schooll-based health education interventions.

3. Recommendation that high-school teachers base the decision about the grade in which the smoking prevention program will be taught on perceived smoking prevalence at their school.

Content of smoking prevention programs

1. Future research to determine if less frequent application of the steps to make a decision will be effective in preventing students from smoking.

2. Future research to assess if repetition of refusal skills by conducting role-play is necessary to enhance preventive effects of the social influence program.

Boosters
1. Further research to assess if regular distribution of newspapers can contribute to long-term effects of the social influence program, to determine if a more intensive use of the newsletters is needed, on which time-interval newsletters should be distributed and till what grade or age.

2. Further research to determine if boosters with decisionmaking related issues, may contribute to long term preventive effects of the decision-making program. 
Long-term

follow-up

Comprehensive efforts
1. Follow-up study to determine the durability of the preventive effects of the programs with boosters.

2. Research to assess which tracking technique is feasible in the Netherlands.

1. Embedding of smoking prevention in a community-wide intervention.

2. Development of preventive activities outside schools and research to study the effectiveness of these activities.

3. Further research and new directions for cessation interventions for adolescents.

4. Initiation of a study on the determinants and channels to reach 15 - to 25 -year-old young people with regard to the development and diffusion of intervention programs for this age group.

5. A far more active role by the Dutch government in enhancing smoking prevention.

6. Implementation of the social influence program with the booster and decision-making program in Dutch high schools.

\section{References}

1. Scenario Commission Cancer (Scenariocommissie Kanker). Kanker in Nederland (Cancer in the Netherlands), part 1. Utrecht: Bohn, Scheltema \& Holkena, 1978.

2. Doll R. The prevention of cancer: Opportunities and challenges. Keynote address. The prevention of cancers: Spreading the message. A European Colloquium of Cancer and Health Promotion Experts “ Lisbon, February, 1989.

3. Doll R, Peto R. The causes of cancer: Quantitative estimate of avoidable risks of cancer in the United States today. Journal of the National Cancer Institute. 1981;66:1191-1308.

4. Dutch Foundation on Smoking and Health. Ammal Reports 1990-1993, The Hague.

5. Botvin GJ, Baker E, Botvin EM, Dusenbury $\mathbb{L}$, Cardwell $\mathbb{J}$, Diaz $T$. Factors pronoting cigarette smoking among black youth: A causal modeling approach. Addictive Behamiors. $1993 ; 18: 397-405$.

6. De Vries H, Dijkstra M, Kok Gl. Succesvolle rookpreventie is realisectbar. Medisch Contact. 1990;43:1285-1287.

7. De Vries $H$, Dijkstra M, Kok GJ . Rookpreventie: Resultaten van een Nederlands jongeren project. Tijdschrift voor Kindergeneeskunde. 1993;61:243-251.

8. De Vries H. Backbier E, Dijstra M, Van Breukelen G, Parcel G, Kok G. A Dutch social influence smoking prevention approach for vocational school students. Health Education Research. 1994:9:365 374. 
9. De Vries H. The ABC of health education and planning; a brief reader for the summer universty course. Maastrich: Department of Health Education. University of Limburg, 1993.

10. Leventhal $H$, Cleary $P D$. The smoking problem: A review of the research and theory in behavioral risk modification. Psychological Bulletin. 1980;88:370-405

11. De Vries H. Smoking prevention in Dutch adolescents. Dissertation. Maastricht: Datawyse, 1989.

12. Mudde AN. The development and evaluation of a community and a mass media approach ro smoking cessation. Dissertation. Maastricht, 1994.

13. De Vries $H_{3}$ Kok $\mathrm{G}$. From determinant of smoking behaviour to the implications for a prevention programme. Health Education Research. 1986:1:85-94.

14. De Vries H, Dijkstra M, Kuhlman P. Self-efficacy: the third factor besides attitude and subjective norm as a predictor of behavioral intentions. Health Education Research. $1988,3: 273-282$

15. De Wries H, Kok G. A program matrix to plan and evaluate behawioral interventions. Submitted for publication.

16. Kok $G$, De Vries $\mathbb{H}$. Primary prevention of cancers: The need for health education and intersectoral health promotion. In: Heller T, Davey B, Baily L. (Eds.) Reducing the risk of cancers (pp. 99-111). London: Hodder and Stoughton, 1989.

17. Green LW, Kreuter MW. Health promotion planning; An educational and environmental approach. Palo Alto: Mayfield Publishing Company, 1991.

18. Basch $\mathrm{CE}$. Research on disseminating and implementing health education programs in schools. School Health Research. 1984;54:57-66.

19. De Vries, H. Diffusie van interventies. In: Damoiseaux V, wan der Molen HT, Kok GJ. (Red.) Gezondheidswoorliching en gedragsverandering (pp. 337-351), Van Gorcum, Assen, 1993.

20. Kolbe LJ, werson DC. Implementing comprehensive health education: Educational innovations and social change. Healkh Education Quarterly. 1981;8:57-80

21. Orlandi $M$. The diffusion and adoption of worksite health promotion innovations: An analysis of barriers. Preventive Medicine. 1986,15:522-536.

22. Orlandi MA. Promoting health and preventing disease in health care settings: An analysis of barriers. Preventive Medicine. 1987;16:119-130.

23. Orlandi MA, Landers $C$, Weston $R$, Haley $N$. Diffusion of health promotion innovations In: Glanz K. Lewis FM, Rimer B. (Eds.) Health behavior and healh education: theory, research and practice. San Francisco: Jossey-Bass, 1990.

24. Havelock R. Planning for innowation throrgh dissemination and utilization of knowledge. Ann Arbor, Michigan: Institute for Social Research, 1971.

25. Dutch Foundation on Smoking and Health. Ammal Repont 1992. The Hague.

26. Van Reek J, Adrianse H. Smoking policy in the Netherlands since the fifties: One factor in the social dynamics of changes in smoking behaviour. Health Policy. 1987;7:361-368.

27. Cleary PD, Hitchcock IL. Semmer N. Flinchbaugh LJ, Pinney J. Smoking behavior and policy. Discussion Paper Series. Cambridge: Institute for the study of smoking behavior and policy, Harkard University, 1986.

28. Bangert-Drowns RL. The effects of school-based substance abuse education: a metaanalysis. Journat of Drug Education. 1988;18:243-264. 
29. Battjes RJ. Prevention of adolescent drug abuse. International Jownal of Addiction. $1985 ; 20: 1113-1134$.

30. Best RJ, Thompson SJ, Sant SM, Smith EA, Brown KS. Preventing cigarette snoking among school children. Ansual Review of Public Health. 1988:9:161-201.

31. Bruwold WH. A Meta-Analysis of Adolescent Smoking Prevention Programs. Americam Joumal of Public Healh. 1993;83:872 880 .

32. Flay BR. Psychosocial approaches to smoking prevention: A review of findings. Health Psychology. 1985;4:449-488.

33. Hansen WB. School-based substance abuse prevention: A review of the state of the art in curriculum, 1980-1990. Health Education Research. 1992;7:403-430.

34. Rundall TG. Bruvold WH. A Meta-analysis of School-based Smoking and Alcohol Use Prevention Programs. Health Education Quarterly. 1988;15:317-334.

35. Tobler NS. Meta-analysis of 143 adolescent drug prevention programs: Quantiative outcome results of program participants compared to a control of comparison group. Journal of Drug Issues. 1986;16:537-567.

36. Snow WH, Gilchrist LD, Sichinke SP. A critique of progress in adolescent smoking prevention. Child Youth Serv Review, 1985;7:1-19.

37. Thompson EL. Smoking Education Programs 1960-1976. American Journal of Public Health. $1978 ; 68: 250-257$.

38. Leventhal H, Cleary PD. The smoking problem: A review of the research and theory in behavioral risk modification. Psychological Bulletin. 1980;88:370-405.

39. Silvestri B, Flay BR. Smoking Education: Comparison of Practice and State-of-the-Art. Prevertive Medicine. 1989;18:257-266.

40. Evans RI, Rozelle RM. Mittelmark MB, Hansen WB, Bane AL, Havis J. Deterring the onset of smoking in children: Knowledge of immediate physiological effects and coping with peer pressure, media pressure and parent modeling. Journal of Applied Social Psychology, 1978;8:126-135.

41. Bandura A. Self-efficacy: Toward a unifying theory of behavior change. Psychological Review. 1977;84:191-215.

42. McGuire WJ. Inducing resistance to persuasion. In: Berkowitz L. (Ed.), Advances in Experimental Social Psychology, Vol 1. New York: Acadenic Press, 1964.

43. U.S. Department of Health and Human Services. Public Health Service Preventing tobacco use among young people. A Report of the Surgeon General. USDHHS NO. (CDC) Washington, DC, Government Printing Office. 1994.

44. Arkin RM, Roemhild HF, Johnson LA, Luepker RV, Murray DM. The Minnesota Smoking Program. The Journal of School Healh. 1981:11:611-616.

45. Best JA, Flay BR, Towson SMJ, Ryan KB, Perry CL. Brown KS, Kersell MW. D"Avernas . Smoking prevention and the concept of risk. Journal of Applied Social Psychology. $1984 ; 14: 257-273$.

46. Biglan $A$, Glasgow $R$, Ary D, Thompson R, Severson $H$, Lichtenstein $E$, Weisnatn $W$, Faller $C$, Gallison $C$. How generalizable are the effects of smoking prevention programs? Refusal skills training and parent messages in a teacher-administered program. Joumal of Behavioral Medicine. 1987; 10,613-628.

47. Botvin GJ, Eng A. A comprehensive school based smoking prevention program. Journal of School Health. 1980;50:209-213. 
48. Botvin G., Baker E, Renick N, Filazzola AD, Botwin EM. A cognitive behavioral approach to substance abuse prevention. Addictive Behaviors. 1984;9:137-147.

49. De Vries H. Dijkstra $M$. Kok $G$. A Dutch smoking prevention project: An overwiew. Hygie 1992;11:14-18.

50. Dielman TE, Lorenger AT, Leech SL, Lyons AL, Klos DM. Fifteen-month follow-up results of an elementary school based smoking prevention project. International Journal of Mealth Education (Hygie). 1985;4:28-35.

51. Flay BR, DAvernas JR. Best IA, Kersell MW, Ryan KB. Cigarette smoking: why young people do it and ways of preventing it. In: MoGrath PI, Firestone P. (Eds.) Pediatric and Adolescent Behavioral Methine. Springer, Wew York, Pp. 132-183, 1983.

52. Gilchrist LD, Schinke SP. Self-control skills for smoking prevention. In: P.F. Engstrom, Anderson PN, Mortenson LE. (Eds.) Advances in cancer control (pp. 125-130). New York: Alan Liss, 1984.

53. Hurd PD, Johnson CA, Pechacek $T$, Bast $L$ P, Jacobs PR, Luepker RV. Prevention of cigarette smoking in seventh grade students. Journal of Behavioral Medicine. 1980;3:1528.

54. McAlister A, Perry C, Maccoby N. Adolescent smoking: onset and prevention. Pediatrics. 1979,63:650-658.

55. Murray DM, Pirie P, Luepker RV, Pallonen U. Five- and six-year follow-up results from four sevently-grade smoking prevention strategies. Jonmal of Behavioral Medicine. $1989: 12: 207-218$.

56. Perry CL., Kullen J, Slinkard LA. Peer teaching and smoking prevention among junior high school students. Adolescence. 1980;15:277-281.

57. Schinke SP, Blythe BJ. Cognitive behavioral prevention of children's smoking. Child Behavior Therapy. 1981;3:25-42.

58. Telch MJ, Killen JD, McAlister AL, Perry CL, Maccoby $N$. Long-term follow-up of a pilot project on smoking prevention with adolescents. Joumal of Behavioral Medicine. $1982 ; 5: 1-7$.

59. Ajzen I, Fishbein M. Understanding Attitudes and Predicting Social Behavior. Englewood Cliffs, NJ: Prentice-Hall; 1980.

60. Bandura A. Social Foundations of Thought and Action. Englewood Cliffs, NJ: PrenticeHall, 1988.

61. Botvin G.. Substance abuse prevention research: Recent developments and future directions. Jownal of School Hearh. 1986;9:369-374.

62. Glynn TJ. Essential Elements of School-Based Smoking Prevention Programs. Journal of School Heath. 1989;59:181-188.

63. Klepp KI, Haper A. Perry CL. The efficacy of peer leaders in drug abuse prevention. Jownal of School Healm. 1986;56:407-411.

64. Perry $\mathrm{CL}$. Telch MJ, Killen MJ, Burke J, Maccaby N. High school smoking prevention: The relative efficacy of varied treatments and instructions. Adolescence. 1983;18:561-566.

65. Murraly DM. Johnson CA. Luepker RV, Mittelmark MB. The prevention of cigarette smoking in children: A comparison of four strategies. Josrnal of Applied Sochal Psychology. 1984; 14:274-288.

66. Tell GS, Klepp KI. McAlister AL, Perry CL, Maccoby N. Long-term follow-up of a pilot project on smoking prevention with adolescents. Journal of Behavioral Medicine. 1982;5:17. 
67. Vartiainen E, Puska $P$. Koskela $K$, Nissinen A, Toumilehto J. Ten-year results of a conmunity-based anti-smoking program (as part of the North Karelia Project in Finland). Heath Education Research. 1986:1:175-184.

68. Perry CL, Murray DM, KJepp KI. Predictors of adolescent smoking and implications for prevention. Morbidity and Mortaliry Weetly Report. 1987;36:415-455.

69. De Vries H, Weyts W, Dijkstra M, Kok G. The utilization of qualitative and quantitative data for health education program planning, implementation and evaluation: A spiral approach. Health Education Quarterly. 1992;19:101-115.

70. Chatrou M. Determinans of smoking and smoking prevention in Duth adolescens. Dissertation. Leiden: DSWO Press, Leiden University, 1992.

71. Kok GJ, De Vries H, Mudde AN, Strecher VJ. Planned health education and the role of self-efficacy: Dutch research. Health Education Research. 1991,6:231-238.

72. Janz NK, Becker MH. The Health Belief Model: A decade later. Healsh Education Quarterly. 1984;11:1-47.

73. Bandura A Social Foundations of thought and action. A sociat cognitive theory. Englewood Cliffs, NJ: Prentice-Hall Inc, 1986.

74. Ajzen 1, Madden IT. Prediction of goal-directed behavior: attiudes, intentions, and perceived behavioral control. Journal of Experimental Social Psychology, 1986;22:453-474.

75. De Vries H. Socio-economic differences in smoking: Dutch adolescents beliets and behaviour. Social Science and Medicine. In Press.

76. Prochaska JO, Velicer WF, Guadagnoli E, Rossi JS, DiClemente CC. Patterns of change: Dynamic typology applied to smoking cessation. Multivariate Behawioral Research. 1991:26:83-107.

77. De Vries $H$, Backbier E. Self-efficacy as an important determinant of quitting among pregnant women who smoke: the Ø-Pattern. Preventive Medicine. 1994;23:167-1.74.

78. Janis IL. Mann L. Decision Making: A Psychological Analysis of Conflict, Chotice, and Conmiment. Free Press, New York; 1978.

79. Basch CE, Sliepcevich EM. Innovators, innovations and implementation: Aramework for curricular research in school health education. Health Education. 1983; March/April:20-24.

80. Brink SG, Levenson-Gingiss P, Gottlieb NH. An evaluation of the effectiveness of a planned diffusion process: The smoke-free class of 2000 project in Texas. Healh Education Research. 1991;6:353-362.

81. Goodman RM, Steckler A. A framework for assessing program institutionalization. The International Journal of Knowledge Trangfer. 1989:2:57-71.

82. Goodman RM, Smith DW, Dawson L, Steckler A. Recruiting school districts into a dissemination study. Healh Education Research. 1991;6:373-385.

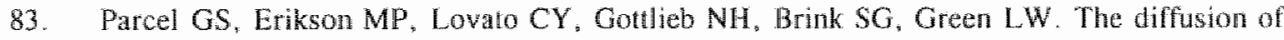
school-based tobacco-use prevention programs: Project description and baseline data. Healh Education Research. 1989;4:1111-124.

84. Parcel GS, Taylor WC, Brink SG, Gottlieb N, Engquist $K$, O'Hara NM, Erikson MP. Translating theory into practice: Intervention strategies for the diffusion of health promotion innovation. Fasnily \& Community Healih. 1989;12:1-13.

85. Parcel GS, Ross JG, Lavin AT, Portnoy B, Nelson GD, Winters F. Enhancing implementation of the teenage health teaching modules. Joumal of School Healh, 1991:61:19-22.

86. Rogers EM. Diffusion of innowations. New York: The Free Press, 1983. 
87. Mesters 1. Implementatie van een voorlichtingsprotocol in de eerste lijn. In: Damoiseatux ฟ, van der Molen HT, Kok GJ. (Red.) Gezondheidswoorlichting en gedragsverandering. Van Gorcum. Assen, 1993.

88. Levenson-Gingiss $\mathrm{P}$, Hamilton R. Determinants of teachers" plans to continue teaching a sexuality education course. Family \& Community Heath. 1989;12:40-53.

89. Parcel GS, Perry CL, Taylor WC. Beyond demonstration; diffusion of health promotion mnovations. In: Bracht $N$. (Ed.) Heath promotion at the community level Sage Publicarions, 1990.

90. Chambers Butler $\$$. Chief state school afficers rank barriers to implementing comprehensive school health education. Joumal of School Heath. 1993;63:130-132.

91. Tortu S, Botvin G. School-based smoking prevention: The teacher training process. Preventive Medicine. 1989:18:280-289.

92. Stein MK, Wang MC. Teacher development and school improvement: The process of teacher change. Teaching and Teacher Education 1988;4:171-187.

93. Connell DB. Tumer RR, Mason EF. Summary of findings of the school health education evaluation: health promotion effectiveness, implementation, and costs. Journal of School Healh. 1985;55:316-323.

94. Smith DW. MaCormick LK, Steckler AB, McLeroy KR. Teachers* use of healin curricula: Implementation of Growing Healthy, Project SMART, and the Teenage Health Teaching Modules. Jownal of School Healh. 1993;63:349-354.

95. Cook TD. Campbell DT. Quasi-experimentanion: Design and analysis issues for field settings. Chicago, Rand McNally. 1979.

96. Abernathy TJ, Bertrand LD. Preventing cigarette smoking among children: Results of a four-year evaluation of the PAL program. Candian Joumal of Public Health. 1992;8390:226-229

97. Akers RL. Massey J, Clarke W, Lauer RM. Are self-reports of adolescent deviance valid? Biochemical measures. randomized response, and the bogus pipeline in smoking belavior. Social Forces. 1983:62:234-251.

98. Botvin GJ, Botvin EM. Adolescent tobacco, alcohol, and drug abuse: Prevention strategies, empirical findings, and assessment issues. Developmental Behavioral Pediatrics. 1992;13 19:290-301.

99. Hansen WB, Malotte CK, Fielding JE. The bogus pipeline revisited: The use of the threat of detection as a means of increasing self-reports of tobacco use. Jownat of Applied Psychology. 1985:70:789-792.

100. Murray DM. Perry Cl. The measurement of substance use among adolescents: When is the 'bogus pipeline' method needed? Addicive Behoviors. 1987; 12:225-233.

101. Ransom MV. Peer perceptions of adollescent health behaviors. Journal of School Health. $1992: 62: 238-242$

102. The healh benefis of smoking cessation: a report of the Surgeon Generat. U.S. Department of Health and Human Services. Public Health Service. DHHS Publication No. (CDC) $90-8416,1990$

103. Johnson CA, Hansen WB. Collins LM, Graham W. High-school smoking prevention: Results of a three-year longitudinal study. Jownal of Behavioral Medicine. 1986;9:439. 452 .

104. Botvin GI, Baker E, Filazzola AD, Borvin EM. A cognitive-behavioral approach to substance abuse prevention: One-year follow-up. Addictive Behaviors. 1990;15:47-63. 
105. Charton A. Evaluation of a familywinked smoking programme in primary schools. Healh Education Journal. 1986;45:140-144.

106. Rawbone RG, Keeling CA. Jenkins A. Guz A Cigarette smoking among secondary schoolchildren in 1975. Jounal of Epidemiology and Commuity Healh 1978,32:53-58.

107. Rawbone RG, Guz A. Cigarette smoking among secondary schoolchildren $1975-79$. Archives of Disease in Childhood. 1982:57:352-358.

108. McCaul KD, Glasgow R. Preventing adolescent smoking: What have we learned about treatment construct validity? Healh Psychology. 1985;4:361-387.

109. Hansen WB, Anderson Johnson C, Flay BR, Graham JW, Sobel. J. Affective and social influence approaches to the prevention of multiple substance abuse among seventh grade students: Results from project SMART. Preventive Medicine. 1988:17:135\%154.

110. Dutch Foundation on Smoking and Health. Annual Report 1993, The Hague.

111. Elder JP. Sallis JF, Woodruff SI, Wildey MB. Tobacco-refusal skills and tobacco use among high-risk adolescents. Journal of Behavioral Medicine. 1993:16:629-642,

112. Flay BR, Koepke D, Thompson SI, Santi S, Best JA, Brown KS. Six-year follow-up of the first Waterloo school smoking prevention trial. American Joumal of Pablic Health. 1989;79:1371-1376.

113. Klepp KI, Oygard L, Tell GS, Vellar OD. Twelwe year follow-up of a school-based health education programme. European Journal of Public Health. 1994:4:195-200

114. Vartiainen E, Fallonen U, McAlister A, Puska P. Eight-year follow-up results of an adolescent smoking prevention program: The North Karelia Youth Project. American Jonrnal of Public Health. 1990;80:78-79.

115. Perry CL, Kelder SH, Murray DM, Kllepp KI. Community-wide smoking prevention: Long-term outcomes of the Minnesota Heart Health Program and the class of 1989 study. American Joumal of Public Health. 1992;82:1210-1216.

116. Pirie PL, Thompson SJ, Mam SL, Peterson AV, Murray DM, Flay BR, Best JA. Tracking and attrition in longitudinal school-based smoking prevention research. Preventive Medicine. 1989;18:249-256.

117. Pirie PL, Murray DM, Luepker RV. Smoking prevalence in a cohort of adolescents, inchuding absentees, dropouts, and transfers. American Jounal of Public Health. 1988;78:176-178.

118. Glymn TJ. Anderson DM, Schwarz L. Tobaccomse reduction among high-risk youth: recommendation of a National Cancer Institute Expert Advisory Panel, Preventive Medicine 1991:20:279-291.

119. Van Teijlingen ER, Friend JAR. Smoking habits of Grampian school children and an evaluation of the Grampian Smoke Busters campaign. Heallh Education Research. 1993:8:97-108.

120. De Vries H. Who are the successfu quitters? Geneva: International Union Against Cancer, 1990.

121. Charlion A. Smoking cessation help for young people: The process observed in two case studies. Heath Education Research. 1992;7:249-257.

122. Mills D. Ewy BM, Dixon J. Smoking cessation in high school. Heallh Educatioft. $1978: 9 \cdot 5-9$

123. Scarlet D. A school smokers" clinic. Health at School 1986;1:145-146. 
124. Weissman W, Glasgow R, Biglan A, Lichtenstein E. Development and Evaluation of a cessation programme for adolescen smokers. The Oregon Research Institute, Oregon, 1986.

125. Chartion A. Smoking cessation in schools and colleges. Journal of Smoking-Related Diseases, 1994;5:289-294.

126. Sweanor D. Canadian Tobacco Tax project 1985-91. Ottawa Non-smokers Rights Association, 1991. 


\title{
Chapter 2
}

\section{The linkage approach applied to a school-based smoking prevention program in the Netherlands}

\author{
Margo Dijkstra, Hein de Vries \& Guy S. Parcel \\ Published in Journal of School Health, 1993, 63, 339-342.
}

\begin{abstract}
Effective diffusion strategies are necessary to enhance use of innovative health promotion programs. One strategy uses the linkage approach to innovationdevelopment and diffusion planning. The linkage approach enhances collaboration among three systems: resource system (university-based researchers), linkage system (district health educators) and user system (teachers). This article illustrates how the linkage approach was applied in a smoking prevention research project. Identification of the linkage system and the collaborative process between the resource system and linkage system are described. Results from a process evaluation indicated the linkage approach was feasible in a school-based smoking prevention project.
\end{abstract}

\section{Introduction}

Numerous studies have reported on the effectiveness of school-based health education programs. However, little is known about the maintained use of these interventions. Diffusion strategies may enhance implementation and use of programs. ${ }^{1-13}$ Diffusion is the process by which a program is communicated through certain channels over time among members of a social system. ${ }^{13}$ The purpose of the diffusion process is to attain awareness, adoption, implementation, and maintenance of the program by a target group. ${ }^{10}$ Contributing to successful diffusion is the involvement of potential users in developnent and diffusion of innovative programs. ${ }^{5}$ The diffusion strategy, however, is often determined by researchers who developed the program. Consequently, other groups may not have been sufficiently involved, which may lower their acceptance and readiness to adopt and implement the program. 
One approach that helps to improve diffusion is the linkage approach to innovation-development and diffusion planning, ${ }^{3,4,6,7,3,14}$ This approach suggests collaboration among three systems during the implementation of an innovation: resource system, linkage system, and user system ${ }^{8}$ (Figure 1). The resource system consists of researchers, developers, trainers, consultants, services, products, and materials. The linkage system can include representatives of the resource system, representatives of the user system, but the linkage system also can consist of an objective third party. ${ }^{6.7}$ The user system consists of individuals, organizations, agencies, groups, and networks that are potential adopters of the innovation.

The linkage system serves as a connection between the resource system, which provides the innovation, and the user system, which adopts, implements, and maintains the innovation. The linkage system bridges the gap between users and providers. ${ }^{67}$ Hence, the linkage system should be familiar with the innovation available from the resource system and with the needs of the user system as well as with the enabling factors and barriers with regard to implementation of the innovation in the user system.

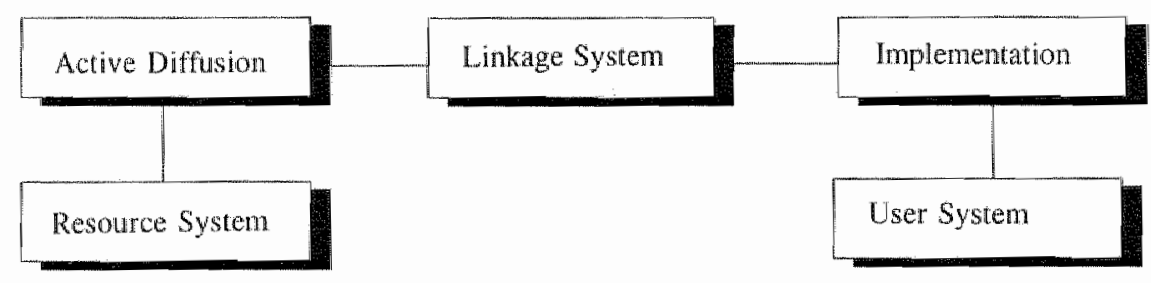

\section{Figure 1}

Livkage approach to imnovation diffusion

(From: Orlandi MA, Landers $\mathrm{C}$, Weston R, Haley $\mathrm{N}$. Diffusion of health promotion innovations. In: Glinz K, Lewis FM, Rimer B. (Eds.) Heath Behavior and Health Education: Theory, Research and Pracice. San Francisco: Jossey-Bass, 1990$)^{8}$

From a planning perspective, it may be useful to determine at which point in the planning process of health education, collaboration among the three systems can be or needs to be developed. Influenced by community organization theories, planning models advocate involvement of the various systems as soon as feasible. ${ }^{315}$ The planning model used in this study, a revised version of the PRECEDE Model, ${ }^{16}$ is the circular $A B C$ health promotion framework that distinguishes three important phases: A. Analysis of health problems, B. 
Behavioral interventions, and $\mathrm{C}$. Continued prevention. ${ }^{17}$ The framework suggests that when starting programs, factors enabling continuation should be analyzed before program development and implementation occurs. As a result various systems, such as the linkage system, should be involved in the analyses of the problem and the definition of priorities.

This case study illustrates how the linkage approach was applied to a schoolbased smoking prevention research project begun in March 1989 by the Department of Health Education at the University of Limburg in the Netherlands. District health educators, asked by the resource system (university-based researchers) to participate in the smoking prevention research project, formed the linkage system. These health educators work for Dutch district health centers which have responsibility for public health care and health protection. The district health centers carry out activities to analyze the health status of the community, to combat infective diseases, and to prevent diseases in youth and other risk groups. The health educators" role is to reduce the risk of diseases in their community by means of health promotion and health education. They were identified as linking agents because they serve as a link between the resource system, which developed the program, and the user system (the schools), the adopters of the program. ${ }^{18}$ Consequently, the linkage system in this study did not consist of representatives of the resource system and the user system, but rather an objective third party. ${ }_{0}^{6.7}$

\section{Implementing the approach}

The goal for integrating the linkage system in the research project was threefold: 1. involvement of the linkage system during implementation of the intervention program; 2. assistance of the linkage system in evaluating the intervention; and 3. provision of feedback on barriers and enabling factors that improve program diffusion in a broader context.

\subsection{Identification of linking agents}

In the 62 district health centers of the Netherlands, health educators have comparable job responsibilities as health educators in community or state health departments in the United States. Identification of the linkage system started in September 1989, and selection of district health educators was aimed at an optimal geographical representation of the districts throughout the Netherlands. Accordingly, health educators in 20 districts received letters inviting them to participate during implementation of the smoking prevention project in the experimental setting. They also were invited to attend a meeting for more 
information about the project. After the meeting, 16 health educators in 15 districts agreed to participate in the research project.

\subsection{Collaboration process}

Implementation of the school-based smoking prevention program involved collaboration between the resource system and linking agents. The collaboration process included six steps:

STEP 1. First meeting. During the first meeting with district health educators in December 1989, the purpose of the research project and their participation in the project was explained. Health educators were given the opportunity to comment and to give advice with regard to methods for project dissemination and implementation as proposed by the researchers.

STEP 2. Implementation manual. After the first meeting a special implementation manual was developed for the participating health educators based on advice and comments they gave during the meeting. The manual contained a time schedule, information about the programs, how to contact the schools, and how to instruct teachers about use of the programs. The manual also contained letters that health educators could use to send to schools. However, they also could write their own letters.

STEP 3. Recruiting schools. Recruitment of schools occurred in January, February, and March 1990. To contact schools, some health educators first sent a letter describing the project to the schools in their district. Schools then were phoned to determine their interest in participation. When a school indicated an interest, they went to the school to explain the project. Other health educators went to the schools immediately, and gave an oral presentation about the project. The implementation manual contained an example of a letter and information for the oral presentation. Schools that agreed to participate, selected a contact person who signed an agreement.

STEP 4. Second meeting. In September 1990, a second meeting was convened to explain implementation methods and how to instruct teachers about use of the programs. In addition to these meetings, health educators and researchers kept regular contact with each other by letters and telephone.

STEP 5. Program implementation. In October 1990, health educators provided teachers at the experimental schools instructions about how to use the program. They also made appointments with participating schools in their district to explain pretest procedures and deliver questionnaires and program materials. In November and December, schools in the experimental condition implemented the programs. 
STEP 6. Program evaluation. At the end of the program in December 1990 , health educators conducted group interviews with the teachers as part of the process evaluation. Before each posttest, health educators contacted the schools to plan the posttest administration. Finally, health educators were responsible for returning the questionnaires to the university.

\section{Evaluating the approach}

After project implementation, 15 of 16 health educators evaluated their role as a linking agent by completing an open-ended questionnaire that addressed three main evaluation questions. The first question assessed support activities provided by the researchers. The second question evaluated time spent on the project and the advantages and disadvantages of participation. It also determined their intention to continue implementation. The third question assessed preferences to participate in the program planning process, and willingness to participate in other research projects. Responses were analyzed by counting answers of the questions with regard to hours spent on the project, involvement in other phases of the project, methods for implementation after the project has been proven effective, and preferences to participate in other research projects. Answers on the remaining questions were listed and frequencies of the answers were coded.

Health educators evaluated superwision by the researchers during the project as very positive, and the meetings as very useful. They reported that, as a result of the meetings they felt more involved in the project. Most of them $(n=9)$ were satisfied with the opportunity to comment and provide advice during the meetings. The implementation manual was evaluated as very clear, effective, and a helpful guidance. The opportunity to make decisions about their involvement was evaluated as good.

On average, health educators spent 41.4 hours on the project (12-104 hours). Most of the time was spent on contacting schools for participation (3-40 hours). Hours spent on the decision to participate in the project (0.2-8 hours), the first meeting (2-8 hours), going over the implementation manual $(0.2-8$ hours), the second meeting (2-8 hours), explaining the program to teachers (2-12 hours), and doing the group interviews (1.5-8 hours) were evaluated as good. Contacting schools (3-40 hours), delivering the program at the schools (1-8 hours), and returning questionnaires to the researchers (0.1-4 hours) were evaluated by some educators as too time consuming. Further, time to travel for the two meetings in the middle of the Netherlands was viewed as too long by some health educators (28 hours). 
Becoming familiar with materials and the potential of the smoking prevention project was reported as the most important advantage of participating in the project. Health educators also reported that serving as a linking agent provided an opportunity to develop or maintain contacts with the schools.

Most health educators $(n=8)$ reported the amount of time required as a disadvantage. Some health educators $(n=4)$, reported the difficulty of fulfilling all the research conditions. One condition concerned the random assignment of schools to the experimental and control conditions by the researchers. Because of random assignment, health educators had to ask schools to decide on participation without knowing the condition they would be in. Another condition made was that participating schools were not allowed to take part in other smoking prevention activities during the project. A few health educators $(\mathbf{n}=3)$ reported no disadvantages as a linking agent.

All health educators $(n=15)$ indicated they were willing to continue involvement with implementation of the program. Most $(n=7)$ intended to implement the program in response to requests of schools for a smoking prevention program, while six health educators planned to offer the program to all schools in their district.

Health educators also reported phases of the program development in which they would like to participate (Table 1). Concerning phase one, analysis of the problem, five health educators cited problem identification as a task for the researchers, while five health educators considered this process to be a collaborative effort of researchers and health educators. Most health educators indicated that project goals should be formulated by the researchers. Concerning the second phase, behavioral change, most health educators considered the choice for type and content of the intervention as a responsibility of the researchers, guided by suggestions of the health educators.

Most health educators regarded contacting schools, delivering the programs at the schools, explaining use of the programs and doing group interviews with teachers as appropriate responsibilities of health educators. Different opinions emerged about who should conduct group interviews with students. Only a small majority considered it a task for health educators. Formulating research questions and developing the questionnaire were reported as a task for the researchers.

For all health educators, this experience was the first time they participated in a research project. When asked to indicate their interest in participating in future research projects, most health educators $(n=14)$ had positive intentions to collaborate in future linkage projects, but under certain conditions. First, they indicated the project had to fit into their planning priorities and second, future participation was dependent on the time needed and available for the project. 
Table 1

Frequencies of the perceptions of roles for heath educators participating in phases of program development.

\begin{tabular}{|c|c|c|c|c|c|}
\hline Project phase & $\begin{array}{l}\text { Solely by } \\
1\end{array}$ & $\begin{array}{l}\text { researchers } \\
2\end{array}$ & 3 & $\begin{array}{l}\text { Solely by } \\
\text { educators } \\
4\end{array}$ & $\begin{array}{l}\text { heallith } \\
5\end{array}$ \\
\hline $\begin{array}{l}\text { Analysis of the Problem } \\
\text { - identification of the health } \\
\text { problem (Is the problem serious } \\
\text { and which behaviors are related to } \\
\text { the problem?) }\end{array}$ & 5 & 1 & 5 & 1 & 2 \\
\hline $\begin{array}{l}\text { goal of the project } \\
\text { (Which risky behaviors can be } \\
\text { altered and which is the target } \\
\text { group?) }\end{array}$ & 7 & 1 & 3 & - & 3 \\
\hline $\begin{array}{l}\text { Behavioral Change } \\
\text { Development of the intervention: } \\
\text { - structure } \\
\text { - content }\end{array}$ & $\begin{array}{l}4 \\
6\end{array}$ & $\begin{array}{l}2 \\
1\end{array}$ & $\begin{array}{l}2 \\
3\end{array}$ & - & $\begin{array}{l}6 \\
4\end{array}$ \\
\hline $\begin{array}{l}\text { Small scale implementation: } \\
\text { - choosing schools } \\
\text { - contacting schools } \\
\text { - delivering materials } \\
\text { - instructing teachers }\end{array}$ & $\begin{array}{l}7 \\
- \\
2 \\
-\end{array}$ & $\begin{array}{l}- \\
1 \\
2 \\
2\end{array}$ & $\begin{array}{l}1 \\
4 \\
2 \\
2\end{array}$ & $\begin{array}{l}- \\
8 \\
7 \\
9\end{array}$ & $\begin{array}{l}5 \\
1 \\
- \\
1\end{array}$ \\
\hline $\begin{array}{l}\text { Evaluation of small scale } \\
\text { implementation: } \\
\text { - determining research questions } \\
\text { - developing questionnares } \\
\text { - interviews with teachers } \\
\text { - interviews with students }\end{array}$ & $\begin{array}{l}8 \\
8 \\
- \\
1\end{array}$ & $\begin{array}{l}1 \\
2 \\
2 \\
2\end{array}$ & $\begin{array}{l}1 \\
2 \\
2 \\
2\end{array}$ & $\begin{array}{l}- \\
- \\
8 \\
4\end{array}$ & $\begin{array}{l}4 \\
4 \\
1 \\
1\end{array}$ \\
\hline
\end{tabular}

\section{Implications for professional practice}

The study applied a linkage system to a smoking prevention research project by creating a linkage system consisting of 16 district health educators. "The health educators evaluated their participation as positive, though some activities took more time than expected. The most important advantage of participation was to become familiar with the materials and potential of the smoking prevention program. The most important disadvantage was the time investment.

The linkage system linked the resource system and the user system. Accordingly, the linkage system should be familiar with the enabling factors and barriers with regard to implementation of the imnovation in the user system. In this study, 
former experience of health educators with schools made it possible to develop an implementation manual in which the methods for implementation were directed to the user system. This manual was evaluated as very clear, effective, and helpful.

The principle of participation states that the practice of health education depends on involving people in the different phases of program development and implementation. ${ }^{15.19}$ Consequently, to make health education more effective, the linkage system should participate in the entire process, ranging from problem analysis to continuation of prevention activities. However, in this study the linkage system participated only during the implementation of the intervention. Most health educators indicated they would like to participate in orher phases as well. The final goal of diffusion is maintenance of an intervention, and most health educators reported they intended to continue their involvement in the project. Based on the literature and on results from this study, five recommendations are offered:

1. When using a linkage system in a research project, clearly inform the linkage person or organization about conditions for participation such as time and responsibilities. This practice will prevent false expectations about tasks and time investment.

2. With regard to successful diffusion of an intervention, researchers should consider participation of a linkage system during analysis of the health problem, development of the behavioral intervention, and during continuation of the intervention.

3. A linkage system familiar with the needs and priorities of the user system can be helpful in planning diffusion of the intervention, thereby demonstrating the importance of critical selection of a linkage person or organization. When the linkage system and the user system do not understand each other's needs and priorities, chances of successful diffusion decrease. ${ }^{3}$

4. An implementation manual, developed in collaboration with the linkage system, provides a helpful guide during program implementation. Consequently, such a manual should include methods for implementation based on needs and priorities of both the linkage and the resource system.

5. When an intervention program has proven effective, health educators who served as linking agents during small-scale implementation can serve as linking agents during large-scale implementation and can assist other health educators. ${ }^{20}$

Finally, this study showed that collaboration between a resource and a linkage system during a smoking prevention research project made small-scale implementation feasible. However, further research is necessary to show the effects of collaboration during large-scale implementation, after the intervention has proven effective in the research project. 


\section{References}

1. Parcel GS, Erikson MP, Lovato $\mathrm{CY}$, Gottlieb NH, Brink $S \mathrm{G}$, Green LW. The diffusion of school-based tobacco-nse prevention programs: Project description and baseline data. Howh Education Research. 1989;4:111-124.

2. Parcel GS, Taylor WC, Brink SG, Gothicb N, Engquist K, OHara NM, Erikson MP. Translating theory into practice: Intervention strategies for the diffusion of health promotion innovation. Family \& Conmunty Health. 1989;12:1-13.

3. Basch $C E$. Research on disseminating and implementing health education programs in schools. School Heath Research. 1984;54:57-66.

4. Kolbe LJ, Iwerson DC. Implementing comprehensive healily education: Educational innowations and social change. Health Education Quarterly. 1981;8:57-80.

5. Parcel GS, Ross $J_{\text {G }}$ Lavin AT, Portmoy $\mathbb{B}$, Nelson GD, Winters $\mathbb{F}$. Enhancing implementation of the teenage health teaching modules. Joumal of School Health. 1991:61:19-22.

6. Orlandi $\mathrm{M}$. The diffusion and adoption of worksite health promotion innovations: An analysis of barriers. Preventive Medicine. 1986;15:522-536.

7. Orlandi MA. Promoting health and preventing disease in health care setings: An analysis of barriers. Prewentive Medicine. 1987;16:119-130.

8. Oriandi MA, Landers $C$, Weston $\mathbb{R}$, Haley $\mathrm{N}$. Diffusion of health promotion innowations. In: Glanz K, Lewis FM, Rimer B. (Eds.) Health behavior and health edncation: theory, research and practice. San Francisco: Jossey-Bass, 1990.

9. Basch CE, Sliepcevich EM. Innovators, innovations and implementation: A framework for curricular research in school health education. Bealh Edacation. 1983;March/April:20-24.

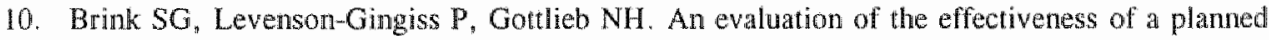
diffusion process: the smoke-free class of 2000 project in Texas. Health Education Research. $1991 ; 6 ; 353-362$.

11. Goodman RM, Steckler A. A framework for assessing program institutionalization. The International Joumal of Knowledge Transfer. 1989;2:57-7॥.

12. Goodman RM, Smith DW, Dawson L, Steckler A. Recruiting school districts into a dissemination study. Health Education Research. 1991;6:373-385.

13. Rogers EM. Diffusion of innovations. New York: The Free Press, 1983.

14. Havelock R. Planning for innovation through dissemination and wilization of knowledge. Anm Arbo: Institute for Social Research, 1971.

15. Green LW, Kreuter MW. Healh proworion planning; an educational and enwironmentat approach. Palo Alto: Mayfield Publishing Company, 1991

16. Green LW, Kreuter MW, Deeds SG, Partridge KB Health educasion planing: a diagnostic approach. Pallo Alto. Mayfield Publishing Company, 1980.

17. De Vries, H. Smoking prevention in Dwch adolescens. Maastricht: University of Limburg. 1989. Dissertation.

18. Goodman RM. Tenney M. Smith DW, Steckler A. The adoption process for health curriculum innovations in schools: A case study. Joumal of Healh Education. 1992;23:215-220.

19. Green LW. The theory of participation: A qualitative analysis of its expression in national and international health policies. Advances in Health Education \& Pronotion. 1986:1:211-236.

20. Bandura A. Soctal foundations of though and action. A social cogritive heory. Chapter 4 . Prentice-Hall, Inc. New Jersey, 1986. 



\title{
Chapter 3
}

\section{Predictors of implementation and continuation of a Dutch smoking prevention program}

\author{
Margo Dijkstra, Hein de Vries \& Guy S. Parcel \\ Submitted for publication
}

\begin{abstract}
An important element in the evaluation of a school health education program is whether-and how-the intervention is implemented. This study evaluated the smallscale implementation of a smoking prevention program in Dutch high schools. In total 59 teachers provided information about several characteristics of the individual (teachers) and of the organization (schools) with regard to the implementation of the smoking prevention program. The results of this study can contribute to the development of a diffusion strategy of a smoking prevention program.
\end{abstract}

\section{Introduction}

An important element in the evaluation of a school health education program is whether--and how--the intervention is implemented. ${ }^{1-4}$ If only outcome-evaluation is done, program planners may think their educational program has failed when in fact they do not know if the program has been fully implemented as intended. Moreover, inconsistent implementation can threaten the validity of statistical conclusions. ${ }^{5}$ According to Basch ${ }^{1.6}$, Type III errors (i.e. failure to find an effect due to inadequate implementation of the program) in evaluations of program effectiveness can be avoided by studying implementation. ${ }^{1,6-8}$

Implementation is one of the four stages in the diffusion process. ${ }^{4.410}$ These four stages are dissemination, adoption, implementation, and maintenance. Elfective diffusion of school health education programs requires that the intervention be disseminated to educators, adopted for use, implemented within the classroom, and maintained as an integral component of the curriculum. ${ }^{11,12}$ Successful diffusion of programs is affected by characteristics of the adopting organization, the innovation, and the individuals who will implement the program. ${ }^{2.10,13-15}$ 
The factors that influence the decision of teachers to adopt and implement a program and the factors that affect the level of implementation are therefore of importance to those developing health education programs. Studying implementation can facilitate the identification of possible problems and solutions as well as circumstances under which diffusion and implementation are likely to succeed.' The results of this type of research may facilitate understanding about the process of implementation, long-term maintenance, and further program dissemination.'

Research revealed several barriers to implementation of school health education. ${ }^{1,3,16-19}$ An oft-mentioned barrier is lack of adequately prepared teachers. For example, the decision of teachers to adopt and implement a health education program is often influenced by the fact that teaching health education is new for them 1.17 , and the instructional approach of these programs usually differs from their usual teaching techniques (e.g., students working in (peer-led) groups, and roleplaying. Furthermore, teachers' perceptions of their own self-efficacy in implementing the program and of the value of the program appear to be related to successful implementation. Other possible barriers include weak local administrative commitment, health education's insufficient credibility as an academic subject, insufficient time, insufficient funds, lack of community or parental support, and controversial topics.

The purpose of the study described in this article is to:

1. determine differences between teachers who implemented a Dutch smoking prevention program completely as planned and teachers who did not use every element of the program;

2. assess predictors of future use of the smoking prevention program;

3. determine elements of the smoking prevention program that are preferable for future use.

This report is part of a study to prevent smoking in the second (13-14-year-old students) and third grade (14-15-year-old students) of high schools of the Netherlands (comparable to grade eight and nine in the U.S.). In total 52 schools participated in the snoking prevention project. These schools were recruited by 16 health educators in 15 districts throughout the Netherlands. ${ }^{20}$ Because of random assignment, health educators had to ask schools to decide on participation without knowing the condition they would be in. The health educators passed the name of the schools to the researchers who matched them on type of school (four-year level versus five/six-year level) and grade (second grade versus third grade) and then assigned them randomly to the experimental $(\mathrm{N}=32)$ or control condition $(\mathrm{N}=20)$. In November and December 1990, schools in the experimental condition implemented a five-lesson smoking prevention program. The control schools did 
not implement any smoking prevention program. The study population of the report described in this paper, were teachers of the experimental schools who were involved with teaching the smoking prevention program.

The intention of the smoking prevention program is to be somewhat teacherindependent. Therefore, the structure and content of the program are presented on video by adolescents. Accordingly, teachers do not have to be an expert in teaching smoking prevention, meaning that the program can be implemented within a variety of subjects. The tasks of the teachers are to coordinate the lessons, to stimulate students and to assist peer-leaders. Teachers received an one-hour training. The lessons do not require much preparation time. The goal of the teacherindependent character of the program is to attain complete implementation.

To evaluate the implementation of the program, several characteristics of the individual (teachers) and organization (schools) were determined. The characteristics of the individual were attitudes, social norms, and self-efficacy with regard to teaching the smoking prevention program. These characteristics were chosen based on a theoretical model that explains behavioral intentions and behavior by determining personal conceptions concerning the behavior (attitude), the social norms about the behavior experienced from other important persons (social norm) and personal expectations about the skills needed to realize the behavior (self-efficacy). ${ }^{21}$ This model is comparable to a model on planned behavior $^{22}$, but in addition measures self-efficacy ${ }^{23}$ instead of behavioral control. Additional individual characteristics included selected demographic variables. Furthermore, characteristics of the organization were measured.

\section{Methods}

\subsection{Intervention}

The format for the smoking prevention program uses video-peer-led instructions. The program consists of five lessons of 50 minutes each. Structure and content are presented on the video by adolescents. Teachers received training from health educators addressing the structure and content of the program, how to interest their students, and how to train student peer-leaders with the help of a special training video. In the classroom, students were required to perform activities in small groups led by a same-class peer-leader. Before the start of the program teachers formed the groups and the groups chose their own peer-leader who had to be a nonsmoker. Sometimes, teachers selected the peer-leaders. The task of the peerleader was not to present information about the program, but to serve as a chairman of the small activity group. The peer-leaders were trained by their 
teacher with the help of a special training video. The training video explained what it means to be a peer-leader, the structure of the program, the tasks of the peerleader (e.g., stimulating the group to work seriously, explaining the activity, and leading group discussions, brainstorming activities, and role plays), and the tasks of the teacher. Furthermore, the video demonstrated the tasks of the peer-leader by showing a group of students working on an activity with a peer-leader who was leading the group discussion. Then the peer-leaders practiced their tasks by realizing an activity. The information on the video was also given in the manual of the peer-leaders and teachers. Students, peer-leaders, and teachers each have their own manuals with activities, and a summary of the information given on the video. The manual of the peer-leaders also gave step-by-step directions for leading the activities.

The core materials of the intervention consisted of the manuals and the five lessons on video. Additional elements are a peer-leadertraining, a special developed peer-leader-trainingvideo, a non-smoking poster, for the names of students who following the last lesson decide not to smoke, and a quit-smoking brochure students could hand out to members of their families and friends who smoke. Each lesson in the intervention includes the following type of classroom activity: working with peer-leaders, working in groups, summaries of the lessons handed out by the teachers at the end of each lesson, and homework assignments.

The video format allowed the program to be implemented during a variety of subjects: biology, sociology, tutorial, religious instruction, Dutch language instruction, geography, chemistry, German language instruction, and history, as well as after school.

\subsection{Data collection}

Data for this study was collected from 32 high schools in the Netherlands that implemented the smoking prevention program. After the last lesson of the program, the teachers received a questionnaire about the implementation and use of the program. They were asked to finish the questionnaire before the health educators were going to conduct interviews with teachers to obtain more in-depth information about the use of the program (results of the interviews are described elsewhere $\left.{ }^{24}\right)$. During the interviews, the health educators collected the questionnaires and send them to the researchers. 


\subsection{Questionnaire}

The level of implementation was assessed by asking teachers which elements they did or did not use in each of the five lessons $(0=$ not used, $1=$ used). In total the core package existed of 30 elements, resulting in a level of implementation score ranging from 0 (no elements used) to 30 (all elements used) (Cronbach's $\alpha=85$ ). The core package including the additional elements existed of 35 elements, resulting in a score ranging from 0 (no elements used) to 35 (all elements used) $(\alpha=.78)$.

Attitudes towards implementation were assessed by 19 questions covering three areas, using a five-point scale ( $2=$ positive attitude, $-2=$ negative attitude). The first area, comprising eight items, concerned the level of success teachers connected to the program. Questions asked teachers to assess the success of the program in reducing the number of students who smoke or start to smoke, making students aware of pressure from peers, changing students" attitudes with regard to smoking, making students aware of the risks of smoking, and teaching the students how to make decisions. They were also asked to assess the degree to which the program facilitated teaching in a pleasant way and teaching in an alternative way, as well as how enthusiastic students became during the lessons. The eight items were summed to form a level of success scale $(\alpha=91)$. The second area, comprising nine items, assessed the perceived complexity of the program. Questions covered the effort needed to go to general information meetings, read the instructions in the manual, train peer-leaders, organize the lessons of the program, prepare the lessons, make the time to teach the program, form groups and choose peer-leaders, motivate the students, and keep order in the class during the lessons. The nine items were summed to form a complexity scale $(\alpha=84)$. The third area comprised two items concerning the fit of the program: "the smoking prevention program fits in the current curriculum" and "the smoking prevention program fits in the current way of teaching." "The two items on fit were handled separately because they did not form a reliable scale.

The social norm was measured by three questions concerning the support of colleagues, school administrators, and students with respect to teaching the program. These items were measured on a five-point scale $(2=$ positive social norm, -2 = negative social norm) and summed to form one social norm scale $(\alpha=, 77)$.

Self-efficacy was measured by one item: "Do you think you are able to teach the program during your lessons?" $(2=$ positive self-efficacy, $-2=$ negative seifefficacy). 
Intention of furure use was assessed by the question, "Do you intend to teach the program in the future?" ( 2 = positive intention, $-2=$ negative intention).

Decision-making characteristics of the organization were assessed with four items, covering whether or not the school administrator, parents' council, administration of the school, or teachers themselves made decisions about programs on smoking prevention $(0=$ no, $1=$ yes $)$.

Teachers were also asked their opinion regarding which elements of the program should be included in future implementations. The 13 items, using a five-point scale ( 2 = strongly agree, -2 = strongly disagree), included the preferred number of lessons, the use of peer-leaders, the requirement for small-group work, teacher control of precisely when the program is taught, teacher control of the grade in which it is taught, the amount of time for activities, teacher discretion over the number of activities per lesson, the need for materials beyond the teacher manual, and cost.

Demographic variables were the teacher's age, gender, years of teaching experience, previous experience in teaching smoking prevention programs, previous experience in teaching health education, if the teacher training was given, and if the peer-leaders were trained.

\subsection{Data analysis}

Analysis of variance and chi-square analysis were used to assess the differences between teachers who completely implemented the program and teachers who did not. "inear regression was used to predict the level of implementation of the program. Logistic regression was employed to predict the intention to use the program in the future. Frequencies were calculated for the decision-making characteristics of the schools and for the elements of the program deemed preferable for future editions.

\section{Results}

\subsection{Sample characteristics}

In total 61 teachers participated in the experimental group. Most of them $(n=59$, $96 \%$ ) returned the questionnaire. Of the 59 teachers, 57 were employed by a total of 32 schools. (Two teachers did not report the name of their school.) The number of teachers per school ranged from one to six. Seventy-five percent of the teachers were male $(n=44)$. The teachers' ages ranged from 26 to 58 with a mean of 40.3 
years $(S D=7.5$ ). They had from 1 to 40 years of teaching experience, average 16. 1 years $(\mathrm{SD}=8.1)$. The majority $(69 \%, \mathrm{n}=40)$ had never taught any smoking prevention program before, and $51 \%(\mathrm{n}=29)$ had never taught any health education program before. However, $91 \%$ of the teachers $(n=53)$ considered smoking prevention an important subject, and $67 \%(\mathrm{n}=38)$ felt smoking prevention was an important teaching priority. The majority of the teachers $(85 \%, \mathrm{n}=49)$ received a teacher training before the start of the program, but nine teachers (15\%) did not.

\subsection{Differences in level of implementation}

In Table 1 the percentages of teachers who used the different elements of the core package of the program in the five lessons are given. The least-implemented element of the program was the summaries teachers were to hand out to students at the end of each lesson. Of the additional materials, the majority of the teachers $(79 \%, \mathrm{n}=44)$ asked the students who decided not to smoke, to write their name on a non-smoking poster and most of them $(89 \%, \mathrm{n}=39)$ hung the poster on the wall in the class. The majority of teachers $(87 \%, n=48)$ also handed out the quitsmoking brochures to the students. A portion of the teachers $(64 \%, \mathrm{n}=38)$ instructed the peer-leaders. And most of them $(83 \%, \mathrm{n}=30)$ used the special training video.

Table 1

Percentages (n) of teachers who used the different elements of the program in the five lessons

\begin{tabular}{llllll}
\hline Lesson & 1 & 2 & 3 & 4 & 5 \\
\hline Manuals & $93 \%$ & $90 \%$ & $90 \%$ & $92 \%$ & $90 \%$ \\
Video & $(55)$ & $(53)$ & $(53)$ & $(54)$ & $(53)$ \\
& $92 \%$ & $90 \%$ & $88 \%$ & $90 \%$ & $88 \%$ \\
Activities & $(54)$ & $(53)$ & $(52)$ & $(53)$ & $(52)$ \\
& $88 \%$ & $86 \%$ & $83 \%$ & $81 \%$ & $80 \%$ \\
Summaries & $(51)$ & $(50)$ & $(48)$ & $(48)$ & $(47)$ \\
& $78 \%$ & $78 \%$ & $80 \%$ & $78 \%$ & $76 \%$ \\
Peer-leader & $(46)$ & $(46)$ & $(47)$ & $(46)$ & $(45)$ \\
& $93 \%$ & $86 \%$ & $86 \%$ & $85 \%$ & $83 \%$ \\
Groups & $(54)$ & $(50)$ & $(50)$ & $(49)$ & $(48)$ \\
& $93 \%$ & $90 \%$ & $90 \%$ & $92 \%$ & $88 \%$ \\
& $(55)$ & $(53)$ & $(53)$ & $(54)$ & $(52)$ \\
\hline
\end{tabular}


Linear regression was used to determine the best linear combination of independent variables to predict the level of implementation of the program. On step one the attitude factors, social norm, and self-efficacy were entered. On the second step, the demographic variables were entered: gender, age, if teacher had received a training, years of teaching experience, previous experience in teaching smoking prevention, previous experience in teaching health education and the subjects in which the program was given. The dependent variable was the level of implementation of the core package, including the additional elements (range: 035). Multiple correlation ( $R$ ) was found to be .52. The level of implementation was best predicted by the social norm $(\mathrm{F}(1,46)=7.57, \mathrm{p}<.01)$ which explained $14 \%$ of the variance, and by previous experience in teaching health education $(F(2,45)=8.43, p<.001)$, which explained $13 \%$ of the variance. The other independent variables did not contribute significantly to regression.

Not all teachers used every element of the program: sixteen teachers $(31 \%)$ implemented both the complete core package and the additional elements (a score of 35 on the level of implementation). The other 36 teachers $(69 \%)$ did not implement all 35 elements (a score below 35 ).

The complete program, including the additional elements, was better implemented by teachers with previous experience with smoking prevention $(59 \%)$ or health education ( $44 \%$ ) compared to their colleagues with no previous experience in smoking prevention $(18 \%)$ or health education $(17 \%) ;\left(X^{2}(1)=8.93, p<.01\right.$ and $\left.\mathrm{X}^{2}(1)=4.55, \mathrm{p}<.04\right)$. More teachers of biology, sociology, and religious instruction $(88 \%)$ used all the elements of the complete program compared to teachers of other subjects $(12 \%)\left(\mathrm{X}^{2}(1)=12.44, \mathrm{p}<.001\right)$. Furthermore, teachers who used all elements expressed a more positive social norm compared to teachers who did not use all the elements $(M=1.10$ versus $0.60, F(1,50)=6.13, \mathbb{P}<.05)$. There were no differences with respect to the attitude factors and self-efficacy, and there was no difference in implementation between teachers who received teacher training and those who did not.

\subsection{Predictors of intended future use of the smoking prevention program}

Table 2 shows the correlations of the attitude factors, social norm, and self-efficacy with the intention to use the program in the future.

Logistic regression was employed to determine the best combination of independent variables to predict the intention to teach the program again in the future. The dependent variable, intention, was grouped in teachers with a positive intention $(n=30,51 \%)$ and teachers with a negative intention $(n=29,49 \%)$. On 
step 1 the attitude factors, social norm, and self-efficacy with regard to teaching the program were entered. On the second step, gender, age, years of teaching experience, previous experience in teaching smoking prevention, and previous experience in teaching health education were entered.

Table 2

Correlations of the artitude factors, the social nom, and selfefficacy with intention $(N=55)$

\begin{tabular}{lllllll}
\hline & Intention & LoS & CoP & FC & FT & SN \\
\hline Level of success (LoS) & $0.41^{*}$ & & & & & \\
Complexify of the program (CoP) & 0.04 & $0.24^{*}$ & & & & \\
Fit in the curriculum (FC) & $0.35^{*}$ & $0.48^{*}$ & 0.15 & & & \\
Fit in the way of teaching (FT) & $0.49^{*}$ & 0.22 & 0.09 & 0.20 & & \\
Social norm (SN) & $0.63^{*}$ & 0.44 & 0.03 & $0.39^{*}$ & $0.33^{*}$ & \\
Self-efficacy (SE) & $0.44^{*}$ & $0.19^{*}$ & -0.08 & $0.42^{*}$ & $0.49^{*}$ & $0.43^{*}$ \\
\hline
\end{tabular}

$* p<.05$

a: significant unique contribution to the prediction of the intention

Table 3 shows that teachers with a positive level of success were more convinced of teaching the program in the future compared to teachers with a negative level of success. Teachers with a positive social norm and high self-efficacy expectations were more convinced of teaching the program in the future compared to teachers with a negative social norm and low self-efficacy expectations, however the difference was not significant $(p<.06, p<.07)$.

Table 3

Significant predictors of the intention to reach the program in the future

\begin{tabular}{llllll}
\hline Variable & B & S.E. & Odds & $p<$ & $95 \% \mathrm{Cl}$ \\
\hline Level of success & -2.19 & 1.02 & 0.11 & 0.05 & $(0.0100 .83)$ \\
Social norm & -1.42 & 0.73 & 0.24 & 0.06 & $(0.05 \% 1.01)$ \\
Self-efficacy & -0.84 & 0.45 & 0.43 & 0.07 & $(0.17 \cdots 1.05)$ \\
\hline
\end{tabular}


3.4 Elements of the program deemed preferable for future use of the program

For future use, the majority of teachers preferred that the program have three lessons $(83 \%, n=43)$, use peer-leaders $(67 \%, n=36)$, require students to work in groups $(89 \%, n=47)$, provide manuals for teachers, peer-leaders, and students $(92 \%, n=49)$, and allow teachers to determine the moment of teaching the lessons $(98 \%, \mathrm{n}=53)$ and the grade in which it is taught $(81 \%, \mathrm{n}=43)$. Teachers also wanted more time to conduct the activities $(66 \%, \mathrm{n}=35)$ and freedom to decide about the number of activities $(76 \%, n=41)$.

\subsection{Characteristics of the organization}

Normally the characteristics of the organization do not differ within a school. However, in this study it seemed that teachers in one school did not agree with regard to the characteristics of the organization. Therefore, it is not possible to use schools as unit of analysis. Accordingly, the results should be interpreted as teachers" perception of the characteristics of the organization.

The majority of teachers $(73 \%, \mathrm{n}=41)$ reported that the school administrator decides if a smoking prevention program will be implemented, and that the teachers decide which smoking prevention program to use $(75 \%, \mathrm{n}=43)$. The majority of teachers $(65 \%, \mathrm{n}=44)$ volunteered to be the ones to teach the present smoking prevention program. There was no difference in level of implementation between teachers who volunteered to be the ones to teach the program and teachers who did not volunteer.

\section{Discussion}

The results of this study suggest that teachers were convinced that smoking prevention is an important subject, although the majority of them had never taught any smoking prevention program before. Furthermore, one-half of the teachers have the intention of teaching the smoking prevention program again in the future.

In general the teachers implemented the program completely. However, this does not guarantee complete implementation when the program will be diffused on a large scale. Further research is necessary to determine the level of implementation when the program is diffused on a large scale without a concurrent effectiveness study. 
Although the present smoking prevention program was teacher-independent, teachers of subjects in which the content and teaching techniques of the program had the best fit, such as biology, religious instruction, and sociology, implemented the program more completely than teachers of other subjects. The level of implementation was best predicted by the social norm and by previous experience in teaching health education.

Other studies in the literature suggest that teacher training is a precondition for successful implementation. ${ }^{1.316 \cdot 19}$ However, the present study showed no difference in level of implementation between teachers who did receive training and those who did not. A possible explanation is that three of the nine teachers who did not receive training did train peer-leaders with the help of the special training video. Consequently they still received information about the content and structure of the program before the start of the lessons. Another possible explanation is that this type of program, teacher-independent, does not require teacher training. Because of the teacher-independent nature, teachers do not have to be experts in teaching smoking prevention. Therefore, they actually do not need a training session about the content, but they should become familiar with the structure of the program. It may be possible that training is not necessary to become familiar with the structure of the program when information about how to teach the program is given in the teachers manual. If teachers read this information carefully before the start of the program, this information may be adequate to attain a high level of implementation.

Once a program is adopted and implemented by a school, the next stage is maintenance, or continuation of the program. In this study teachers with a positive attitude towards the level of success of the program were more convinced of teaching the program in the future compared to teachers with a negative attitude with regard to the level of success.

A majority of teachers preferred a program of three lessons instead of five. Because of the tight Dutch curriculum in which teachers have to fit the program, the number of lessons is a relevant factor to consider during the diffusion of the program. There are three alternatives in handling this problem. The first is to modify the innovation and make a program of three lessons. However "research has shown that at least five lessons are necessary to make an effective program. ${ }^{2.5}$ The second alternative is to incorporate a message into the diffusion strategy to change the perceptions teachers have with regard to the number of lessons, i.e., it must be made clear that a program of two or three lessons may be ineffective. In the literature a minimum length of two five-session blocks delivered in separate school years or a one year five-session program with booster sessions in following school years, is recommended. ${ }^{26}$ Sessions may be delivered contiguously or during 
the course of the school year. ${ }^{26}$ The third alternative is to make the program part of a more comprehensive approach to health education, so that topics such as peergroup pressure are also dealt with when discussing other subjects, such as alcohol, gambling, and AIDS prevention. ${ }^{27}$

The results of this study suggest that over one-half of the teachers will use the program again if they can determine the grade in which the program will be taught. However, a smoking prevention program is usually developed for a specific grade level. The program reported here, for instance, is designed for 13- to 15year-old students, because the incidence of smoking increases rapidly at that age. Teaching the program at another age level may reduce its effectiveness. Finally, 98\% of the teachers report they will teach the program again if they can determine the moment of teaching. In Dutch schools this is usually possible.

According to the present study, the decision to implement a smoking prevention program is usually made by the school administrator, while the teachers usually choose the specific program to use.

A limitation of the study analyzing teachers' self-efficacy is that it is not clear if the question on self-efficacy measures teachers' perceived self-efficacy with regard to teaching the program, or for example their perception with regard to the fit of the program in their lessons or that they have time or permission to teach the program. Therefore, for future research it is recommended to explicate this question further, for example, "Do you think you are able to guide a role-play in which students practice refusal skills?" or "Do you think you are able to guide peer-leaders in performing their tasks during the activities?".

\section{Conclusion}

The findings of this study can contribute to the development of a diffusion strategy of a smoking prevention program. Starting with the dissemination of the program, the school administrators should receive information on the importance of teaching smoking prevention at schools. When school administrators are convinced of the importance of smoking prevention, they can ask teachers to participate. It is preferable to ask teachers who have prior experience teaching lessons on health education or teachers of subjects in which the content and teaching techniques of the program has the best fit. With regard to the adoption of the program, teachers should be given information about the program's perceived and actual level of success, complexity, and organizational fit. Once the decision is made to adopt, the goal is successful implementation. Regarding the relation of program effectiveness and level of implementation, it is important to develop a program with a high chance of being implemented completely. The present study suggests that a 
teacher-independent smoking prevention program can attain a high level of complete implementation, even without teacher training. Furthermore, results of this and of a former Dutch teacher-independent smoking prevention program showed positive effects in preventing adolescents from smoking. ${ }^{28.29}$ However, it is important that teachers who are going to implement a smoking prevention program perceive a positive social norm from colleagues, school administrators, and students. Furthermore, it must be explained to teachers why the program should be given in a particular grade. Finally, concerning the maintenance stage, it is important to pay attention to teachers' attitudes, social norms and self-efficacy with regard to teaching the program.

\section{References}

1. Basch $\mathrm{CE}$. Research on disseminating and implementing health education programs in schools. Joumal of School Healih. 1984;54:57-66.

2. Kolbe LJ, Iverson DC. Implementing comprehensive health education: Educational innovations and social change. Health Education Quarterly. 1981;8:57-80.

3. Levenson-Gingiss P, Hamilton R. Determinants of teachers" plans to continue teaching a sexuality education course. Family \& Community Heath. 1989; 12:40-53.

4. Parcel GS, Perry CL, Taylor WC. Beyond demonstration; diffusion of health promotion innovations. In: Bracht N. (Ed.) Health promotion at the community level. Sage Publications. 1990.

5. Cook TD, Campbell DT. Quasi-experimentation. Design and analysis issues for field sertings. Chicago, Rand McNally, 1979.

6. Basch CE, Sliepcevich EM, Gold RS, Duncan DF, Kolbe LJ. Avoiding type III errors in health education program evaluations: A case study. Health Education Quarterly. 1985;12:315-331.

7. Botvin GJ, Dusenbury L, Baker E, James-Ortiz S, Kerner I. A skills training approach to smoking prevention among Hispanic Youth. Journal of Behavioral Medicine. 1989;12:279-296.

8. Kishchuk N, O’Loughlin J, Paradis S, Masson P, Sacks-Silver G. Illuminating negative results in evaluation of smoking prevention programs. Journal of School Health. 1990;60:448-451.

9. Parcel GS, Eriksen MP, Lovato CY, Gottlieb NH, Brink SG, Green LW. The diffusion of school-based tobacco-use prevention programs: Project description atd bascline data. Heolth Education Research. 1989:4:111-124.

10. Rogers EM. Diffusion of inmovarions. New York: The Free Press, 1983.

11. Brink SG, Levenson-Gingiss P, Gotheb NH. An evatuation of the effectiveness of a planned diffusion process: The smoke-free class of 2000 project in Texas. Healh Education Research. $1991 ; 6: 353-362$.

12. Parcel GS, Taylor WC, Brink SG, Gotlieb N, Engquist $K$, OHara NM, Eriksen MP. Translating theory into practice: intervention strategies for the diffusion of a health promotion innovation. Family \& Community Healh. 1989:12:1-13.

13. Zalman $\mathrm{G}$, Duncan R. Strategies for planned change. New York: John Wiley, 1977.

14. Basch CE, Sliepcevich EM. Innovators, innovations and implementation: A framework for curricular research in school health education. Health Educanion. 1983; March/April:20-24, 
15. Onandi MA, Landers $\mathrm{C}$, Weston $\mathrm{R}$, Haley $\mathrm{N}$. Diffusion of health promotion innowations, In Glanz K, Lewis FM, Rimer B. (Eds.) Health behavior and healh education. Theory, Research and Practice. San Franciseo. Jossey-Bass, 1990.

16. Chambers Butler $\mathrm{S}$. Chief state school officers rank barriers to implementing comprehensive school health education. Jownal of School Health. 1993;63:130-132.

17. Tortu $\$$, Botwin GI. School-based smoking prevention: The teacher training process. Preventive Medicine. 1989;18:280.289.

18. Stein MK, Wang MC. Teacher development and school improvement: The process of teacher change. Teaching \& Teacher Education. 1988;4:171-187.

19. Connell DB, Tumer RR, Mason EF. Summary of findings of the school health education evaluation: Health promotion effectiveness, implementation, and costs. Journal of School Health. $1985 ; 55,316-323$.

20. Dijksira $M$, De Vries $H$, Parcel GS. The linkage approach applied to a school-based smoking prevention program in the Netherlands. Journal of School Health. 1993;63;339-342

21. De Vries H, Dijkstra M, Kuhlman P. Selfefficacy: The third factor besides attitude and subjective norm as a predictor of behavioral intentions. Health Education Research. 1988;3:273282 .

22. Ajzen I, Madden JT. Prediction of goal-directed behavior; Attitudes, intentions, and perceived behavioral control fournal of Experimental Social Psychology. 1986;22:453-474

23. Bandura A. Social Foundations of thought and action: A social cognitive theory. Englewood Cliffis, NJ: Prencice-Hall luc, 1986.

24. Dijkstra M, De Vries H. Program evaluation of two smoking prevention programs.. An application of the program matrix (submitted for publication).

25. Best JA, Thomson SJ, Santi SM, Smith EA, Brown KS. Preventing cigarette smoking among school children. Anmual Review of Public Health. 1988;9:161-201.

26. Glym TJ. Essential elements of school-based smoking prevention programs. Journal of School Health. 1989;59:181-188.

27. Murray DM, Pirie P, Luepker RV, Pallonen U. Five- and six-year follow-up results from four Seventh-grade smoking prevention strategies. Joumal of Behavioral Medicine. 1989;12:207-218.

28. De Vries $H$, Backbier E, Dijkstra $M$, Van Breukelen $G$, Parcel $G$, Kok G. A Dutch social influence smoking prevention approach for vocational school students. Health Education Researdh. 1994,9:365-374.

29. Dijksira M, De Vries H., Van Breukelen G. Effectiveness of two Dutch smoking prevention programs and boosters (submitted for publication). 


\title{
Chapter 4
}

\section{Program evaluation of two smoking prevention programs: an application of the program matrix}

\author{
Margo Dijkstra \& Hein de Vries \\ Submitted for publication.
}

\begin{abstract}
This study examines the program evaluation of a Dutch smoking prevention project. Two peer-led smoking prevention programs on video (a social influence program and a decision-pnaking program) and boosters (three newspapers) were developed on the basis of a program matrix to plan behavioral interventions. This matrix was also used to evaluate the prograns. The sample for the program evaluation consisted of students of 32 high schools in the Netherlands who received either the decision-making program or the social inftuence program. Linear regression analyses showed that students receiving the social influence program evaluated the program more positively compared to those receiving the decision-making program. Furthermore, both programs were more positively evaluated by four-year education students compared to five/six-year education students, by second grade students compared to third grade students, by girls compared to boys, and by pre-treatment nonsmokers compared to pretreatment smokers. The evaluation of the boosters revealed that only small. percentages of students reported having read all three newspapers. Interviews with teachers indicated that the students enjoyed the lessons of the program. It can be concluded that the sources and channels used in the two programs are workable to provide information about non-smoking.
\end{abstract}

\section{Introduction}

This study reports on the program evaluation of a Dutch smoking prevention project. The project started in 1989 with the development of two smoking prevention programs (a decision-making program and a social influence program) with boosters for Dutch high school students. The major goal of the 
project was to prevent smoking in second (13-14-years-old) and third grade (1415-years-old) high school students. This project is a follow-up of the first Dutch smoking prevention project.' During the first project a social influence program on video was developed for second grade vocational and high school students. The results of this project showed differential effects for vocational and high school students. Recommendations were made to adapt the social influence program to the educational level of high school students because of the low educational level of the program, to implement it in a higher grade because of the low smoking incidence in second grade high school students, and to develop a decision-making program for high school students, because of their need to process information cognitively. ${ }^{1-3}$ Based on these recommendations, two different programs with boosters were developed for second and third grade high school students. Dutch high schools consist of three different educational levels: a four-year education, a five-year education, and a six-year education which prepares students for university. An effect evaluation was conducted to assess the behavioral effects of the programs with boosters. In this evaluation intervention schools were compared with control schools on three occasions. The results indicated that four months after the implementation of the interventions, both programs were effective in preventing smoking among students who were nonsmokers at pretest. Ten and sixteen months after the intervention, the social influence program with the booster was more effective in preventing smoking compared to the social influence program without the booster and compared to the control group. The decision-making program without the booster was more effective compared to the control group at ten months after the intervention. ${ }^{3}$

Many smoking prevention programs have been developed and evaluated on their behavioral effects. Recently process evaluation has received increased attention because program utilization and implementation influences the effectiveness of the intervention. ${ }^{4-10}$ This article reports on the process evaluation of the smoking prevention project. Process evaluation itself can be divided into implementation evaluation and program evaluation. In this article the program evaluation of the study will be described. The dissemination and implementation evaluation are described elsewhere. 11.12 The program evaluation contains students' and teachers' evaluation of the two programs and the boosters.

Until now, no really effective method to describe program evaluation has been available. Therefore, a program matrix to plan behavioral interventions is used. ${ }^{13}$ According to this matrix behavioral change can be considered as a process where four phases can be distinguished: 1 . attention to and comprehension of the message; 2 . changes in determinants of behavior (attitudes, social 
influences and self-efficacy); 3. a change in behavior; and 4. maintenance of the behavior. According to the matrix, the persuasive impact of the message is determined by four types of input or communication variables: target group, message, channel, and source variables. Target group variables refer to the characteristics of the target group that influence information processing (e.g., educational level, gender and age). The message needs to be adapted to the educational level of the target group to ensure that the information will be understood. Message variables focus on the persuasive effect of the message. Channel variables refer to the methods by which messages are delivered (e.g., newspapers, television, local newsletters, schools). Source variables focus on who is going to deliver a message to the target group (e.g., a doctor, famous artists, adolescents). The matrix served as a guideline to develop the programs.

The goal of the present study is to discuss the program evaluation of two Dutch smoking prevention programs by applying the program matrix. It was expected that four-year education students would evaluate the sources and channels of the social influence program more positively, while five/six-year education students would evaluate the sources and channels of the decisionmaking program more positively. This expectation is based on the assumption that, because their educational level is higher, students of five/six-year education have a stronger need to process information cognitively compared to students of four-year education. Based on the results and recommendations of the first Dutch smoking prevention program, differential results of evaluation of both programs were expected for smokers and nonsmokers due to the non-smoking accent of both programs, for girls and boys, and also for second (13-14-yearsold) and third grade (14-15-years-old) students. Differences between girls and boys were assessed because if the sources and channels of the programs were evaluated differentily, further research might reveal how the programs could be adapted more to either the girls or the boys. Furthermore, with regard to future use of the programs it is of importance to assess the differences in evaluation of the sources and channels between grade two and three. Based on these results it is possible to recommend schools in which grade they might use the program.

\section{Method}

\subsection{Program development}

The development of both programs was based on the program matrix to plan behavioral interventions. 
Attention The target group for the intervention were students of the second and third grade of high schools. To increase the chance of exposure to the intervention, schools were used as the place of the intervention. Because of the positive evaluation of the structure of the first Dutch social influence program, the same structure was used with some small changes. Therefore, for both programs a video peer-led approach was developed to attract attention by interesting video messages, which alternated with small group activities. Each lesson of both programs consisted of an introduction to the lesson on video, followed by a peer-led activity in small groups, feedback on the activity and continuation of the lesson on video, a second peer-led activity, feedback on the wideo on the second activity, and, finally, in some lessons home-activities were explained on video. A manual summarizing the information and activities was a second important channel. To attract attention, the sources on the video were adolescents who introduced the lessons, explained the activities, played real-life situations, and conducted interviews. Other sources were peer-leaders from the same class who stimulated students during the activities, and the students themselves when working in groups.

Comprehension The most important characteristic of the target group was their educational level. Hence, the content of the two programs was adapted to the level of the target group. The script for the programs was screened by teachers, students and experts. The channels to enhance comprehension were the video, the manual, and the activities. The intention of the activities was to improve active participation: instead of providing students with information, students were stimulated to search for relevant information, to discover lacks in their knowledge about smoking, which will make them more receptive for new information. ${ }^{14.15}$ The activities were realized in small groups of four or five students and were led by a peer-leader. Important sources to enhance comprehension were the adolescents on video, and the peer-leaders.

Attitude Research into the determinants revealed that important characteristics of the target group were their focus on short-term advantages and disadvantages of smoking. ${ }^{1,16,17}$ Therefore, to influence attitudes about smoking both programs contained information about the short-term advantages of non-smoking and short-term disadvantages of smoking, reasons why people do or do not smoke and why they quit, the dangers of experimentation with smoking, passive smoking, addiction, quitting smoking, and governmental measures against smoking. Students received a quit smoking brochure to hand out to a smoking person at home or in their enviromment. Plhysical effects, such as trembling and temperature of hands, the heart-rate, and the amount of tar were demonstrated on video by an adult expert to a group of adolescents in a lab. Other effects, 
such as the expense, were discussed on video. Alternative behaviors for smoking were discussed, as smoking has positive outcomes which can be realized by other behaviors as well. The main channels used were the quit smoking brochure, the tests in the lab on video, the manual, and the activities. The sources were the experts and adolescents who showed the physical effects and the students during the activities.

Social influences The study on the determinants indicated that smokers experienced pressure to smoke from friends and classmates. Moreover, most students were relatively unaware of the impact of indirect social influences. ${ }^{15}$ Both programs discussed the difference between direct and indirect social influences and showed various different manifestations of social influences. The channel used was the video. The sources were the adolescents on video.

Self-efficacy Both programs focused on demonstrating awareness of social pressures and raising self-efficacy in handling social pressures and finding alternatives for smoking. Both programs also focused on how to react when bothered with smoke. The channels used were the video to demonstrate assertiveness and refusal techniques, while role-play was used to raise levels of selfefficacy. The sources were the adolescents on video who demonstrated how to react to pressure to smoke and how to role-play. Other sources were the students during the role-plays.

Behavior change To change behavior, as indicated above, refusal skills were trained by role-play. Furthermore, students receiving the decision-making program practiced how to make a decision using five steps: 1 . What is the situation in which you have to make a decision? 2. What are the possible decisions? 3. What are the pros and cons of the possible decisions? 4 . How can one make a decision based on the pros and cons? 5. How can one practice the decision? Most activities in the decision-making program were based on these five steps. In both programs students had to make the decision to smoke or not, and students on the decision-making program used the five steps to make this decision.

Behavior maintenance Finally, to enhance maintenance of the behavior, students of both programs were asked to conclude a non-smoking contract for which they received as a reward a non-smoking poster of the Dutch Foundation on Smoking and Health. Furthermore, they could write their name on a nonsmoking poster which was clearly visible at school, and consequently by other students (public commitment). The channels used were the video, the non smoking contract and poster with regard to the commitment procedures and the non-smoking poster as a reward. The sources were the adolescents on the video. 
Moreover, to enhance maintenance of the non-smoking behavior, boosters were added to the program. Because of the teachers ${ }^{*}$ tight curriculum, it was not feasible to develop additional lessons on smoking prevention. Therefore, three newsletters were developed containing information also given on the video. Teachers were asked to give the newspapers to the students, who could read them at home or during a break at school. In the three newspapers famous national and international singers and sportsmen and women served as models and gave their opinion on smoking. There were interviews with non-smoking actors from the video and with a Greenpeace activist. Information was given on effects of smoking, passive smoking, helping other people to quit smoking, and on reasons not to smoke. Furthermore, each newspaper included a competition, a cartoon about smoking, and letters to the editor.

The main difference between the two programs is the decision-making component which is only present in the decision-making program. In the first lesson of this program five steps to make a decision are explained and most activities are based on these five steps. The five steps are based on the five decision-making stages described by Janis. ${ }^{18}$ The social influence component is included in both programs because according to the literature, prevention programs that focus on the social influences approach have successfully reduced the rate of initiation of smoking..$^{19-26}$

The messages of both programs were pretested during several phases of the development of the programs. A group of students, teachers and experts were asked to read and comment the scripts of both programs. This resulted in some changes. Then, the scripts were discussed with a film director. The director put the two scripts on fillm. The same group of students were asked to view the programs and give comments. During the viewing, the reactions of the students were observed. Based on the comments and reactions of the students the film. director adapted the video-programs. Finally, the first lesson of both programs was pretested in two high schools, which resulted in only some small changes.

Teachers received a one-hour training from health educators consisting of information about the structure and content of the program, how to stimulate students, and how to train peer-leaders. To training the peer-leaders a special Iraining video was developed, in which their task is explained. Peer-leaders were thus trained by teachers with help of the training video. Both programs consisted of five lessons, each of 45 minutes and were given in weekly sessions in the second and third grade of high schools. 


\subsection{Sample}

The sample for the program evaluation consisted of second or third grade students of 32 high schools in the Netherlands who received either the decisionmaking program or the social influence program. All students of a school received the same program. Of the 32 schools 27 four-year education classes and 24 five or six-year education classes received the social influence program, while 32 four-year education classes and 32 five or six-year education classes received the decision-making program.

\subsection{Design}

The pretest was in October 1990, and the implementation of both programs took place in November and December. The first post-test was in April 1991. The first booster session was in September 1991, with the second post-test in October 1991. The second and third booster session were in January and March 1992. In April 1992 the third post-test was conducted.

\subsection{Questionnaire}

At the end of each lesson students and peer-leaders were asked to evaluate the different channels and sources used in that lesson on a five-point scale $(-2=$ negative evaluation; $+2=$ positive evaluation). The questionnaire from each lesson contained the same questions.

The sources of the programs were evaluated by questions on the peer-leaders and teacher. The "peer-leader" scale consisted of two questions (at the end of each lesson) evaluated by peer-leaders (It was easy/difficult to be a peer-leader; It was nice/boring to be a peer-leader; Cronbach's $\alpha=89$ ). Furthermore, the questionnaire at the end of each lesson contained a question on the assistance from the peer-leader (answered only by sudents and summed to form one "assistance from peer-leader" scale, $\alpha=86$ ), and the assistance by the teacher (summed to form one "assistance from teacher" scale, $\alpha=86$ ).

The channeis of the programs were evaluated by questions about the video, the activities, working in groups and the manual. A "lessons on video" scale evaluated the lessons on video by two questions (The video in this lesson is $\mathrm{good} / \mathrm{bad}$; To watch the video for this lesson is nice/boring; $\alpha=92$ ). The "activities" scale consisted of 14 questions (one question on each (home) activity: The (home) activity for this lesson is good/bad; $\alpha=.93$ ). Working in 
groups was evaluated by three questions (Working in groups is good/bad; Working with a peer-leader is good/bad; The collaboration in the group was good/bad; $\alpha=92$ ). The manual was evaluated by a question about the explanation of the activities of each lesson in the manual and a question about working with the manual during each lesson, resulting in one "manual" scale $(\alpha=.90)$.

The three newspapers (boosters) were evaluated during the third post-test (T4) by asking students if they had read the newspapers (yes/no), if they liked the newspapers, the colors, the interviews, the cartoons about smoking, the subjects in the newspapers, the opinions of famous singers about smoking, and the competitions $(-1=$ negative evaluation; $+1=$ positive evaluation $)$.

Furthermore the training the peer-leaders received before the start of the program was evaluated at the end of the first lesson: The training I received as a peer-leader was good/bad.

Teachers also evaluated the sources and channels of the programs on a fivepoint scale $(-2=$ negative evaluation; $+2=$ positive evaluation). The source of the video was evaluated by a question on the functioning of the peer-leaders in each lesson (summed to form one "functioning of the peer-leader" scale, $\alpha=89$ ). The channels were evaluated by questions on the lessons on video (summed to form one "lessons on video" scale, $\alpha=.71$ ), questions about the two activities during the lessons and the home activities (summed to form one "activities" scale, $\alpha=84$ ), a question about working in groups in each lesson (summed to form one "working in groups" scale, $\alpha=.69$ ), and finally a question about the explanation of the activities of each lesson in the manual (summed to form one "explanation of activities in manual" scale, $\alpha=.79$ ).

Beside the teachers' evaluation of the sources and channels by questionnaire, at the end of each lesson, interviews were conducted after the end of the program to obtain more in-depth information.

\subsection{Analysis}

Linear regression was used to assess students' evaluation of the programs. Assistance by peer-leader and assistance by teacher (the sources), and the lessons on video, (home) activities, working in groups with a peer-leader, and the manual (the channels) were summed to form one scale on program evaluation $(\alpha=86)$. For the linear regression the following model was used. Evaluation of the program was predicted from the variables treatment (decisionmaking program, social influence program), type of school (four-year education, five/six-year education), class (grade two, grade three), gender, pretreatment smoking behavior, and the interactions of treatment with type of 
school, class, gender and pre-treatment smoking behavior. Furthermore, analyses of variance was used to analyze differences in students" and/or peer. leaders' and teachers' evaluation of both programs. ANOVA was also employed to analyze differences in the evaluation of the booster. All statistical tests were performed using the SPSS-X statistical computer package.77

\section{Results}

The linear regression analysis resulted in no significant interaction effects, suggesting that the program evaluation did not differ per type of school, class, gender and pre-treatment smoking behavior. Therefore, all interactions were eliminated from the regression model. Table 1 shows that students receiving the social influence program evaluated the program more positively compared those receiving the decision-making program. Furthermore, both programs were more positively evaluated by four-year education students compared to five/six-year education students, by students of the second grade compared to third grade students, by girls compared to boys, and by pre-treatment nonsmokers compared to pre-treatment smokers.

Table 1

Differences in program evaluation $(N=1851)$

\begin{tabular}{llllll}
\hline Variable & $B$ & SE & $T$ & $P<$ & $95 \% \mathrm{CI}$ \\
\hline Dec. making ws social infl. & 0.22 & 0.03 & 6.87 & .001 & $(0.15-0.29)$ \\
Four ws five/six-year educ. & -0.24 & 0.03 & -8.19 & .001 & $(-0.28 \cdots-0.18)$ \\
Second grade ws third grade & -0.13 & 0.04 & -3.44 & .001 & $(-0.20 \cdots-0.05)$ \\
Boys ws girls & 0.32 & 0.03 & 11.35 & .001 & $(0.26-0.38)$ \\
Nonsmokers vs smokers & -0.29 & 0.04 & -6.49 & .001 & $(0.38 \cdots 0.20)$ \\
\hline
\end{tabular}

To test the expectations regarding the evaluation of the different programs, differences between students who received the social influence program and those who received the decision-making program were analyzed, as well as differences in program evaluation between second and third grade students, girls and boys, and between smokers and nonsmokers. Table 2 shows that students of both programs positively evaluated the different sources and channels. However, students receiving the social influence program were significantly more 
positive about the lessons on video, the activities, working in groups, the manual, and the assistance of the teacher. The difference in the evaluation of the assistance of the peer-leader was almost significant. With regard to the different educational levels, the results show that four-year education students were more positive than five/six-year education students in their ratings of the lessons on video, the (home) activities, working in groups with a peer-leader, and the assistance of the peer-leader (Table 2). There was no significant difference in the evaluation of the assistance of the teacher.

Table 2

Means of students evaluanion of the different sources and channels of the programs $(-2=$ negative evaluation $+2=$ positive evaluation $)$

\begin{tabular}{lllllll}
\hline Iten & $\begin{array}{l}\text { Dec. } \\
\text { mak. } \\
(\mathrm{N}=992)\end{array}$ & $\begin{array}{l}\text { Social } \\
\text { infl. } \\
(\mathrm{N}=982)\end{array}$ & $\begin{array}{l}\text { Four } \\
\text { year } \\
(\mathrm{N}=921)\end{array}$ & $\begin{array}{l}\text { Five/six } \\
\text { year } \\
(\mathrm{N}=945)\end{array}$ & $\begin{array}{l}\text { Second } \\
\text { grade } \\
(\mathrm{N}=1303)\end{array}$ & $\begin{array}{l}\text { Third } \\
\text { grade } \\
(\mathrm{N}=563)\end{array}$ \\
\hline $\begin{array}{l}\text { Lessons on video } \\
\text { Activities }\end{array}$ & 0.60 & $0.97^{* * *}$ & 0.92 & $0.64^{* * *}$ & 0.88 & $0.53^{* * *}$ \\
$\begin{array}{l}\text { Working in } \\
\text { groups }\end{array}$ & 0.47 & $0.83^{* * *}$ & 0.74 & $0.52^{* * *}$ & 0.71 & $0.43^{* * *}$ \\
$\begin{array}{l}\text { Manual } \\
\text { Teacher }\end{array}$ & 1.07 & $1.16^{* *}$ & 1.19 & $1.05^{* * *}$ & 1.12 & 1.11 \\
$\begin{array}{l}\text { assistance } \\
\begin{array}{l}\text { Peer-lleader } \\
\text { assistance }\end{array}\end{array}$ & 0.44 & $0.80^{* * *}$ & 0.70 & $0.47^{* * *}$ & 0.67 & $0.37^{* * *}$ \\
\hline
\end{tabular}

$\mathrm{p}<<.06, " \mathrm{p} p<.01, " \mathrm{p} \mathrm{p}<.001$

Table 2 also showes that second grade students were more positive about the lessons on video, the (home) activities, the manual and the assistance of the teacher, compared to third grade students. However, there were no significant differences between both groups in the evaluation of working in groups with a peer-leader, and the assistance by the peer-leader. Table 3 shows that nonsmokers evaluated all items of the program significantly more positivelly compared to smokers, and that girls evaluated all items significantly more positively than boys.

Peer-leaders evaluated their training and tasks positively. However, peerleaders on the social influence program $(\mathrm{N}=277)$ were more positive about the raining compared to those on the decision-making program $(\mathrm{N}=264)$ 
(respective means: 0.76 vs. $0.52 ; p<.05$ ). Furthermore, peer-leaders on the social influence program were more positive about being a peer-leader (respective means: 0.97 vs. $0.81 ; p<.05$ ).

Table 3

Means of students evaluation of the different sources and chamels of the programs $(-2=$ negative evaluation; $+2=$ positive evaluation $)$

\begin{tabular}{lllll}
\hline Item & $\begin{array}{l}\text { Boys } \\
(\mathrm{N}=935)\end{array}$ & $\begin{array}{l}\text { Giris } \\
(\mathrm{N}=1029)\end{array}$ & $\begin{array}{l}\text { Nonsmokers } \\
(\mathrm{N}=1637)\end{array}$ & $\begin{array}{l}\text { Smokers } \\
(\mathrm{N}=214)\end{array}$ \\
\hline Lesson on video & 0.68 & $0.84^{* *}$ & 0.82 & $0.49^{* *}$ \\
Activities & 0.49 & $0.73^{* *}$ & 0.67 & $0.33^{* *}$ \\
Working in groups & 0.92 & $1.28^{* *}$ & 1.14 & $0.96^{* *}$ \\
Manual & 0.40 & $0.73^{* *}$ & 0.62 & $0.27^{* *}$ \\
Teacher assistance & 0.58 & $0.81^{* *}$ & 0.74 & $0.48^{* *}$ \\
Pear--Ieadier assistance & 0.65 & $1.13^{* *}$ & 0.94 & $0.77^{*}$ \\
\hline
\end{tabular}

$\mathrm{p}<.05, " \mathrm{p}<.001$

Of the students on the decision-making program who received the three newspapers $(\mathrm{N}=339), 27 \%$ reported having read no newspaper, $73 \%$ reported having read at least one newspaper, $58 \%$ at least two newspapers, and $42 \%$ all three newspapers. Of the students on the social influence program who received the three newspapers $(\mathrm{N}=509)$, the respective figures were $41 \%, 59 \%, 45 \%$, and $36 \%$. Students receiving the decision-making program were more positive about the lay-out and topics (Table 4). No more significant differences were found in the evaluation of the booster between students of the decision-making program and the social influence program. Table 4 also shows that four-year education students and girls evaluated all aspects of the boosters significantly more positively than five/six-year education students and boys. With regard to grade, students of the second grade were more positive about the opinions about smoking of famous people $(p<.05)$. There were no differences in evaluation of the boosters between smokers and nonsmokers. 
Table 4

Means of sudents evaluation of the boosters $(-1=$ negative evaluation: $+1=$ positive evaluation

\begin{tabular}{|c|c|c|c|c|c|c|}
\hline liem & $\begin{array}{l}\text { Dec. } \\
\text { mak. } \\
(N=322)\end{array}$ & $\begin{array}{l}\text { Social } \\
\text { inf. } \\
(N=488)\end{array}$ & $\begin{array}{l}\text { Four } \\
\text { year } \\
\text { (N }=340)\end{array}$ & $\begin{array}{l}\text { Five/six } \\
\text { year } \\
(\mathrm{N}=471)\end{array}$ & $\begin{array}{l}\text { Boys } \\
(N=368)\end{array}$ & $\begin{array}{l}\text { Girls } \\
(N=44)\end{array}$ \\
\hline Lay out & 0.17 & $0.07^{x}$ & 0.23 & $0.01^{* * *}$ & -0.08 & $0.26^{x * 2}$ \\
\hline Colors & 0.04 & -0.03 & 0.14 & $-0.110^{2 n x}$ & -0.17 & $0.14^{* \ldots}$ \\
\hline miterviews & -0.003 & -0.08 & 0.03 & $-0.10^{* m}$ & -0.20 & $0.08^{x=\alpha}$ \\
\hline Cartoons & 0.22 & 0.14 & 0.33 & $0.06^{8.8 x}$ & 0.05 & $0.28^{* * *}$ \\
\hline Subjects & 0.16 & 0,04 & 0.20 & $0.01^{\text {mant }}$ & -0.04 & $0.19^{* *}$ \\
\hline $\begin{array}{l}\text { Opinions about } \\
\text { smoking }\end{array}$ & 0.19 & 0.19 & 0.34 & $0.09^{x+4}$ & -0.01 & $0.35^{10 * x}$ \\
\hline Competitions & 0.22 & 0.18 & 0.36 & $0.07^{\alpha w}$ & 0.01 & $0.34^{* * *}$ \\
\hline
\end{tabular}

$p<05, " p<01, * 0<0.001$

ANOVA was performed to assess the differences between teachers of the two programs in the evaluation of the different sources and channels of the prow grams. No differences were found (Table 5).

Table 5

Mears of teachers of the decision-making program and the social influence program $(-2=$ negative evaluation $;+2=$ positive evaluation $)$

\begin{tabular}{lllc}
\hline Item & $\begin{array}{l}\text { Decision making } \\
(\mathrm{N}=21)\end{array}$ & $\begin{array}{l}\text { Social influence } \\
(\mathrm{N}=19)\end{array}$ & $\mathrm{P}<$ \\
\hline Lessons on video & Mean & Mean & .92 \\
Activities & 0.78 & 0.76 & .74 \\
Working in groups & 0.83 & 0.77 & .21 \\
Explanation of activities in manual & 1.17 & 0.67 & .39 \\
Functioning of peer-leader & 0.71 & 1.33 & .10 \\
\hline
\end{tabular}

The interviews with the teachers showed that they were satisfied with the programs and that the students liked the lessons. The video-peer-led approach of the programs was a welcome break from the regular classes. Teachers indicated 
that an advantage of the activities was that students got to talk about the subjects handled in the lessons. However, some teachers of the decision-making program said that applying the steps to make a decision in most activities was boring: The teachers were positive about working in groups during the activities. They indicated that this increased involvement and self-reliance of the students. However, some teachers of four-year education students mentioned that these students needed support in working in groups. Regarding to the peer-leaders, the teachers said that they were surprised about the ability of the peer-leaders to stimulate the students in their groups. Some teachers indicated that the task of the peer-leaders was carried out by the whole group. Teachers recommended shortening the programs, because five lessons was too much: the students were less interested during the last lessons. About their task daring the lessons some teachers indicated that because of the video-peer-led nature, they had time to observe the students. Teachers of four-year education students said that their students needed intensive support during the lessons. Some teachers indicated that they would like to have the opportunity to go further into matters that were discussed or happened during the lessons. Finally, some teachers said that because of the program they had quit smoking.

\section{Discussion}

Based on the program matrix two smoking prevention programs have been developed. An advantage of using this matrix is that it can serve as a checklist to determine if important issues have been forgotten. The application of the matrix resulted in a video-peer-led approach for second and third-grade high school students. This matrix can also be used for the development of the process evaluation of the intervention. Accordingly, in this study the different channels and sources of the programs were evaluated by determining students" and teachers' appreciation of the channels and sources.

The results of the program evaluation revealed that in general students and teachers evaluated the programs positively. Although it was expected that the social influence program would be evaluated better by four-year education students and the decision-making program by five/six-year education students, there were no interactions between type of school and treatment. Nevertheless, students of the social influence program evaluated the program more posilively compared to students of the decision-making program. The results showed that the different sources and channels of the social influence program were more positively evaluated compared to the sources and channels of the decisionmaking program. Furthermore, four-year education students evaluated both 
programs more positively compared to five/six-year education students. With regard to the different sources and channels of the program, four-year education students were more positive about the lessons on video, the (home) activities, working in groups with a peer-leader, the manual and the assistance by the peer-leader, compared to five/six-year education students.

It was hypothesized that second grade students compared to those in the third grade, girls compared to boys and nonsmokers compared to smokers, would differ in their evaluation of both programs. The results confirmed these expectations: second grade students, girls and nonsmokers evaluated both programs more positively. Concerning the different sources and channels of both programs, second grade students were more positive about the lessons on video, the (home) activities, the manual, and the assistance by the teacher compared to third grade students. No significant differences existed between second and third grade students regarding working in groups with a peer-leader and the assistance of the peer-leader. Girls and nonsmokers evaluated all sources and channels more positively compared to boys and smokers.

Students on both programs received the same newspapers. Few students on either program reported having read all three newspapers. A possible explanation for the small percentages is that the students could read them where and when they preferred. Hence, the students were not guided in reading the boosters. Students on both programs differed in their evaluation of the lay-out and the subjects of the newspapers. These components were better evaluated by students receiving the decision-making program. However, qualitative interviews did not reveal why these differences occurred. Moreover, girls and fouryear education students evaluated all items of the boosters more positively compared to boys and five/six-year education students.

Teachers of both programs did not differ in their evaluation of the different channels and sources. The interviews with the teachers revealed that they liked the video-peer-led approach of the programs. Moreover, the teachers indicated that the students enjoyed the lessons.

It can be concluded that the sources and channels used in the two programs are effective in providing information about non-smoking. However, students evaluated the sources and channels of the social influence program more positively than those of the decision-making program. Moreover, teachers indicated that students on the decision-making program tired of applying the five steps to make a decision during most of the activities. Furthermore, the results of the effect-evaluation revealed that the social influence program with the boosters showed the best preventive effects. ${ }^{3}$ The increase in smoking sixteen months after the intervention in the social influence group with the 
boosters was $9.7 \%$ compared to $14.9 \%$ in the control group. Therefore, teachers can be recommended to use the social influence program with the boosters. However, because only small percentages of students reported having read all three newspapers, the behavioral effects of the boosters should be taken with some caution and it can be recommended to advise teachers to discuss the newspapers at class level. Moreover, further research should reveal how the boosters can be made more attractive to boys and five/six year education students.

With regard to diffusion of the program it is of importance to consider factors that influence the decision of teachers to adopt and implement a program, for example the number of lessons. During the interviews teachers indicated that five lessons were too many to keep the students interested and recommended shortening the programs. However, research has shown that at least five lessons are necessary to make an effective program. ${ }^{22}$ A possible solution for this problem is to make the program part of a more comprehensive approach for health education, in which topics such as peer-group pressure are also dealt with when discussing other subjects, such as alcohol, gambling and AIDS prevention. ${ }^{24}$ Another solution is that if teachers prefer to use the program flexibly, they should be advised to focus on the most important topics such as social pressures and raising self-efficacy towards handling social pressures by role-play.

Some teachers indicated that they would like to have the opportunity to go further into matters that were discussed or happened during the lessons. However, during the lessons there is no time left for further discussion. For future video-peer-led programs it is recommended to allow time during the lessons to give teachers the opportunity to go further into matters that were discussed or happened during the lessons.

\section{References}

1. De Vries H. Smoking prewention in Dutch adolescents. Maastricht: Datawyse, 1989.

2. De Vries H, Backbier E. Dijkstra M, Van Breukelen G. Parcel G, Kok G. A Dutch social influence smoking prevention approach for vocational school students. Healh Education Research. 1994:9:365-374.

3. Dijkstra $M$, De Vries $H$, Van Breukelen $G$, Parcel $G$. Effectiveness of two Dutch smoking prevention programs and boosters. Submitted for publication.

4. Madsen J, Sallis JF, Rupp JW, Senn KL, Patterson TL, Aikins CJ, Nader PR. Process variables as predictors of risk factor changes in a family bealth behavior change program. Health Educarion Research. 1993;8:193-204. 
5. Winnegan JR, Rooney $\mathrm{B}$, Viswanah $K$, Elmer P, Graves $K$, Baxter J, Hertog J, Mullis $R$. Potter J. Process evaluation of a home-based program to reduce diet-related cancer risk: The win a home series. Heath Education Quarterly. 1992;19:233-248.

6. Flora IA, Lefebre RC, Murray DM, Stone EJ, Assaf A, Mittelmark MB, Finnegan JR. A community education monitoring system: Methods from the Stanford Five-City project, the Minnesota Heart Health Program and the Pawtucket Heart Health Program. Health Education Research 1993;8:81-95.

7. Wickizer TM, Von Korff $M$, Cheadle A, Maeser I, Wagner EH, Pearson D, Beery W, Psaty BM. Activating communities for health promotion: A process evaluation method. American Joumal of Public Health. 1993;83:561-567.

8. Sussman S, Dent CW, Stacy AW, Hodgson CS, Burton D, Flay BR. Project towards no tobacco uste: Implementation, process and post-test knowledge evaluation. Heallh Education Research. 1993;8:109-123.

9. Windsor RA, Baranawski T, Clark N, Cutter G. Evaluation of health promotion and education programs. Palo Alto: Mayfield Publishing Company, 1984

10. Green LW, Kreuter MW. Health promotion planning: An educational and environmentat appronch. Mountain View, CA: Mayfield, 1991.

11. Dijkstra M. De Vries H, Parcel G. The linkage Approach Applied to a School-Based Smoking Prevention Program in the Netherlands. Journal of School Health. 1994;63:339. 342 .

12. Dijkstra M, De Vries $H$, Parcel GS. Predictors of implementation and continuation of a Dutcl smoking prevention program. Submitted for publication.

13. De Vries H, Kok GJ. A program matrix to plan and evaluate behavioral interwentions. In preparation.

14. Flay BR, D'Avernas JR, Best JA, Kersell MW, Ryan KB. Cigarette smoking: Why young people do it and way's of preventing it. In: McGrath PJ, Firestone P. (Eds.) Pediatric and adolescent behavioral medicine (pp. 132-183). New York: Springer, 1983.

15. De Vries $H_{2}$ Dijkstra M, Kok G. A Dutch smoking prevention project: An overview. Hygie. 1992;11:14-18.

16. De Vries H, Kok GJ. From determinants of smoking behavior to the implications for a prevention program. Heath Education Research. 1986; 1:85 94 .

17. De Vries H, Dijkstra M. Kuhlman P. Self-efficacy: The third factor besides attitude and subjective norm as a predictor of behavional intentions. Health Education Research. 1988;3:273-282.

18. Janis IL, Mann L. Decision Making. A Psychological Analysis of Conftict, Choice, and Commitment. New York: Free Press, 1977.

19. Flay BR. Psychosocial approaches to smoking prevention: A review of findings. Health Psychology. 1985;4:449-488.

20. Botvin GJ. Substance abuse prevention research: Recent developments and future directions. Jownal of School Health. 1986:9:369-374.

21. Tobler NS. Meta-analysis of 143 adolescent drug prevention programs: Quantitative outcome results of program participation compared to a control or comparison group. Journal of Drug Issues, 1986;16:537-567.

22. Best JA, Thomson SI, Santi SM, Smith EA, Brown KS. Preventing cigarette smoking among school children. Annual Review of Public Health. 1988;9:161-201. 
23. Bruwold TG, Rundall WH. A Meta-analysis of School-based Smoking and Alcohol Use Prevention Programs. Health Education Quarferly. 1988;15: 317.334.

24. Murray DM, Pirie P, Luepker RV. Pallonen U. Five- and six-year follow-up resulks from four seventh-grade smoking prevention strategies. Journal of Behaworal Medicine. $1989 ; 12: 207-218$.

25. Hansen WB. School-based substance abuse prevention: A review of the state of the art in curriculum, 1980-1990. Health Education Research. 1992;7:403-430.

26. Bruwold TG. A meta-analysis of adolescent smoking prevention programs. American Journol of Public Health. 1993;83:872-880.

27. SPSS Inc. SPSS-X user's guide. Chicago, Illl: SPSS Inc, 1988. 



\title{
Chapter 5
}

\section{Effectiveness of two Dutch smoking prevention programs with boosters}

\author{
Margo Dijkstra, Hein de Vries, Gerard van Breukelen \& Guy S. Parcel \\ Submitted for publication.
}

\begin{abstract}
Objectives, This paper reports results of two Dutch smoking prevention programs with boosters.

Methods. A social influence (SI) and a decision making (DM) peer-led program on video, including booster-sessions were developed and implemented in second and third grade high schools. An experimental design was used with a pretest and three posttests. Boosters were implemented in half of the experimental groups. Treatment effects on smoking behavior were evaluated with logistic and linear regression analysis, taking relevant covariables into account.

Results. Four months after the interventions, both programs were effective in preventing smoking among pretest nonsmokers. Ten and sixteen months after the interventions, the SI program with the booster was more effective compared to the SI program without the booster and compared to the control group. The DM program without the booster was more effective compared to the control group at ten months after the interventions.

Conclusions. Regarding the behavioral effects and the results of the formative evaluation it is recommended to implement the SI program with the boosters or the DM program without the booster.
\end{abstract}

\section{Introduction}

Reviews of smoking prevention programs have presented classifications of commonly used program approaches. ${ }^{1,2}$ The newer programs based on social reinforcement and social norms have shown positive behavioral effects. ${ }^{2-11}$ An important goal of the social influences approach is to make adolescents aware of 
the social influences to smoke and provide them with social skills to resist such pressures. ${ }^{12}$ Most of these programs also provide information on the short-term physiological and social consequences of smoking. Decision making skills and a public commitment procedure are also often included. ${ }^{12}$ Many of these programs resulted in positive behavioral effects up to two years after the conclusion of the programs. Two studies failed to find a long-term effect and suggested adding boosters to improve the effect of smoking prevention programs since one single intervention may not be sufficient to produce permanent effects. ${ }^{9.13}$ Accordingly, several studies included booster sessions, which were mostly given in the second and sometimes in the third year of the prevention study, and contained three to 20 class sessions. ${ }^{7.14 .16}$ Although booster sessions may help to enhance intervention effects ${ }^{16}$, experimental designs in which an additional effect of boosters is demonstrated were not used.

The present study reports results from a follow-up study of a Dutch smoking prevention project for high school students. This project was based on the first smoking prevention project for vocational and high school students, which used a social influence peer-led program on video for 13-14-year-old adolescents. This program was effective in preventing the onset of regular smoking among vocational school students and thus national implementation of the program in vocational schools was recommended. However, the program did not have an impact on regular smoking for high school students. ${ }^{17,18}$ Process evaluation suggests three explanations for this absence: a relatively low educational level of the program, a low smoking incidence in second grade high school students, and a need to discuss the decision-making process more elaborately. ${ }^{10}$ Petty \& Cacioppo $^{20}$ have suggested that behavioral change can be the result of processing information cognitively or affectively. Important factors for cognitive information processing are factors within the individual (e.g., educational level, intelligence, a person's need for coherent cognitive structures and level of involvement with the issue). It is conceivable that high school students have a strong need to process information cognitively before behavioral change or maintenance can be induced. ${ }^{19}$ Botwin ${ }^{5}$ has developed an approach that includes various aspects of cognitive-behavioral psychological training such as training of decision-making skills, which are general skills for coping with life. The decision-making component was designed to foster the development of critical thinking and responsible decision-making. ${ }^{21}$ The life skills approach has shown promising results.

Recommendations, based on the results of the first prevention project, suggested further research with regard to development of effective smoking prevention programs for high schools. It was recommended to adapt the social 
influence program to the educational level of high school students, to implement it in a higher grade, and to develop a decision-making program for high school students. Dutch high schools consist of three different educational levels. The lowest level has a four-year education track, the middle level has a five-year education track, and the highest level has a six-year education track preparing students for university. Furthermore, a general suggestion was made to develop booster sessions to enhance maintenance of program effects in high schools. ${ }^{22}$

As a result, the second Dutch smoking prevention project developed two different smoking prevention programs for second (13-14-years-old) and third grade (14-15-years-old) high school students, to compare the results with a control group. Half of the experimental group received three boosters, while the other half did not. The programs were implemented in the three different tracks within the high schools, and in the second and the third grade, which are equivalent to grade 8 and 9 in the U.S.

The goal of this article is to describe the effects of the smoking prevention programs and boosters, as well as possible differential treatment-effects between the four-year education students and the five/six-year education students, and possible differential treatment-effects between students of the second and third grade.

It was expected that the social influence program (SI program) would be more effective than the decision-making program (DM program) in preventing or delaying smoking in four-year education students, while the reverse was expected for the students of the five/six-year track. This hypothesis was based on the assumption that students of five/six-year education have a stronger need to process information cognitively compared to students of four-year education. Furthermore, it was hypothesized that the programs with the boosters would be more effective than the programs that did not include them. Moreover, differential effects between second and third grade students were analyzed. Finally, we expected that the programs would result in increased knowledge about the effects of smoking, less favorable attitudes towards smoking, higher self-efficacy levels for non-smoking, a negative intention to smoke, and a negative social norm regarding smoking.

\section{Methods}

\subsection{Sample}

Dutch high schools consist of three different educational levels. Some schools provide one education, others two or three. It appeared impossible to match an 
equal number of schools with similar education. Students of the five- and sixyear educational level were united in one group because otherwise the number of students needed would have given organizational difficulties. In total 52 schools participated in the project. In each school students in second or third grade participated in the project. All students of one school were in the same condition and received either the SI program, the DM program, or served as a control group. The 52 schools were matched on type of school (four-year education versus five/six-year education) and grade (second grade versus third grade) and then randomly divided in 32 experimental schools and 20 control schools. Twenty-seven four-year education classes and 24 five- or six-year education clasises received the SI program, while 32 four-year education classes and 32 five or six year education classes received the DM program. Furthermore, 35 four-year education classes and 32 five- or six-year education classes served as the control group.

With regard to the boosters, the two experimental conditions were matched on type of school (four-year education versus five/six-year education) and grade (second grade versus third grade) and then randomly divided in a group with boosters and a group without boosters.

\subsection{Design}

The pretest was in October 1990 (T1), program implementation occurring during November and December. The first posttest (T2) was in April 1991. The first booster session was in September 1991. The second posttest (T3) was in October 1991, and the second and third booster sessions were in January and March 1992. In April 1992 the third posttest (T4) was conducted. The time left between implementation and the different posttests was based on both theoretical and practical factors. Because we wanted to assess changes in cognitive factors as well as in behavior, three posttests were conducted. According to Ajzen and Fishbein $^{23}$, cognitive factors have to change first, before behavior change will take place. Therefore we conducted three posttests to follow the pattern of changes in cognitive factors and in smoking behavior. The practical factor was that the project was funded for only four years and we had to consider the school holidays.

Program effects on smoking at T2, T3 and T4 will be described. With regard to effects on attitude, knowledge, social norms, perceived behavior, pressure, self-efficacy, and intention only the results at T2 and T4 will be described. To maximize numbers of subjects and minimize possible attrition artifacts, all subjects who participated at any posttest survey who could be matched with 
pretest data were included. This resulted in overlapping but not identical samples at $\mathrm{T} 2(\mathrm{~N}=4060), \mathrm{T} 3(\mathrm{~N}=3653)$ and $\mathrm{T} 4(\mathrm{~N}=3104)$.

\subsection{The programs and boosters}

The structure used was the same as in the first Dutch smoking prevention program with some small changes. Both programs consisted of five lessons, each of 45 minutes and were given in weekly sessions in the second and third grade of high schools. Structure and content of both programs, presented on video by adolescents, can be summarized as follows: a. introduction of the theme on video, b. peer-led activity, c. feedback on the activity and continuation of the lesson on video, $d$, peer-led activity, e. feedback on the activity, and $f$. home work assignments.

Peer-led activities were conducted in small groups consisting of four or five students. Before the first lesson groups were formed by the teachers and peerleaders, who had to be nonsmokers, were chosen by the groups or by the teacher. The peer-leader was a student from the same class as the students and served as a chairperson of the small activity group. Teachers coordinated the lessons, stimulated students and assisted peer-leaders. Teachers received one hour of training from health educators consisting of information about the structure and content of the program, how to stimulate students, and how to train peer-leaders. For the training of the peer-leaders a special training video was developed in which their task was explained. Peer-leaders were trained by teachers with help of this video. Teachers, peer-leaders and students received their own manual with activities, and information on their tasks. At the end of each lesson teachers handed out a summary of the lesson, which could be added to the manuals.

Social influence program. The first lesson focused on the reasons why people do or do not smoke and why people quit smoking, and the differences between direct and indirect pressure to smoke. The second lesson dealt with the shortterm effects of smoking, the dangers of experimentation with smoking, passive smoking, addiction, and quitting smoking. Students received a brochure about how to quit smoking to hand out to a smoking person at home or in their environment. The third lesson focused on resisting peer pressure and acquiring skills to resist it. The fourth lesson discussed how to react when bothered by smoke, indirect pressure to smoke from adults and advertisements, and measures from the government against smoking. The last lesson focused on alternatives for smoking, making the decision to smoke or not, and commitment 
to non-smoking behavior. To increase commitment, students were asked to conclude a non-smoking contract, and to write their name on a non-smoking poster that could be clearly seen in the school, and consequently by other students (public commitment). As a reward for their non-smoking nonsmokers received a non-smoking poster.

Decision-making program. The first lesson discussed five steps to make a decision: 1. What is the situation in which you have to make a decision? 2 . What are the possible decisions? 3. What are the pros and cons of the possible decisions? 4. Make a decision based on the pros and cons; 5. Practice the decision. Most activities in this program were based on these five steps. Reasons why people do or do not smoke and why they quit were discussed as well. The second lesson dealt with the short-term effects of smoking, the dangers of experimentation, addiction and passive smoking. The third lesson focused on how to react when bothered with smoke, measures of the government and quitting smoking. At the end of the third lesson students received a quit-smoking brochure to give to a smoking person at home or in their environment. The fourth lesson dealt with direct pressure from peers and indirect pressure from adults and advertisements. The last lesson was about alternatives and decision making based on the five steps with respect to future smoking. This lesson also included the public commitment.

Boosters. Because of the tight curriculum of the teachers it was not feasible to develop additional lessons on smoking prevention. Therefore, three newsletters were developed containing information that was also given on the video. Teachers were asked to give the newspapers to the students, who could read them at home or during a break at school. In the three newspapers famous national and international singers and sportspersonalities served as models and gave their opinion on smoking. There were interviews with non-smoking actors from the video and with a co-worker of Greenpeace. Information was given on effects of smoking, passive smoking, helping other people to quit smoking, and on reasons not to smoke. Furthermore, each newspaper included a competition, a cartoon about smoking, and letters to the editor from students.

\subsection{Procedure}

Health educators working in district health centers recruited schools to participate in the project. ${ }^{24}$ They obtained formal consent from school boards 
since this is the standard procedure in the Netherlands. No parental consent was needed. ${ }^{18}$

Questionnaires for the effect evaluation were distributed by teachers. Subjects were assured of anonymity and confidentiality and that no one but the researchers had access to the data. When subjects finished their questionnaire, teachers put them in an envelope, sealed it and sent it via the health educators to the researchers.

\subsection{Questionnaire}

The questionnaire was based on the Attitude -- Social influence -- Self-efficacy model (ASE model). ${ }^{19}$ According to this model, behavior is determined by people's attitude toward the behavior, social influences and self-efficacy. An attitude represents a person's general feeling of favorableness or unfavorableness towards a behavior, and is determined by perceived positive and negative consequences of the behavior. ${ }^{23}$

Social influences can be divided in social norms, modeling and pressure. ${ }^{19}$ Social norms refer to the perceived subjective norms from other people. Modeling refers to perceived behavior of other people, and pressure refers to perceived pressure from others to conduct the specific behavior. Self-efficacy refers to a person's expectation regarding his capability to realize a (desired) behavior. ${ }^{25}$ Attitudes, social influences and self-efficacy predict the intention to perform the behavior which, in turn, predicts the behavior itself. External variables, such as demographic variables, influence behavior via the three determinants and the intention. Between intention and behavior there may be barriers or lack of skills which may hinder the realization of the intention.

Attitudes were assessed by 13 beliefs (b) and corresponding evaluations (e) according to the procedure described by Ajzen \& Fishbein. ${ }^{24}$ Beliefs and evaluations, assessed on a seven-point scale, measured the health, social and personal consequences of smoking. The beliefs were multiplied with the evaluations and then summed ( $\Sigma b^{*} \mathrm{e}$; Cronbach's $\alpha=.78$ ). Factor analysis revealed three attitude factors: 1. Health disadvantages of smoking (bad for your health, breathing problems, passive smoking, bad physical condition, coughing, unwise; $\alpha=.74$ ); 2 . Social acceptance (acceptance by friends, making contacts, being pestered less, sociable; $\alpha=.61) ; 3$. Personal advantages of smoking (relieving boredom, relieving tension, tastes good; $\alpha=47$ ). Knowledge about the effects of smoking was measured by 12 questions $(\alpha=.15)$. Because no meaningful factors were found, the questions were summed to form one knowledge index. 
Sociall norms were also measured according to the procedure of Ajzen \& Fishbein. Six questions assessed the normative beliefs of the important persons ( $\mathrm{nb}$ ) and the corresponding motivations to comply with these opinions (mc). Normative beliefs were measured on a seven-point scale (e.g., "My parents think that I certainly should, should, probably should, neutral, probably should not, should not, certainly should not smoke"). Motivations to complly were measured on a five-point scale (e.g." "With respect to smoking I very often, often, sometimes, hardly, do not comply with the opinion of my parents"). The normative beliefs and motivations to comply were multiplied and summed to form one social norm scale ( $\Sigma \mathrm{nb}^{*} \mathrm{mc} ; \alpha=.76$ ).

Pressure to smoke was assessed by six items on a five point scale (e.g., "How often did you feel pressure to smoke from your parents: very often, often, sometimes, hardly ever, never"). The items on pressure were summed to form one pressure scale $(\alpha=.62)$. Perceived behavior refers to the smoking behavior of important persons. The six items were measured on a two-point scale (e.g., "My father smokes, does not smoke"). The items were summed to form one scale $(\alpha=48)$. The social norms, pressure, and perceived behavior scales included different important persons: father, mother/parents, brothers/sisters, friends, best friend, family. The social norms and pressure scales also included cigarette industries.

Self-efficacy expectations were assessed by seven questions on a seven-point scale (e.g. "Do you believe you are able to refuse an offered cigarette? Yes, certainly/certainly not"). The items were summed to form one scale which measured perceived capacity to refrain from smoking $(\alpha=.74)$.

Intention to smoke was measured by five items on a seven-point scale ("I certainly do, do, probably do, neutral, probably do not, do not, certainly do not intend to smoke: in general, in discos, with friends, in my own room, with parents"). The items were summed to form one scale $(\alpha=.94)$.

Smoking behavior was based on self-reports, categorizing a student as: 1. never smoker: never smoked one (puff of a) cigarette; 2 . initial smoker: tried smoking up to five times; 3 . quitter; 4. occasional smoker: smokes occasionally but not every week; 5 . weekly smoker: smokes at least one cigarette per week; 6. daily smoker: smokes at least one cigarette per day.

No procedures to enhance self-report validity were used because of organizational difficulties. However, self-reports have been demonstrated to be accurate when anonymity and confidentiality were assured and an identification coding system was used. ${ }^{26-32}$ At each assessment students provided an identification code consisting of the subjects initials, date of birth, gender, school, and class. Furthermore, anonymity was assured. 


\subsection{Analysis}

Program impact was evaluated using linear regression for quantitative effect measures, and logistic regression for binary effect measures. Since the program had a three-level sample (schools, classes, students), multilevel analyses using VARCL were performed to check the results of SPSS-X logistic and linear regression (which ignored the nested character of our sample) against VARCL logistic and linear regression. ${ }^{33-35}$ Since VARCL only gives an approximation to logistic regression which sometimes runs into computational problems, model reduction was done using SPSS. The initial models were reanalyzed with VARCL to check if any substantial inter-school or inter-class effects occurred that might distort the SPSS results. ${ }^{18}$ Since for both the binary measures and the quantitative measures less than $5 \%$ of the residual variance was due to betweenclass and between-school effects and Betas and Standard Errors did not substantially differ between VARCL and SPSS, the final models were conducted with SPSS, because the same results would be obtained with VARCL. This may be due to the inclusion of the pre-treatment recording of the dependent variable as covariable, which probably contains (most of the) class and school effects.

For the treatment effects on smoking, occasional, weekly and daily smokers were combined to form one group of smokers, while never smokers, initial smokers and quitters formed one group of nonsmokers $(0=$ nonsmokers, $1=$ smokers). For this binary measure the following strategy was used. Posttreatment smoking was predicted from the school-level factors: treatment (T2: SI program, DM program, no program; T3 and T4: SI program with and without boosters, DM program with and without boosters, no program; using dummy coding), type of school ( 0 = four-year education, $1=$ five/six-year education), and their interaction; the class-level factors: class $0=$ grade two, $1=$ grade three), and the interaction of class with treatment; the person-level covariates: age, gender $(0=$ boys, $1=$ girls), pre-treatment smoking, and their interactions with treatment. Furthermore pretreatment measures of attitude, social norms, pressure, perceived behavior, self-efficacy, and intention were entered as covariates, since previous research showed that these were predictors of smoking. ${ }^{18,36}$ Non-significant interactions were deleted stepwise $(\alpha=.05)$. If at significant interaction remained, the sample was stratified according to the covariate interacting with the treatment.

For quantitative measures a comparable linear regression model was used. Posttreatment outcome was predicted from the school-level factors, the classlevel factor, the person-level covariates, the pre-treatment value of the dependent variable, and their interactions with treatment. 
All analyses were done separately for the first, second and third posttest. Separate analysis per posttest were done instead of repeated measures MANOVA for the following reasons. 1. The primary dependent variable, smoking, is binary. 2. There are three treatment groups at T2, but five at T3 and T4, which rules out a simple repeated measurement MANOVA. Two-tailed significance tests $(\alpha=.05)$ were used.

\section{Results}

Attrition from pretest (T1) to posttest 1 (T2) was $15.9 \%(\mathrm{~N}=766)$. Logistic regression analyses with attrition as dependent variable suggested that girls $(\mathrm{OR}=.74 ; 95 \% \mathrm{Cl}=.63-.88)$, younger students $(\mathrm{OR}=1.31 ; 95 \% \mathrm{Cl}=1.16-1.48)$, students in the DM program $(\mathrm{OR}=.39 ; 95 \% \mathrm{CI}=.31-.48)$ and in the SI program $(\mathrm{OR}=.69 ; 95 \% \mathrm{Cl}=.56-.85)$ compared with control group students, and fouryear education students $(\mathrm{OR}=1.21 ; 95 \% \mathrm{CI}=1.01-1.43)$, were less likely to drop out. Attrition at T1 was not related to pretest smoking behavior.

Attrition from pretest (T1) to posttest 2 (T3) was $24.3 \%(\mathrm{~N}=1172)$. Girls $(\mathrm{OR}=.84 ; 95 \% \mathrm{CI}=.73-.97)$, younger students $(\mathrm{OR}=1.32 ; 95 \% \mathrm{CI}=1.19-1.47)$, nonsmokers $(\mathrm{OR}=1.34 ; 95 \% \mathrm{CI}=1.20-1.49)$, second grade students $(\mathrm{OR}=1.62$; $95 \% \mathrm{CI}=1.33-1.96)$, and four-year education students $(\mathrm{OR}=1.33$; $95 \% \mathrm{CI}=1.14-1.54$ ) were less likely to drop out at the second posttest.

Attrition from pretest (T1) to posttest 3 (T4) was $35.7 \%(\mathrm{~N}=1722)$. Girls $(\mathrm{OR}=.85 ; 95 \% \mathrm{Cl}=.74-.96)$, younger students $(\mathrm{OR}=1.18 ; 95 \% \mathrm{CI}=1.07-1.31)$, nonsmokers $(\mathrm{OR}=1.38 ; 95 \% \mathrm{Cl}=1.05-1.82)$, students in the control group compared with students in the DM program ( $\mathrm{OR}=1.57 ; 95 \% \mathrm{CI}=1.36-1.82)$, students in the SI program compared with control group students (OR $=.61$; $95 \% \mathrm{Cl}=.51-.72)$, four-year education students $(\mathrm{OR}=1.22 ; 95 \% \mathrm{Cl}=1.07-1.39)$, and students with a negative intention to start smoking (OR=1.02; $95 \% \mathrm{Cl}=1.004-1.03$ ), were less likely to drop out at time of the third posttest.

At T2, T3 as well as T4 there were no significant interactions between pretest smoking and treatment condition.

\subsection{Program effects on smoking}

At $\mathrm{T} 2$ a significant interaction between treatment and pre-treatment smokingbehavior was found. Therefore, separate analyses were conducted for pretest nonsmokers and pretest smokers (see Table 1). Analyses for pretest nonsmokers showed a significant treatment effect of the decision-making group compared with the control group, and of the social influence group compared with the 
control group. No treatment effect was found for smokers. Furthermore, students with a positive attitude and intention towards smoking, students with important people in their social environment who smoke (perceived behavior), and students who perceived pressure to smoke had an increased risk of being smokers at $T 2$. No significant effects were found for the sociall norms, selfefficacy expectations, age, gender, class and type of school.

Table 1

Significant predictors of smoking at $T 2(N=4060)$

\begin{tabular}{|c|c|c|c|c|c|}
\hline Variable & B & $\mathrm{SE}$ & $\begin{array}{l}\text { Odds } \\
\text { ratio }\end{array}$ & $p<$ & $95 \% \mathrm{Cl}$ \\
\hline Pretest attitude & 0.02 & 0.005 & 1.02 & 0.001 & $(1.01-1.03)$ \\
\hline Pretest intention & 0.10 & 0.01 & 1.11 & 0.001 & $(1.08-1.13)$ \\
\hline Pretesi modeling & 0.28 & 0.06 & 1.33 & 0.001 & $(1.18 \cdots 1.49)$ \\
\hline Pretest pressure & 0.06 & 0.02 & 1.06 & 0.01 & $(1.02-1.10)$ \\
\hline \multicolumn{6}{|l|}{ Nonsmokers $(\mathrm{N}=3666)$} \\
\hline Dec. mak. vs no treatment & -0.46 & 0.19 & 0.63 & 0.05 & $(0.44-0.92)$ \\
\hline Soc. infl. vs no treatment & -0.62 & 0.22 & 0.54 & 0.01 & $(0.35 \omega 0.83)$ \\
\hline Dec. mak. vs soc. infl. & 0.17 & 0.23 & 1.18 & ns & $(0.75-1.86)$ \\
\hline \multicolumn{6}{|l|}{ Smokers $(N=394)$} \\
\hline Dec. mak. ws no treatment & 0.29 & 0.32 & 1.34 & ns & $(0.72-2.49)$ \\
\hline Soc. infl. vs no treatment & 0.35 & 0.40 & 1.42 & $\mathrm{~ns}$ & $(0.65-3.15)$ \\
\hline Dec. mak. vs soc. infl. & -0.06 & 0.38 & 0.94 & ns & $(0.44-1.98)$ \\
\hline
\end{tabular}

Effects of pretest attitude etc. are based upon the final regression model for the total sample. including interaction of treatment * pretest smoking.

Effects of treatment are based upon the same final model, minus pretest smoking main and interaction terms, for pretest smokers and nonsmokers separately.

The dummy coding scheme used for the results at $\mathrm{T} 3$ and $\mathrm{T} 4$ is shown in Table 2. At T3 no significant interactions with treatment were found. A significant effect was found for the SI program with the booster compared to the SI program without the booster and compared to the control group (Table 3). However, no significant effect was found for the SI program without the booster compared to the control group. With regard to the DM program there was a significant effect for this program without the booster compared to the control group. No significant effect was found for the DM program with the booster compared to that program without the booster. The SI program with the booster was more effective in preventing smoking compared to the DM program with the booster, but the SI program without the booster was less 
effective than the DM program without the booster. Older students, pretest smokers, students with a positive attitude, and a positive intention, and students who perceived important smoking others, had an increased risk of being a smoker at T3. No significant effects were found with regard to the factors social norms, self-efficacy expectations, pressure, gender, type of school and class.

Table 2

Coding scheme for results at $\mathrm{TH}$ and $\mathrm{TA}$

\begin{tabular}{l|ccccc}
$\begin{array}{c}\text { Group } \\
\text { Dummy }\end{array}$ & A & B & C & D & E \\
\hline X1 scon & 0 & 1 & $\mathbb{1}$ & 0 & 0 \\
X2 sboos & 0 & 0 & $\|$ & 0 & 0 \\
X3 dcon & 0 & 0 & 0 & 1 & 1 \\
X4 dboos & 0 & 0 & 0 & 0 & 1
\end{tabular}

scon $=$ soc. influence $\mathrm{vs}$ control group $\left(\beta_{1}\right)$

sboos $=$ soc. influence with booster vs soc. influence $\left(\beta_{2}\right)$

dcon $=$ dec. making vs control group $\left(\beta_{3}\right)$

dboos $=$ dec. making with booster ws dec. making $\left(\beta_{4}\right)$

Table 3

Significant predictors of snoking at $T 3(N=3653)$

\begin{tabular}{|c|c|c|c|c|c|}
\hline Variable & B & SE & $\begin{array}{l}\text { Odds } \\
\text { ratio }\end{array}$ & $p<$ & $95 \% \mathrm{Cl}$ \\
\hline Soc. infl. vis no treatment & 0.07 & 0.15 & 1.08 & ns & $(0.79-1.45)$ \\
\hline Soc. infl $+B$ ws soc int. & -0.89 & 0.21 & 0.41 & .001 & $(0.26-0.63)$ \\
\hline Soc infl $+B$ vs no treatment ${ }^{*}$ & -0.82 & 0.19 & 0.44 & .05 & $(0.30-0.65)$ \\
\hline Dec. mak vs no treatment & -0.47 & 0.16 & 0.62 & .005 & $(0.45-0.86)$ \\
\hline Dec. mak + $B$ ws dec. mak. & 0.28 & 0.19 & 1.32 & ns & $(0.91-1.91)$ \\
\hline Dec. mak + B ws no treatment" & -0.19 & 0.15 & 0.83 & ns & $(0.61-1.12)$ \\
\hline Dec mak vs soc. infl. & -0.54 & 0.19 & 0.58 & .005 & $(0.40-0.85)$ \\
\hline Dec. mak + B ws soc. inf $1+B$ & 0.63 & 0.22 & 1.88 & .005 & $(1.22-2.88)$ \\
\hline Age (in years) & 0.22 & 0.08 & 1.25 & .01 & $(1.06-1.47)$ \\
\hline Pretest smoking & 1.23 & 0.20 & 3.42 & .001 & $(2.31-5.04)$ \\
\hline Pretest attitude & 0.01 & 0.004 & 1.01 & .001 & $(1.00-1.03)$ \\
\hline Pretest intention & 0.11 & 0.01 & 1.11 & .001 & $(1.08-1.15)$ \\
\hline Pretest perceived behavior & 0.15 & 0.02 & 1.17 & .001 & $(1.12-1.22)$ \\
\hline
\end{tabular}

"Combination of two or more dummies, for example: soc. influence $+B$ ws no treatment $=\beta_{1}+\beta_{2}$ $+\mathrm{B}=$ with boosters 
As at T3, at T4 too no significant treatment interactions were found (Table 4). A significant effect was found for the SI program with the boosters compared to the SI program without the boosters and compared to the control group. There was no significant effect for the SI program without the booster compared to the control group. An almost significant effect was found for the DM program without the boosters compared to the control group. No significant difference existed for the DM program with the booster compared to that program without the booster. The difference between both programs was not significant, whether the booster was included or not. Furthermore, pre-treatment smokers, students with a positive attitude, and a positive intention towards smoking, and students who perceived important smoking others and who experienced pressure to smoke had an increased risk of being a smoker at $T 4$. No significant effects were found with regard to the factors social norms, self-efficacy expectations, gender, age, class and type of school.

\section{Table 4}

Significant predictors of smoking at $T 4(N=3104)$

\begin{tabular}{|c|c|c|c|c|c|}
\hline Variable & $\mathrm{B}$ & $\mathrm{SE}$ & $\begin{array}{l}\text { Odds } \\
\text { ratio }\end{array}$ & $\mathrm{p}<$ & $95 \% \mathrm{Cl}$ \\
\hline Soc, infl. ws no treatment & 0.0004 & 0.15 & 1.0004 & ns & $(0.74-1.34)$ \\
\hline Soc infl + B us soc infl. & -0.47 & 0.19 & 0.62 & .05 & $(0.43-0.90)$ \\
\hline Soc infl. + $-\mathrm{B}$ vs no treatment & -0.47 & 0.17 & 0.62 & .005 & $(0.45-0.87)$ \\
\hline Dec. mak. vs no treatment & -0.30 & 0.16 & 0.74 & .07 & $(0.54-1.02)$ \\
\hline Dec. mak. + B vs dec. mak. & 0.09 & 0.21 & 1.09 & ns & $(0.73-1.64)$ \\
\hline Dec. mak. + B vs no treaiment" & -0.22 & 0.18 & 0.81 & ns & $(0.57-1.14)$ \\
\hline Dec. mak. vs soc. infl. & -0.30 & 0.19 & 0.94 & ns & $(0.51-1.08)$ \\
\hline Dec. mak. + B vs soc infl $+B$ & 0.26 & 0.21 & 1.29 & ns & $(0.85-1.96)$ \\
\hline Pretest smoking & 1.18 & 0.22 & 3.26 & .001 & $(2.11-5.01)$ \\
\hline Pretest artitude & 0.007 & 0.004 & 1.007 & .05 & $(1.00-1.01)$ \\
\hline Pretest intention & 0.09 & $0.0 \Perp$ & 1.10 & .001 & $(1.07-1.12)$ \\
\hline Pretest modeling & 0.30 & 0.05 & 1.35 & .001 & $(1.22-1.49)$ \\
\hline Pretest pressure & 0.06 & 0.02 & 1.06 & .01 & $(1.02-1.11)$ \\
\hline
\end{tabular}

"Combination of two or more dummies, for example: soc. influence $+B$ ws no treatment $=\beta_{1}+\beta_{2}$ $+B=$ with boosters

The attrition analysis indicated that treatment was a factor of attrition at both $T 2$ and T4. Therefore, "intention to treat" analyses ${ }^{37}$ including all students were conducted, substituting the last recorded smoking status for the missing data of drop-outs; that is, a missing at $T 2$ was replaced by the $T 1$ recording, a missing 
at $\mathrm{T} 4$ was replaced by the $\mathrm{T} 3$ recording and, if $\mathrm{T} 3$ was also missing by the $\mathrm{T} 2$ recording, and if the $T 2$ recording was missing by the $T 1$ recording. These analyses resulted in $\mathrm{B}$ 's, standard errors and $\mathrm{p}$-values similar to those of the analyses excluding dropouts.

Table 5 shows the increase from pretest to posttests in smoking in the decision making group, the social influence group, and the control group.

Table 5

Percentage smokers at T1, T2, T3, and T4

\begin{tabular}{|c|c|c|c|c|c|}
\hline Smokers & $\begin{array}{l}\text { Dec. } \\
\text { making }\end{array}$ & $\begin{array}{l}\text { Dec. making } \\
+ \text { Booster }\end{array}$ & Soc inft. & $\begin{array}{l}\text { Soc. infl. }+ \\
\text { Booster }\end{array}$ & Control \\
\hline \multicolumn{6}{|c|}{ Pretest ws posttest 1} \\
\hline $\mathrm{TI}$ & 13.5 & & 7.5 & & 8.0 \\
\hline $\mathrm{T} 2$ & 15.6 & & 9.5 & & 11.9 \\
\hline Increase & 2.1 & & 2.0 & & 3.9 \\
\hline$N$ & $(1381)$ & & $(1221)$ & & $(1458)$ \\
\hline \multicolumn{6}{|c|}{ Pretest vs posittesi 2} \\
\hline pi & 13.2 & 10.6 & 7.2 & 5.6 & 7.1 \\
\hline $\mathrm{T} 3$ & 21.3 & 21.2 & 19.4 & 11.2 & 19.7 \\
\hline Increase & 8.1 & 10.6 & 12.2 & 5.6 & 12.6 \\
\hline$N$ & $(567)$ & $(567)$ & $(613)$ & (538) & (1368) \\
\hline \multicolumn{6}{|c|}{ Pretest vs positest 3} \\
\hline Til & 13.5 & 7.7 & 7.3 & 5.3 & 6.4 \\
\hline $\mathrm{T} 4$ & 23.9 & 20.5 & 21.2 & 15.0 & 21.3 \\
\hline Increase & 10.4 & 12.8 & 13.9 & 9.7 & 14.9 \\
\hline $\mathrm{N}$ & $(460)$ & (351) & $(575)$ & (526) & $(1192)$ \\
\hline
\end{tabular}

3.2 Effects on attitude, knowledge, social norms, perceived behavior, pressure, self-efficacy, and intention

All significant differences between the treatment groups in attitude, knowledge, social norms, perceived behavior, pressure, self-efficacy and intention at T2 and T4 are shown in Table 6. 
At I2 students on the SI program were more convinced of the health disadvantages of smoking than control group students. Third grade students on the DM program were less convinced of the social acceptance of smoking than the control group. For knowledge significant interactions were found between grade and treatment, type of school and treatment, and pretest knowledge and treatment. For both programs the effects on knowledge for the different combinations of grade, treatment and pretest knowledge, were in the same direction; students in both programs had a higher level of knowledge compared to those in the control group. Second grade students on the SI program reported more smokers in their environment than the control group did. Regarding selfefficacy, nonsmokers on both programs and smokers on the DM program had higher levels of self-efficacy compared to nonsmokers and smokers in the control group respectively. Finally, third grade students of both programs had a higher negative intention to smoke compared to third grade students of the control group.

At T4 five/six-year education students in the SI program with boosters were less convinced of the social acceptance of smoking compared with students in the SI program without the boosters. Furthermore, five/six-year education students in the DM program without the boosters were less convinced of the social acceptance of smoking compared to the control group and the students of the DM program with the boosters. Second and third grade students of both programs had higher levels of knowledge compared to the control group. Moreover, students in second grade who also received the boosters had higher levels of knowledge compared to students who did not receive the boosters. Four-year and five/six-year education students in second grade who received the SI program with the boosters experienced a higher negative social norm about smoking compared to students who received the SI program without the boosters. However, second grade five/six-year education students on the SI program experienced a more positive social norm about smoking compared to the control group. Students on the DM program reported more smokers in their environment compared to the control group. Second grade students in the SI program with the boosters perceived more pressure to smoke compared to those in the SI program without the boosters. Finally, four-year education students in third grade who received the DM program had a higher negative intention to smoke compared to their controls. 
Table 6

Program effects on atitude, knowhedge, social noms, perceived behavior, pressure, self-eficacy. and intention. ( $>$ more negative aganst smoking)

\begin{tabular}{llllll}
\hline Variable & $\begin{array}{l}\text { Interaction } \\
\text { Treatment } \\
\text { with }\end{array}$ & T2 & $p<$ & $\begin{array}{l}\text { Interaction } \\
\text { Treatment } \\
\text { with }\end{array}$ & T4 \\
\hline
\end{tabular}

\begin{tabular}{|c|c|c|c|c|c|c|}
\hline \multirow{2}{*}{$\begin{array}{l}\text { Heal th dis- } \\
\text { adv. } \\
\text { Social accept. }\end{array}$} & \multirow[b]{2}{*}{ grade } & \multirow{2}{*}{$\begin{array}{l}\text { SI }>\text { Con } \\
\text { grade } 3: \\
\text { DM }>\text { Con }\end{array}$} & \multicolumn{2}{|l|}{.001} & \multirow[b]{2}{*}{$\begin{array}{l}\text { 5/6 year level: } \\
\mathrm{SI}+\mathrm{B}>\mathrm{SI} \\
\mathrm{DM}>\mathrm{Con} \\
\mathrm{DM}>\mathrm{DM}+\mathrm{B}\end{array}$} & \multirow[b]{2}{*}{$\begin{array}{l}.05 \\
.05 \\
.005\end{array}$} \\
\hline & & & .05 & $\begin{array}{l}\text { type of } \\
\text { school }\end{array}$ & & \\
\hline Knowledge & $\begin{array}{l}\text { grade } \\
\text { type of } \\
\text { school } \\
\text { pretest } \\
\text { knowledge }\end{array}$ & $\begin{array}{l}\text { SI }>\text { Con } \\
\text { DM }>\text { Con }\end{array}$ & $\begin{array}{l}.05 \\
.05\end{array}$ & grade & $\begin{array}{l}\text { grade 2: } \\
\text { SI }>\text { Con } \\
\mathrm{DM}>\text { Con } \\
\mathrm{SI}+\mathrm{B}>\mathrm{S} \mathbb{} \\
\mathrm{DM}+\mathrm{B}>\mathrm{DM} \\
\text { grade } 3 \\
\mathrm{SI}>\text { Con } \\
\mathrm{DM}>\text { Con }\end{array}$ & $\begin{array}{l}.001 \\
.001 \\
.001 \\
.05 \\
\\
.001 \\
.001\end{array}$ \\
\hline Social norm & & & & $\begin{array}{l}\text { grade } \\
\text { type of } \\
\text { school }\end{array}$ & $\begin{array}{l}4 \text { yr level/ } \\
\text { grade } 2 \\
S I+B>S I \\
5 / 6 \text { yr level/ } \\
\text { grade } 2 \\
\text { SI }<\text { Con } \\
\text { SI }+B>\text { SI }\end{array}$ & .06 \\
\hline $\begin{array}{l}\text { Perceived } \\
\text { behavior }\end{array}$ & grade & $\begin{array}{l}\text { grade 2: } \\
\text { SI > Con }\end{array}$ & .05 & & $\mathrm{DM}>\mathrm{Con}^{*}$ & .05 \\
\hline Pressure & & & & grade & $\begin{array}{l}\text { grade } 2 \\
S I+B>S I\end{array}$ & .05 \\
\hline Selferficacy & $\begin{array}{l}\text { pretest smo- } \\
\text { king }\end{array}$ & $\begin{array}{l}\text { Smokers: } \\
\text { DM > Con } \\
\text { nonsmo- } \\
\text { kers: } \\
\text { SI }>\text { Con } \\
\text { DM }>\text { Con }\end{array}$ & $\begin{array}{l}.001 \\
.05\end{array}$ & & & \\
\hline Intention & grade & $\begin{array}{l}\text { grade 3: } \\
\text { SI }>\text { Con } \\
\text { DM }>\text { Con }\end{array}$ & $\begin{array}{l}.05 \\
.005\end{array}$ & $\begin{array}{l}\text { grade } \\
\text { type of } \\
\text { school }\end{array}$ & $\begin{array}{l}4 \text { yr level } \\
\text { grade 3: } \\
\text { DM> Con }\end{array}$ & .05 \\
\hline
\end{tabular}

$">=$ percewing more smokers in the environment 


\section{Discussion}

The results indicated that in the short term both the SI and the DM program prevented the onset of smoking among nonsmokers at pretest. No treatment effects were found for smokers. The differential effects for nonsmokers and smokers may be caused by the fact that both programs favor non-smoking, which, at first, may evoke resistance in smokers. However, at T3 and T4 these differential effects did no longer existed. At T3 and T4 the SI program including the booster resulted in a preventive effect on smoking for the entire high school population, whereas the SI program without the booster failed to show an effect. A possible explanation for this short-term effect of the SI program is that a program of five lessons is not enough for effective training of skills to resist smoking. At T3 the DM program without the booster was effective in preventing smoking compared to the control group. At T4 this effect was smaller and just failed to be statistically significant. With regard to the DM program, at $\mathrm{T} 3$ as well as $\mathrm{T} 4$, boosters did not contribute to a greater effect and even appeared to be counter-productive. It is not clear why the booster reduced the effectiveness of the DM program. A possible explanation is that the newspapers had a better link with the SI program, since their content focused mostly on issues related to social influence. Although the booster was effective in combination with the SI program, process evaluation showed that only small percentages of students of both programs reported having read all three newspapers. ${ }^{3}$ Therefore, the behavioral effects of the boosters in combination with the SI program should be interpreted with some caution. It is possible, on the one hand that boosters are read by more students than have been reported, while on the other hand, it may be that merely receiving the boosters and glancing through them functioned as a cue causing recognition. The effectiveness of the booster may be improved by stimulating teachers to discuss the content at class level. Further research to assess the effects of the boosters is needed.

Comparing betas of the different treatment effects at T3 and T4, we can conclude that the SI program with the booster shows the best effects, followed in turn by the DM program without the booster, the DM program with the booster, and finally the SI program without the booster.

Attrition is a major problem in longitudinal studies. In this study at T3 and T4 attrition was related to pretest smoking. However, although treatment was a factor of attrition at $\mathrm{T} 2$ and at $\mathrm{T} 4$, there was no differential attrition for interventions and control subjects regarding pretest smoking. Although students were not informed about the time of assessments, and attrition can partly be 
attributed to factors such as illness and changing to another school, the treatment effects on attrition required that the effects at both measurements were reanalyzed with dropouts receiving the last recorded smoking status they had. The results of these reanalysis were comparable with the results of the analysis without the dropouts. Consequently, the assumption can be made that the preventive effects of both programs at $\mathrm{T} 2$ and $\mathrm{T} 4$ are reliable.

Although it as hypothesized that the programs would have different effects for the different types of school, no interactions were found between type of school and treatment. Similarly, because of the low smoking prevalence in the second grade of high schools, better preventive effects were expected in the third grade. However, no differential effects were found.

Less consistent results were found for the effects on attitude, knowledge, social norms, perceived behavior, pressure, self-efficacy, and intention. The clearest results were found regarding knowledge, self-efficacy and intention. With regard to knowledge, at $\mathrm{T} 2$ and $\mathrm{T} 4$ both programs resulted in an increase in knowledge compared with the control group. In grade two the boosters had a contribution in the increase. With respect to self-efficacy, in the short term both programs resulted in higher levels of self-efficacy for nonsmokers, and the DM program also for smokers. However, at $\mathrm{T} 4$ these effects disappeared. It may be that repeatedly practicing the skills to resist pressure to smoke through roleplays is necessary to attain long-term effects. A change in intention to smoke was only achieved in the third grade. At $\mathrm{T} 2$ both programs resulted in a higher negative intention to smoke, whereas at $\mathrm{T} 4$ only the DM program resulted in such an outcome. Results at T3 were not reported, but showed the same patterns.

A limitation of this study is that no procedures to enhance self-report validity have been used. However, self-reports have been demonstrated to be accurate when anonymity and confidentiality are assured and an identification coding system is used.

As explained in the method section, separate analyses were done for $\mathrm{T} 2$, T3 and T4, rather than MANOVA, for several reasons. This 'multiple testing' increases the risk of type I errors. A simple solution is the Bonferroni correction; that is, taking $\alpha=.05 / \mathrm{k}$, where $\mathrm{k}$ is the number of tests done ( $\mathrm{k}=3$ for smoking, $k=2$ for the other outcome variables). As tables 1,3 and 4 show, this does not affect the conclusions about treatment effects on smoking substantially, since most p-values were either $>.05$ or $<.02$, and trends were consistent between T3 and T4.

Finally, it can be concluded that both programs can be used to prevent smoking in the second as well as the third grade of high schools. When the SI 
program is used, the booster should be included, while the DM program is more effective without the booster. Further research is needed to assess the long-term effects of the SI program with the booster and to examine if a more intensive use of the booster is necessary. The effects of the DM program without the booster almost disappeared at T4. Therefore, further research should determine whether boosters (newspapers) with DM-related issues, e.g., issues based on the five steps to make a decision, may contribute to long-term effects of the DM program.

\section{References}

1. Hansen WB. School-based substance abuse prewention: A review of the state of the art in curriculum, 1980-1990. Heath Education Research. 1992;7:403-430.

2. Bruvold WH. A meta-analysis of adolescent smoking prevention programs. American Journal of Public Health. 1993;83:872-880.

3. Bangert-Drowns RL. The effects of school-based substance abuse education: A meta-analysis. Jounal of Drug Education. 1988;18:243-264.

4. Best JA, Thomson SJ, Santi SM, Smith EA, Brown KS. Preventing cigarette smoking among school children. Anmal Review of Public Heath. 1988;9:161-201.

5. Botvin GJ. Substance abuse prevention research: Recent developments and future directions. Joumal of School Healih. 1986:9:369-374.

6. Bruvold WH, Rundall TG. A meta-analysis and theoretical review of school based tobacco and alcohol intervention prograns. Psychological Healh. 1988:2:53 78.

7. Flay BR, Ryan KB, Best JA, et al. Are social-psychological smoking prevention programs effective? The Waterloo Study. Journal of Behavioral Medicine. 1985;8:37-59.

8. Johnson CA, Hansen WB, Collins LM, Graham W. High-school smoking prevention: Results of a three-year longitudinal study. Journal of Behaworal Medicine 1986;9:439-452.

9. Murray DM, Pirie P, Luepker RV, Pallonen U. Five- and six-year follow-up results from four seventh-grade smoking prevention strategies. Journal of Behavioral Medicine. $1989: 12: 207-218$

10. Perry $C L$, Pirie P. Holder W. Halper A, Dudovitz B. Parent unvolvement in cigatette smoking prevention: Two pilot evaluations of the "unpuffables program". Joumal of Shool Heath. 1990;60:443-447

11. Tobler NS. Meta-analysis of 143 adolescent drug prevention programs: Quantiative outcome results of program participan compared to a control or comparison group. Joamal of Drig Issues. 1986; ]6:537-567.

12. Flay BR, Hansen WB. Anderson Johnson $C$, et al. Implememation effectiveness trial of a social influences smoking prevention program using schools and television. Heallh Education Research. 1987:2:385-400.

13. Flay BR, Koepke D. Thomson SI, Santi S, Best JA. Brown S. Six-year follow-lip of the lirst Waterloo school smoking prevention trial. American Joumal of Public Heakth. 1989;79:13711376. 
14. Borvin G. Renick NL, Baker E. The effects of scheduling format and booster sessions on a broad-spectrum psychosocial approach to smoking prevention. Joumal of Behavioral Medicine. 1983;6:359-379.

15. Botvin GJ, Baker E, Dusenbury L, Ton $\$$, Botvin EM. Preventing adolescent drug abuse througly a multimodal cognitive-behavioral approach: Results of a 3 -year study. Joumal of Consulting \& Clinical Psychology. 1990;58:437-446.

16. Bowin GJ, Baker E, Filazzola AD, Botvin EM. A cognitive-behavioral approach to substance abuse prevention: One-year follow-up. Addictive Behaviors. 1990;15:47-63.

17. De Vries H, Weyts W, Dijkstra M, Kok GI. The willization of qualitative and quantitative data for healh education program planning, implementation and evaluation: A spiral approach. Healh Educarion Quarterly. 1992;19:101-115.

18. De Vries 4 , Backbier E, Dijkstra M, Van Breukelen G. Parcel G, Kok G. A Dutch social jntluence smoking prevention approach for vocational school sudents. Health Education Research. 1994:9:365-374.

19. De Vries H. Snoking prevenion in Duch adolescents. Maastricht: Datawyse, 1989.

20. Petly RE, Cacioppo IT. The elaboration likelihood model of persuasion. In: Berkowitz L. (Ed.) Adwances in Experimental Social Psychology, vol. 19, London: Academic Press, 1986.

21. Botvin GJ. Prevention of adolescent substance abuse through the development of personal and social compentence. In: Preventing adolescent drug abuse; intervention strategies, NIDA, Research Monograph series, 47, 1983.

22. Flay BR, D'Awernas JR, Best JA, Kersell MW, Ryan KB. Cigarette smoking: Why young people do it and ways of preventing it. In: McGrath PJ, Firestone P. (Eds.) Pediatric and adolescent behavioral medicine (pp. 132-183). New York: Springer, 1983.

23. Ajzen I, Fishbein M. Understanding Atitudes and Predicting Social Behavior. Prentice-Hall, Englewood Cliffs, NJ, 1980 .

24. Dijlstra M, De Vries H, Parcel G. The linkage approach applied to a School-Based Smoking Prevention Progrant in the Netherlands. Jaumal of School Health. 1993;63:339-342.

25. Bandura A. Social Foundation of thought and action: A social cognitive theory. Englewood Cliffs, NJ: Prentice-Hall Inc, 1986.

26. Akers RL. Massey J, Clarke W, Lauer RM. Are self-reports of adolescent deviance valid? Biochemical measures, randomized response, and the bogus pipeline in smoking behavior. Social Forces. 1983;62:234-251.

27. Hansen WB, Malote CK, Fielding JE. The bogus pipeline revisited: The use of the threat of detection as a means of increasing self-reports of tobacco use. Journal of Applied Psychology. 1985;70:789-792.

28. Murray DM, Perry CL. The measurement of substance use among adolescents: When is the 'bogus pipeline' method needed'? Addicive Behaviors. 1987; 12:225-233.

29. Ransom MV. Peer perceptions of adolescent health behaviors. Joumal of School Health. $1992 ; 62: 238-242$

30. Abernathy TJ, Bertrand LD. Preventing Cigarette smoking among children: Results of a four-year evaluation of the PAL program. Canadion Joumal of Public Healsh. 1992;83:226229

31. Botwin GJ, Botvin EM. Adolescent tobacco, alcohol, and drug abuse: Prevention strategies, empirical findings, and assessment issues. Developmental Behavioral Pediatrics. 1992;13:290-301. 
32. U.S. Deparment of Health and Human Services. The healh benefits of swokng cessation: report of the Surgeon General. Public Healh Service. DHHS Publication No. (CDC) 90 $8416,1990$.

33. Bryk AS, Raudenbusch SW. Hierarchical Linear Models: Applications and Dorta Analyis Methods. Sage Publications, Newbury Park, CA, 1992.

34. Longford NT. A fast scoring algorithm for maximum likelihood estimation in unbalanced mixed madels with nested random effects. Biomerika. 1987;74:817-827.

35. Longford NT. VARCL: Software for variance component analysis of data with hieranchically nested randon effects (maximum likethood). Manual. Princeton: Educational Testing Service. 1988.

36. De Vries H, Kok GI. From determinants of smoking behaviour to the implications for a prevention programme. Health Edacation Research. 1986;1:85-94.

37. Pocock SJ. Clinical Trials: A Practical Approach. John Wiley \& Sons Lid. Chichester, 1983.

38. Dijkstra $M$, De Vries $\mathbb{H}$. Program Evaluation of two Duch smoking prevention programs: An application of the program matrix. (Submitted for publication) 



\section{Summary}

This thesis describes the development, implementation and evaluation of two smoking prevention programs (social influence program and decision-making program) with booster (three newspapers) for second and third grade high school students. The goal of the programs and booster was to prevent adolescents from starting to smoke. Diffusion of the programs occurred in collaboration with 16 health educators in 15 districts in the Netherlands. Health educators recruited schools for participation in the project. The schools $(\mathrm{N}=52)$ were divided in two experimental groups $(\mathrm{N}=32)$ and a control group $(\mathrm{N}=20)$. Teachers of the experimental schools implemented one of the programs, while the control schools did not receive a program. Half the experimental group received the booster. Both the effects and the process of the smoking prevention project were evaluated.

In Chapter 1 the systematic approach of the research project is described. Then, the consequences of smoking and smoking prevalence, and incidence in the Netherlands are discussed. Furthermore, this chapter briefly summarizes smoking prevention programs that have been researched during the last two decades. Accordingly, the development, diffusion and implementation of the programs are briefly discussed and the most important results and implications are given. Finally, methodological issues and implications for further research are discussed.

Chapter 2 describes participation of 16 health educators during the diffusion of the programs and evaluation of the participation. Health educators were asked by the researchers to collaborate during the implementation of the programs, because, according to the linkage approach, collaboration between three groups (resource system, linkage system, and user system) may improve effective diffusion of innovations. In the research project described in this thesis, university-based researchers formed the resource system, health educators formed the linkage system, and schools formed the user system. The goal of the linkage system was to serve as a link between the resource system, which developed the programs, and the user system, the adopters of the programs. The goal of the evaluation of the participation of health educators in the project was to assess the support activities provided by the researchers, to evaluate the time spent on the project, to deternine the advantages and disadvantages of participation, to assess the intention to continue implementation of the programs, to determine the willingness to participate in other phases of the planning process and in other research projects. The results showed that 
collaboration between a resource system and a linkage system during a smoking prevention research project made small-scale implementation feasible. Health educators evaluated their participation in the project positively and they were satisfied with the support of the researchers. However, some activities took more time than expected, and time appeared to be the most important disadvantage of participation. The most important advantage was to become familiar with the materials and potential of the smoking prevention program. Most health educators reported they intended to continue involvement in the project, and they will, under specified condition, participate in other research projects as well. It can be concluded that health educators were the right persons to serve as a linkage system. However, further research is necessary to determine the effectiveness if participation in other phases of the planning process, and to show effects of collaboration of a linkage system during largescale implementation. The most important conditions for using the linkage approach are discussed.

In Chapter 3 the implementation of the programs by teachers and the evaluation of implementation are discussed. The goal of implementation evaluation was to assess differences between teachers who implemented the programs completely as planned and teachers who did not use every element of the program, to assess predictors of future use of the smoking prevention programs, and to determine elements of the smoking prevention program that are preferable for future use. After the last lesson teachers received a questionnaire. From the 32 schools, 59 teachers returned the questionnaire. The results showed that in general teachers implemented the programs completely. Further, teacher training was not a precondition for complete implementation. A predictor of future use of the programs was a positive attitude towards the level of success of the programs. Furthermore, for future use of the programs teachers prefer a program of three lessons instead of five, to have the ability to assess the grade in which the program will be taught, and to have the ability to determine the moment of teaching. It can be concluded that the structure of the programs enhanced complete implementation of the programs. A diffusion strategy based on the results of the implementation evaluation is given.

In Chapter 4 the development of the programs and booster and the evaluation of the use of the programs and booster by students and teachers are reported. The development of the programs and booster was based on a program matrix to plan behavioral interventions. Data were gathered at the end of each lesson. Students, peer-leaders, and teachers answered questionnaires containing questions about the different sources and channels used in the lessons. The booster was evaluated during the third posttest of the effect evaluation. 
Furthermore, health educators conducted interviews with teachers for more indepth information about the use of the programs. The results showed that in general teachers and students positively evaluated the programs. However, students who received the social influence program were more positive about the channels and sources compared to those of the decision-making program. The evaluation of the booster revealed that only small percentages of students of both experimental groups read all three newspapers. The interviews with the teachers indicated that teachers were positive about the channels and sources of the programs. According to the teachers, students enjoyed the lessons, though they were less interested during the last lesson. Students who received the decision-making program got bored with applying the steps to make a decision in most activities.

Chapter 5 reports the design and results of the effect evaluation of the project. In the effect evaluation the effects on smoking behavior of the programs with and without booster and the control group, were compared. Data were collected during a pretest and three posttests using questionnaires. The questionnaire was based on the 'Attitude-Social influences-Efficacy" model (ASE mode1). According to the results, the social influence program with the booster showed the best preventive effects, followed in turn by the decisionmaking program without the booster, the decision-making program with the booster, and the social influence program without the booster.

The most important conlusion is that a smoking prevention program based on the educational level of high schools can be effective in preventing smoking. The structure of the programs contributed to complete implementation of the programs. Further it can be concluded that the linkage approach is an appropriate strategy for the diffusion of school health educations programs. Based on the results further research is recommended to determine long-term effects of both programs complete with the booster. 



\section{Samenvatting}

Dit proefschrift beschrijft de ontwikkeling, implementatie en evaluatie van twee rookpreventie programma's (sociale invloed programma en keuze programma) met 'herhalingsinformatie" (boosters: drie kranten) voor Mavo, Havo en Vwo leerlingen van de tweede en derde klas. Het doel van de programma's met booster was voorkomen dat jongeren gaan roken. De diffusie van de programma"s vond plaats in samenwerking met $16 \mathrm{GVO}$-functionarissen in 15 regio's in Nederland. De GVO-functionarissen benaderden scholen voor participatie in het project. Deze scholen $(\mathrm{N}=52)$ zijn verdeeld in iwee experimentele groepen $(N=32)$ en een controle groep $(N=20)$. De leerkrachten van de experimentele scholen implementeerden éen van de programma's, terwijl de controle scholen geen programma kregen. De helft van beide experimentele groepen ontvingen de booster. Zowel het effect als het proces van het rookpreventieproject zijn geëvalueerd.

In Hoofdstuk 1 wordt de systematische aanpak van de in dit proefschrift beschreven studie beschreven. Dan wordt aangegeven wat de gevolgen van roken zijn en hoe groot het rookprobleem in Nederland is. Er wordt een bondig overzicht gegeven van wat er tot nu toe aan rookpreventie op scholen gedaan is. Vervolgens worden de ontwikkeling, diffusie en implementatie van de programma's kort beschreven en worden de belangrijkste resultaten besproken. Tenslotte wordt ingegaan op een aantal methodologische aspecten van de studie en worden aanbevelingen voor verder onderzoek gegeven.

In Hoofdstuk 2 wordt de medewerking van 16 GVO-functionarissen tijdens de diffusie van de programma's en de evaluatie hiervan gerapporteerd. GVOfunctionarissen zijn door de onderzoekers gevraagd om mee te werken aan de implementatie van de programma's omdat, volgens de zogenaande linkage approach, samenwerking tussen drie groepen: 'resource system', 'linkage system' en 'user system", diffusie van innovaties bevorderd. In het in dit proefschrift beschreven onderzoeksproject, vormden de onderzoekers het 'resource system', de GVO-functionarissen het 'linkage system' en de scholen het 'user system'. Het doel van het 'linkage system', de GVO-functionarissen. was te fungeren als een link tussen de onderzoekers die de programma"s hebben ontwikkeld en de scholen die de programma's zouden implementeren. Het doel van de evaluatie van medewerking van de GVO-functionarissen was na te gaan hoe de ondersteuning van de onderzoekers werd ervaren, hoe de ijd die nodig was voor medewerking aan het project werd geëvalueerd, wat de voor-en nadelen van participatie in het project waren, of GVO-functionarissen de 
intentie hadden om implementatie van de programma's te continueren, of ze zouden willen participeren in ander fasen van het onderzoeksproject en tenslotte of ze in de toekomst weer zouden participeren in een onderzoeksproject. De resultaten lieten zien dat het mogelijk is om bimen een onderzoeksproject een 'linkage system' te laten participeren tijdens de diffusie van de interventie. De GVO-functionarissen evalueerden hun participatie in het project positief en waren tevreden over de ondersteuning van de onderzoekers. Echter, sommige aktiviteiten kosten meer tijd dan verwacht. De tijd werd dan ook als belangrijkste nadeel gezien. Het grootste voordeel van participatie was het bekend raken met de materialen en mogelijkheden van de rookpreventie programma"s. Verder gaven de GVO-functionarissen aan van plan te zijn om de implementatie van de programma's te continueren en dat ze in de toekomst, onder bepaalde voorwaarden, ook in andere onderzoeksprojecten zouden willen participeren. Geconcludeerd werd dat GVO-functionarissen de juiste personen waren om te fungeren als "linkage system" en dat verder onderzoek nodig is om na te gaan of participatie in andere fasen van een onderzoeksproject en tijdens groot-schalige diffusie van preventieprogramma's, effectief is. De belangrijkste voorwaarden voor het gebruik van de linkage approach worden besproken.

In Hoofdstuk 3 wordt de implementatie van de programma's door leerkrachten en de evaluatie hiervan beschreven. Het doel van de evaluatie was om verschillen te achterhalen tussen leerkrachten die het programma volledig hebben geïmplementeerd en leerkrachten die dit niet volledig hebben gedaan. Een tweede doel was het bepalen van predictoren van implementatie van het programma in de toekomst en welke elementen wan de programma's voorwaarden zijn voor toekomstig gebruik. Leerkrachten ontvingen een vragenlijst na de laatste les. Van de 32 scholen waar de programma's zijn geimplementeerd, vulden 59 leerkrachten de vragenlijst in. Uit de resultaten bleek dat over het algemeen de leerkrachten de programma's volledig hadden geimplementeerd. Verder bleek dat de training voor de leerkrachten geen voorwaarde was voor volledige implementatie. Een predictor van toekomstig gebruik van het programma was een positieve attitude ten aanzien wan de succesgraad van de programma's. Voorwaarden voor continuering van de programma's zijn drie lessen in plaats van vijf, het kunnen bepalen van de klas waarin het programma wordt gegeven en van het moment waarop de lessen worden gegeven. Geconcludeerd werd dat de structuur van de programma's volledige implementatic van het programma heeft bevorderd. Een op de resultaten gebaseerde diffusiestrategie wordt gegeven.

In Hoofdstuk 4 wordt de ontwikkeling van de programma's en 'herhalingsinformatie' (boosters) en de evaluatie van de programma's en 
boosters door leerlingen en leerkrachten, beschreven. De ontwikkeling van de programma's en boosters is gebaseerd op een programma matrix voor planning van gedragsinterventies. De gegevens werden verzameld aan het eind van elke les. Leerlingen, groepsleiders en leerkrachten beantwoorden vragenlijsten met vragen over de verschillende kanalen en bromen die zijn gebruikt in de lessen. De booster is geèvalueerd tijdens de derde nameting in het kader van de effectevaluatie. Daarnaast zijn leerkrachten aan het eind van de programma's geinterviewd door GVO-functionarissen om meer informatie te krijgen over het gebruik van de programma's. Uit de resultaten kwam naar voren dat over het algemeen leerkrachten en leerlingen de programma's positief evalueerden. Echter, leerlingen die het sociale invloed programma hadden gevolgy evalueerden de bronnen en kanalen positiever vergeleken met leerlingen die het keuze programma hadden gevolgd. Uit de evaluatie van de boosters bleek dat slechts een klein percentage van de leerlingen van beide programma's aangaven alle drie de kranten te hebben gelezen. Uit de interviews met de leerkrachten kwam naar voren dat de leerkrachten positief waren over de meeste bronnen en kanalen van de programma's. De leerlingen volgden met plezier de lessen, maar aan het einde van het programma waren ze minder geïnteresseerd. Verder bleek dat leerlingen van het keuze programma het steeds herhalen van de vijf stappen om een keuze te maken, saail vonden.

In Hoofdstuk 5 worden de opzet en resultaten van de effectevaluatie beschreven. In de effectevaluatie werden de effecten op het rookgedrag van de programma's met en zonder booster en de controle groep vergeleken. Er werden een voormeting en drie nametingen verricht door middel van schriftelijke vragenlijsten. Het theoretisch model dat aan de vragenlijst ten grondslag lag was het 'Attitude-Sociale invloed-Eigen effectiviteit' model (ASEmodel). De resultaten lieten zien dat het social invloed programma met de booster de beste resultaten heeft geleverd in het voorkomen dat jongeren gaan roken, gevolgd door respectievelijk het keuze programma zonder de booster, het keuze programma met de booster en het sociale invloed programma zonder de booster.

De belangrijkste conclusie is dat een rookpreventie programma dat is afgestemd op het niveau van Mavo, Havo en Vwo leerlingen, effectief kan zijn in de preventie van roken. De structuur van de programma"s heeft bijgedragen aan volledige implementatie. Verder kan geconcludeerd worden dat de linkage approach geschikt is voor effectieve diffusie van preventieprogramma"s voor scholen. Op basis van de resultaten wordt aanbevolen om verder onderzoek te doen naar de lange termijn effecten van de programma's aangevuld met boosters. 


\section{Curriculum vitae}

Margo Dijkstra was born on June 23, 1964 in Oss. After she received her VWO diploma at the Maasland College in Oss, she studied Health Education at the University of Limburg. In september 1986 she graduated. During the first two years after graduating she worked as assistent at the Department of Health Education of the University of Limburg on a smoking prevention project. From 1989 to 1993 she was employed as research associate at the Department of Health Education. In this period she conducted the study described in this thesis, which was financed by the Dutch Cancer Society (Nederlandse Kankerbestrijding/KWF). Since November 1993 till March 1995 she worked at the Public Health Department of Midden-Limburg on a community health project to stimulate women to participate in a national breastcancer-screening-program. Only recently, in April 1995, she started to work as a health educator at the BNMO-center (Bond van Nederlandse Militaire Oorlogs- en Dienstslachtoffers) in Doorn. 